ص ص[

\author{
استخدام الحاسوب في إعادة هندسة إعادة المادة

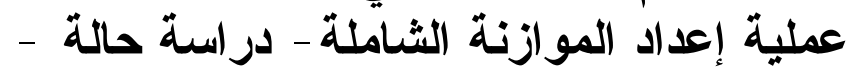

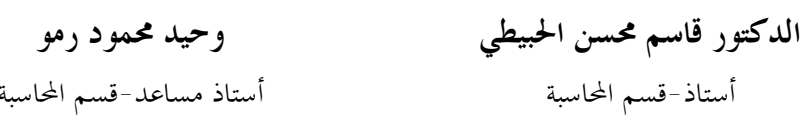 \\ كلية الإدارة والاقتصاد -جامعة الموصل
}

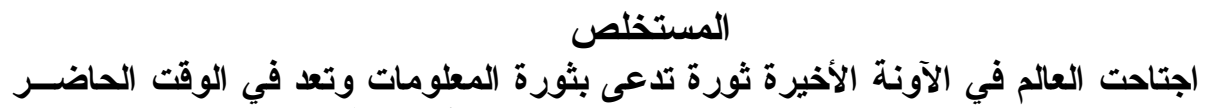

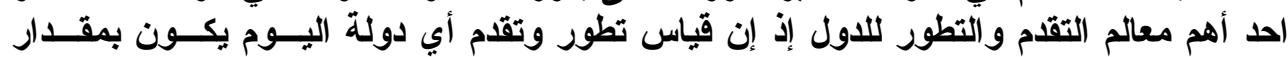

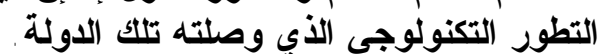

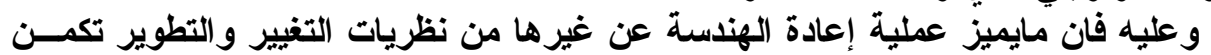

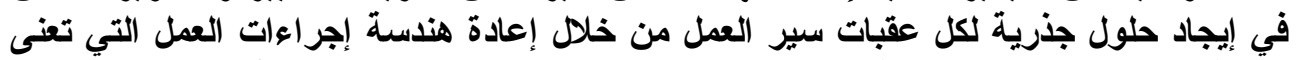

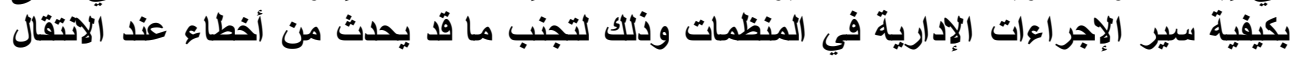

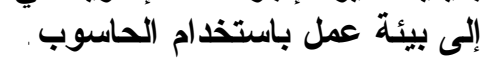

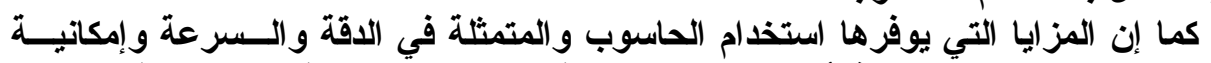

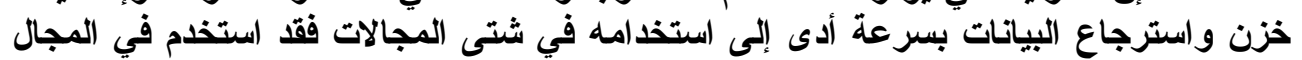

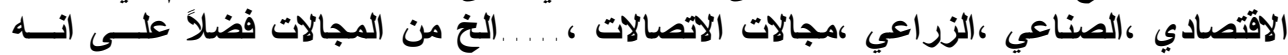
اوجد المبرر لعملية إعادة هندسة العمليات لغرض التئية التطوير والتحسين.

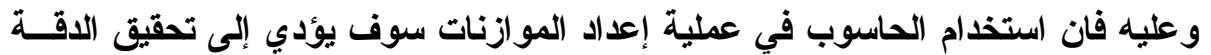

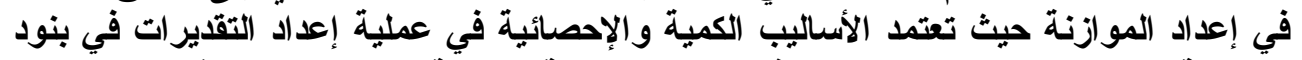

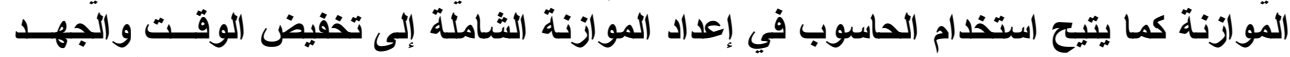

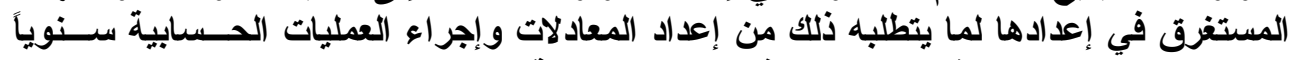

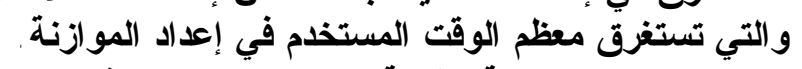

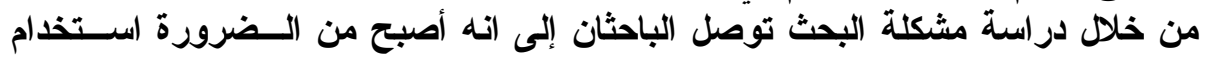

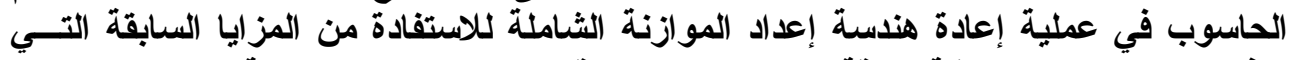

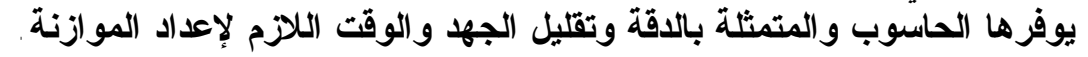




\title{
Using Computers in Reengineering in the Preparation of Balance Budget Sheet
}

\author{
Qasim M. Al-Hubaiti (PhD) \\ Professor \\ Department of Accountancy \\ University of Mosul
}

\author{
Wahid M. Rammo \\ Assistant Professor \\ Department of Accountancy \\ University of Mosul
}

\begin{abstract}
A revolution called information revolution has recently invaded the world. It is currently considered one of the most important properties of development to the countries of the world. Hence, the recognition of reengineering among other theories of innovation may be posited in finding radical procedures to overcome all obstacles in framework operations. This can be seen in reengineering the framework operations of management procedures in the organizations to avoid errors of transferring into computerized environment. The criteria provided by computers such as accuracy, speed, time saving storage and restore have led them to be widely used in economy, industry, agriculture, communications, etc, as well as being the major finder of reengineering the operations of innovation. The use of computers in the preparation of budgets will lead to achieve accuracy. Since, the operation draws upon the statistic and quantity estimations about budget items, the computerized balance sheet may save time and effort of preparing mathematical equations annually. According to the problem of study, the researchers concluded that it is necessary to use computers in reengineering the budget of balance sheet to save time and effort of preparation.
\end{abstract}

المقدمة

يعد الحاسوب في الوقت الحاضر أحد أهم معالم التقدم و التطور للاول، اذ إن قيــاس

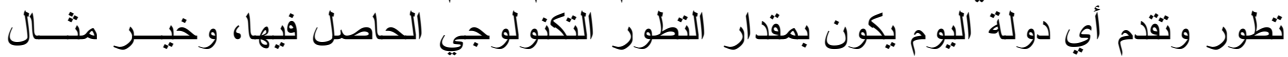

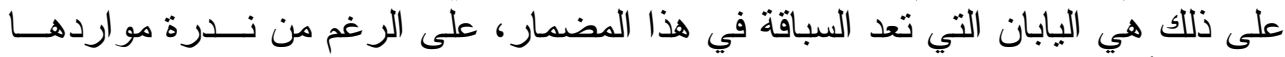

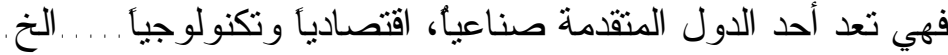

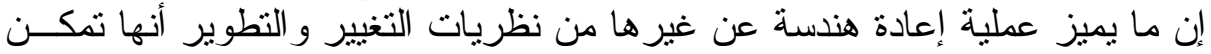

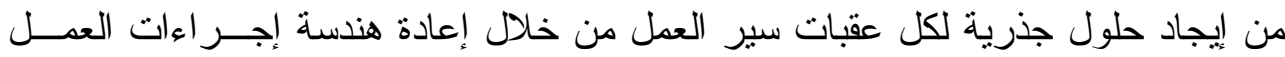

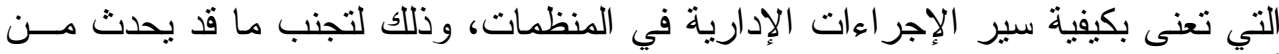

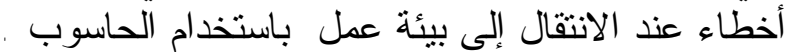

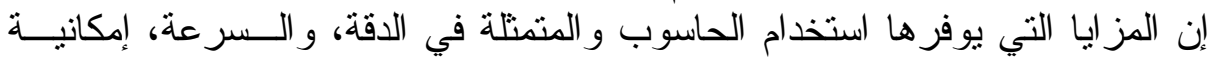

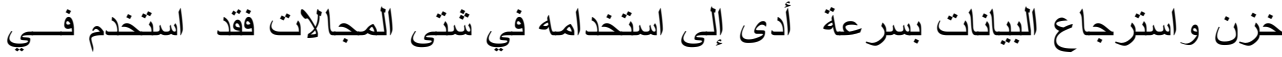

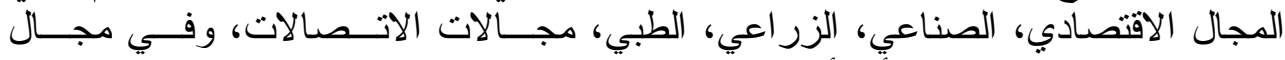

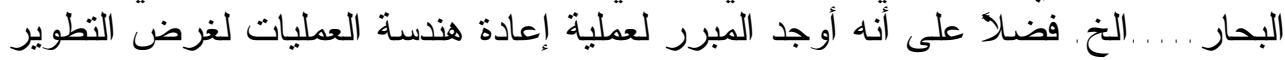

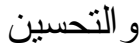

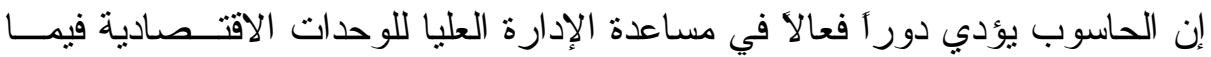

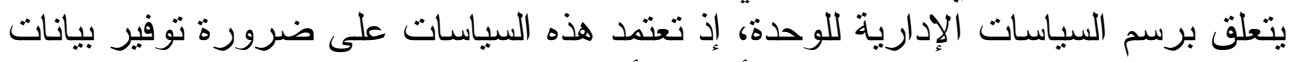

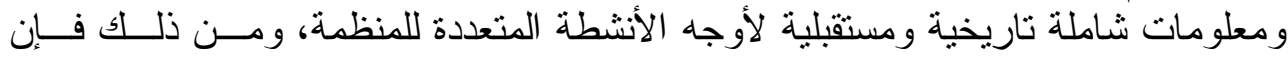

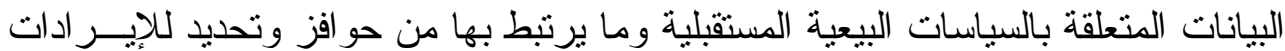




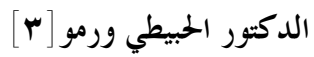

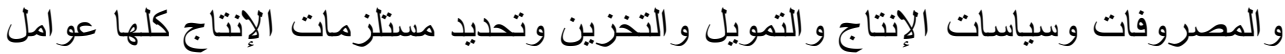

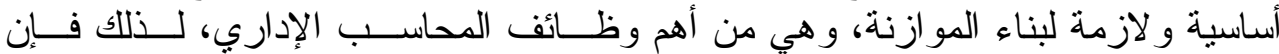

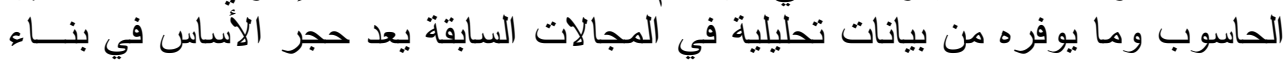
الموازنة بوصفها خطة مالية لأنشطة المنظمة المختلفة معبر أ عنها بصور مالية.

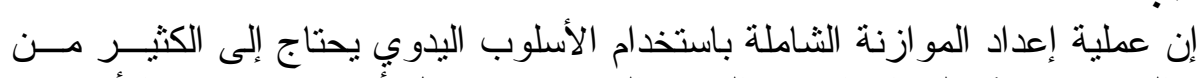
مشكلة البحث

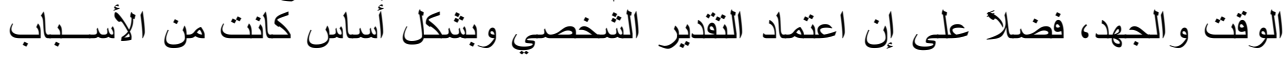

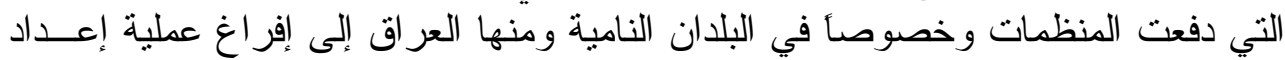

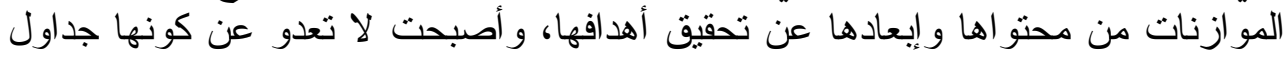

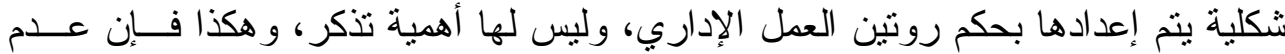

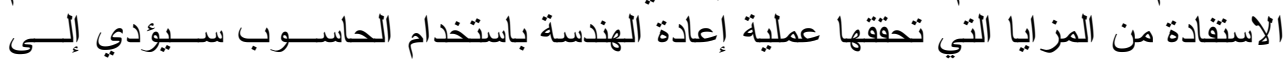

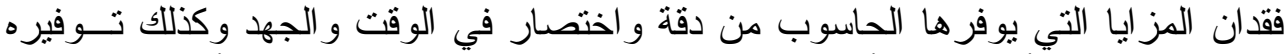

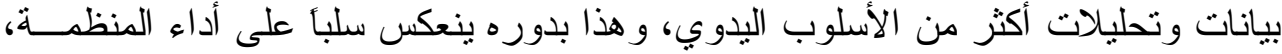
لأن الموازنة هي ترجمة لنشاط المنظمة لسنة قادمة معبر أ عنها بصورة مالية.

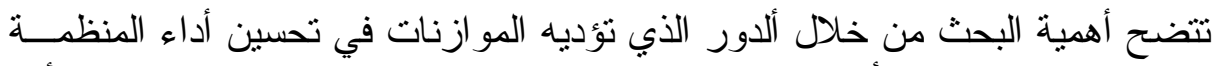
أهمية البحث

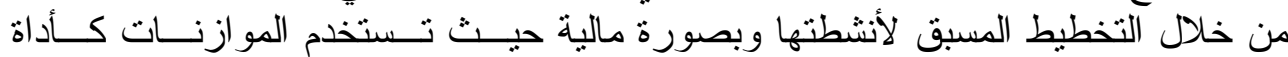

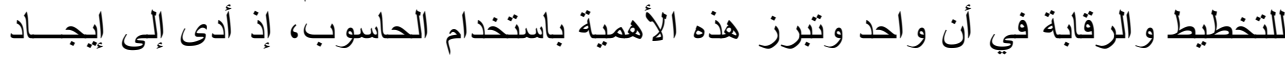

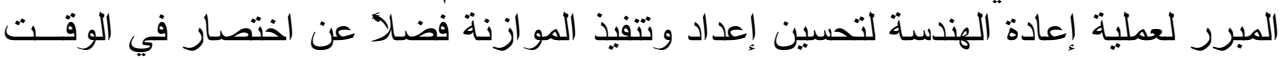

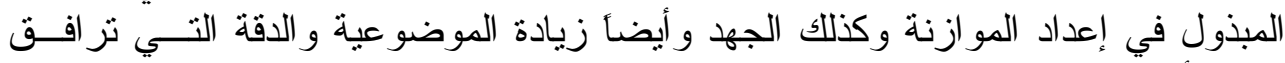

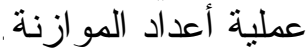

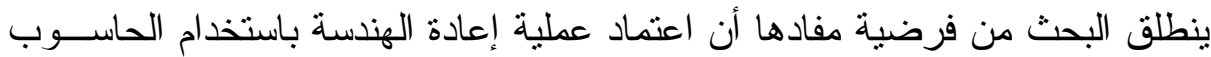
فرضية البحث

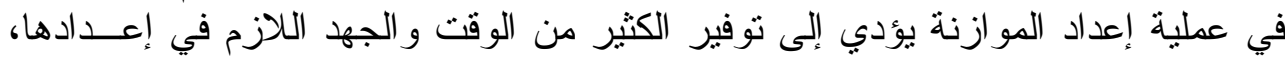

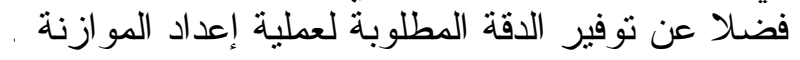

\section{مفهوم الموازنات وأنواعها

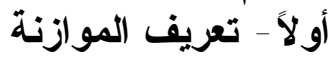

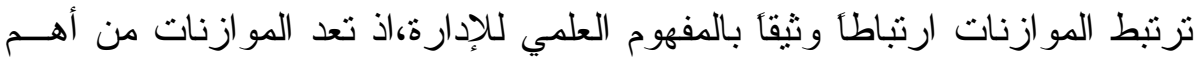

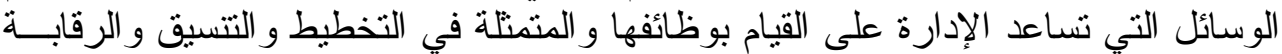

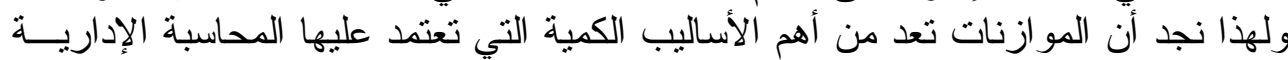
لمساعدة الإدارة لاتخاذ مختلف القر ارار ات في مختلف المسنويات الإن الإدارية.

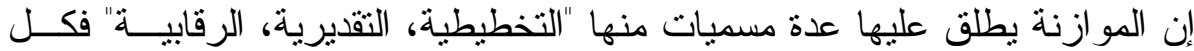

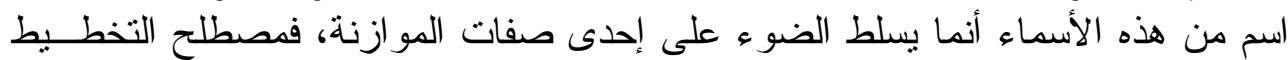

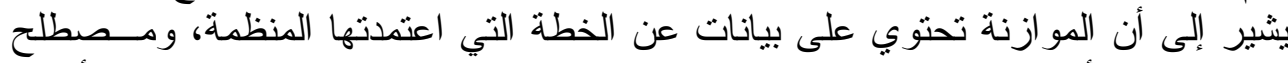

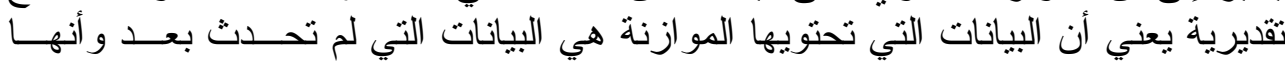




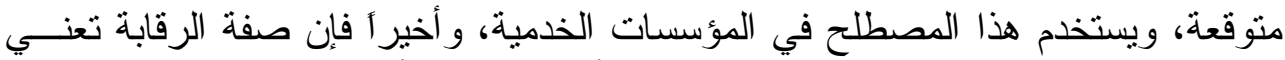

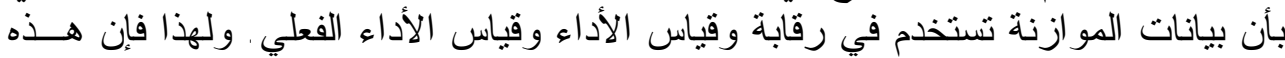

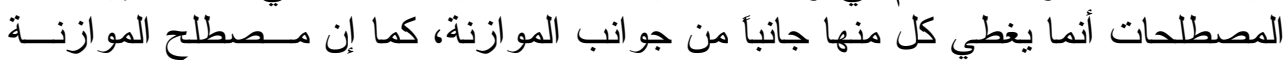

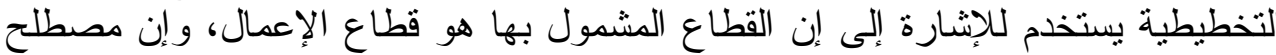

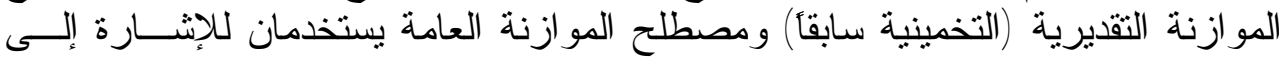

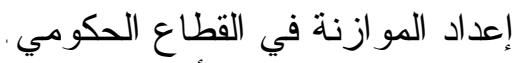

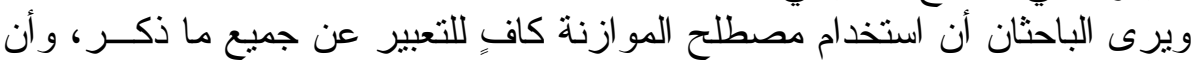

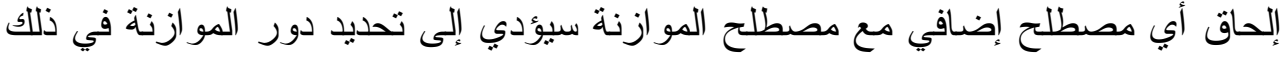

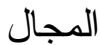

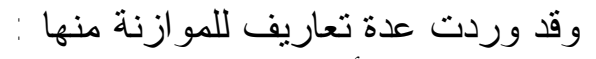

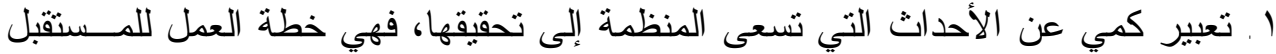

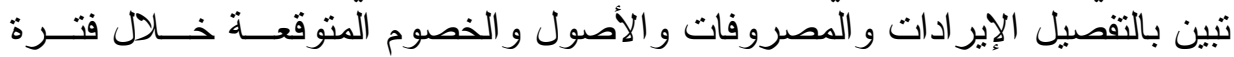

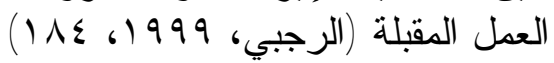
r . خطة معبر عنها بالاصطلاحات المالية و الكمية، أي إنها تعبير مالي وكمي عن الخطة

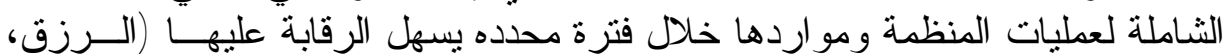
(r.人 ، 1994 r. التعبير الكمي لخطة موضوعة عن أنشطة المنظمة لفترة محددة وتساعد بناءً على ذلك الكا

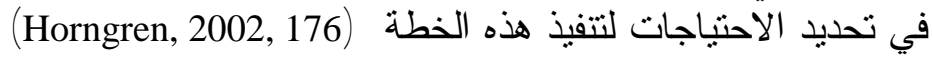

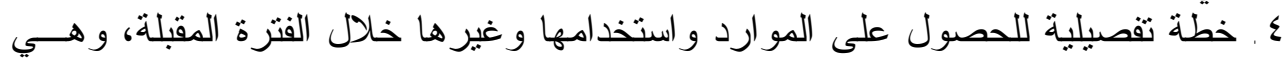

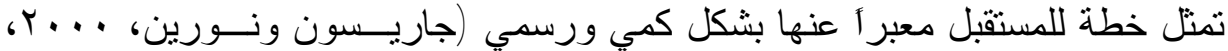

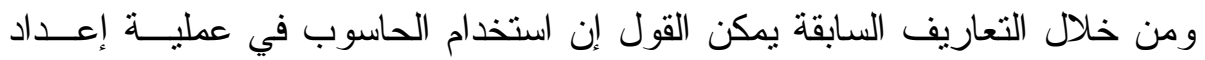

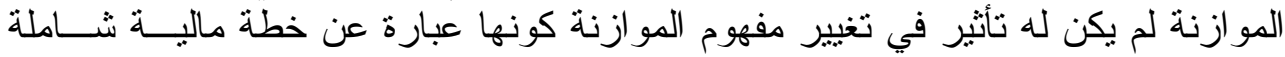

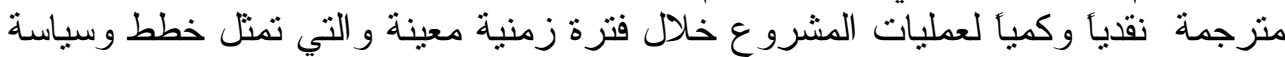

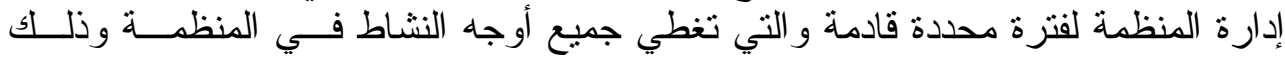

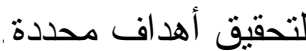

$$
\text { ثانياً - أنواع الموازنة }
$$

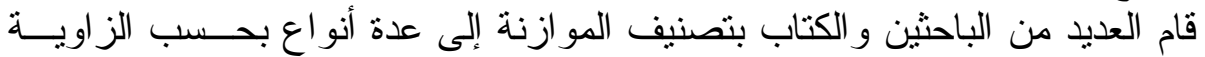

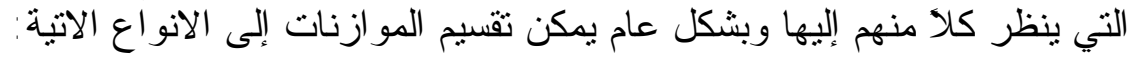

$$
\begin{aligned}
& \text { أولاً - من حيث الفترة التي تغطيها الموازنة }
\end{aligned}
$$

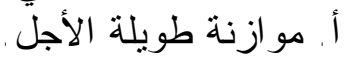

$$
\begin{aligned}
& \text { ب. ب. موازنة قصيرة الأجل. } \\
& \text { ثانياً - من حيث المرونة أنة المبرة } \\
& \text { أ. الموازنة المرنة. } \\
& \text { ب. الموازنة الثابتة. }
\end{aligned}
$$

ثالثاً - من حيث طبيعة العمليات و النشاط الأي تغطية الموازنة

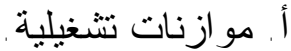




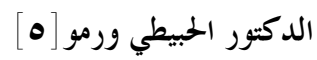

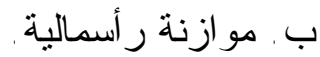

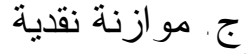

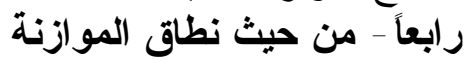

$$
\begin{aligned}
& \text { أ. ألموازنة الوظيفية (الفرعية) } \\
& \text { ب. الم الموازنات الثناملة (الرئيسة) }
\end{aligned}
$$

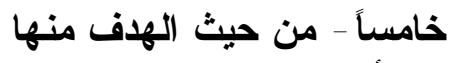

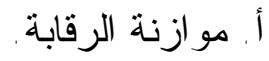

$$
\begin{aligned}
& \text { ب. ب. موازنة البر امج و الأداء (مو ازنة الأداء). }
\end{aligned}
$$

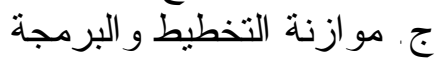

$$
\begin{aligned}
& \text { سادسأ - من حيث الموضنوع الثيط الذي تغطيه }
\end{aligned}
$$

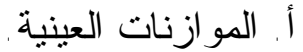

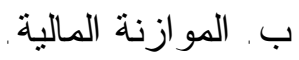

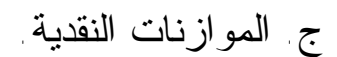

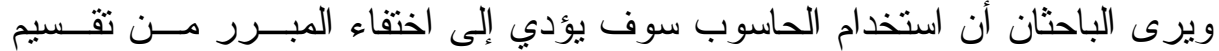

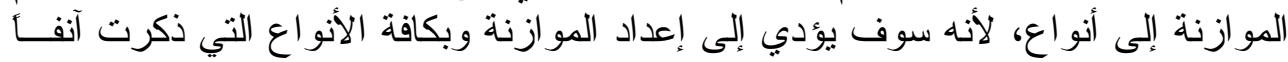

\section{مفهوم عملية إعادة الهندسة وأهميتها}

يعد استخدام الحاسوب في معظم المنظمات الحكومية أو الأهلية من أكثر المو اضـئيع

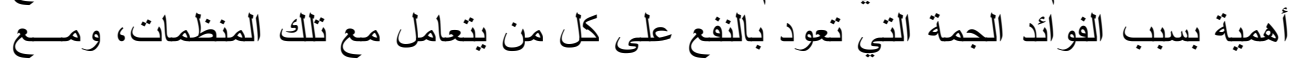

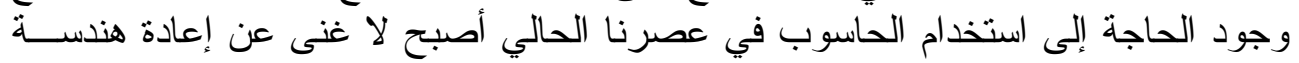

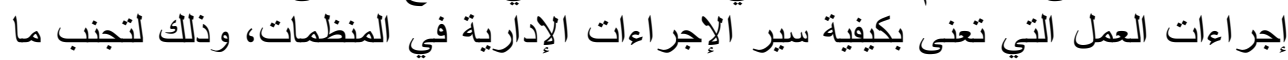

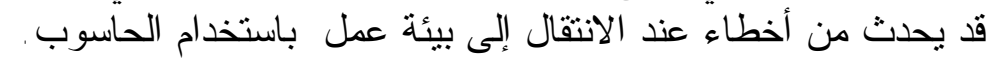

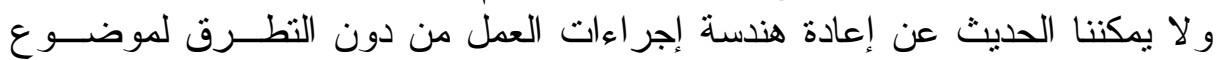

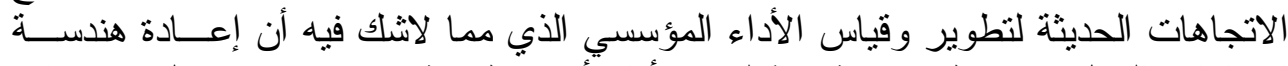

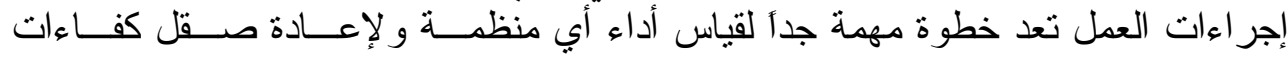

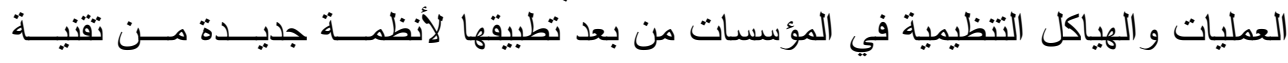

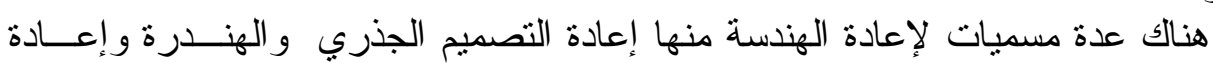
الهنسة التتظيمية و إعادة هيكلة العملية، وقد وردت العديد من التعــاريف لعمليــة إعـادة العادة

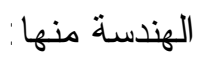


( . تحليل و إعادة تصميم تتابع العمل و عمليات التشغيل داخل المنظمات وبينهــا Neill) and Sohal , 1999, 573 )

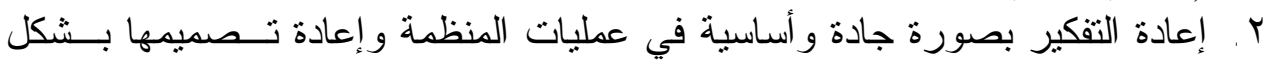

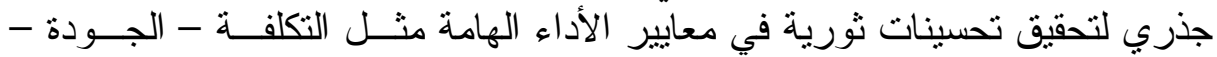
الخدمة - سر عة الانجاز (Hammer and Champy, 1993, 24)

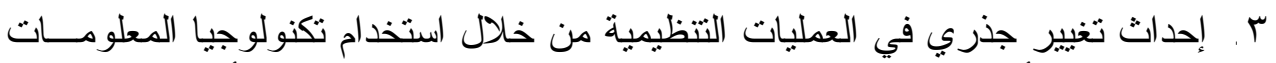

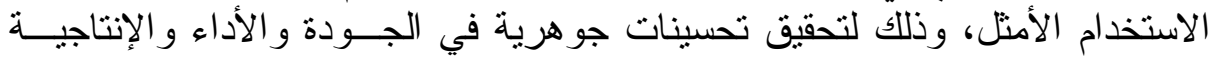

(Raymond, et al ., 2003, 72)

ويرى الباحثان أنه يمكن تعريف إعادة الهندسة بأنها قيام الشركة بإعادة التـصميم

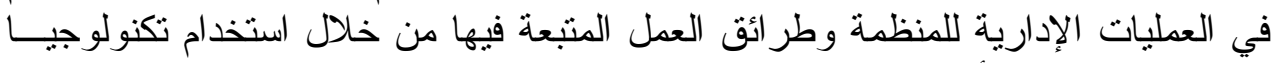

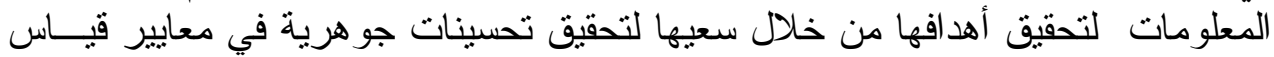

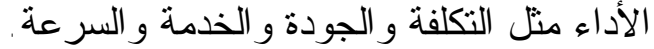

من خلال التعاريف السابقة يتبين أن جميعها تشنتركة في في عدد من العناصر و أهمها

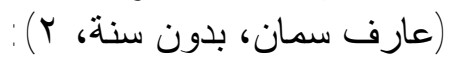

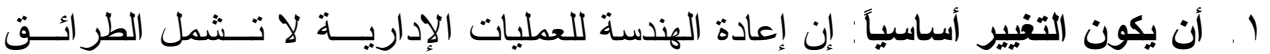

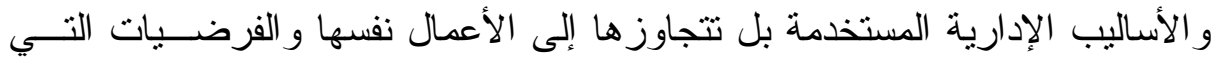
تقوم عليها . الاسبا الإن

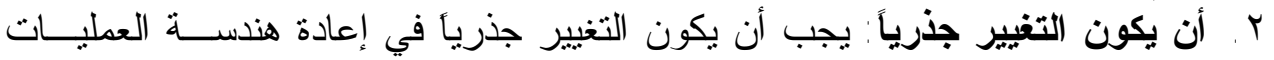

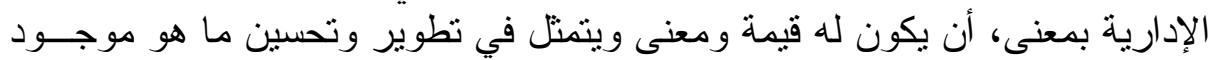

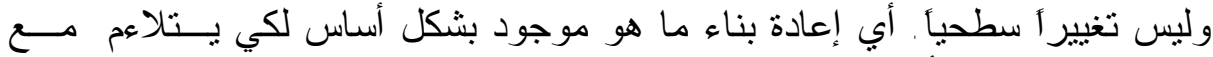

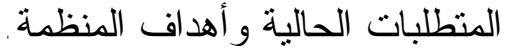

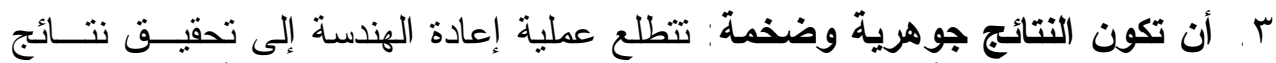

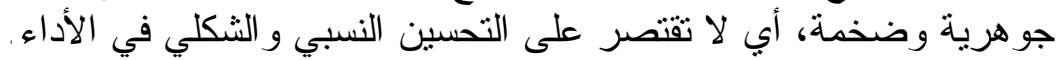

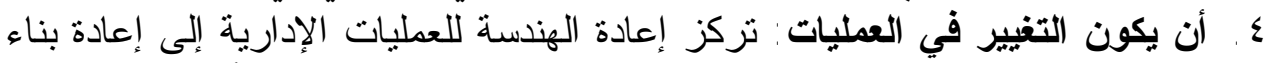

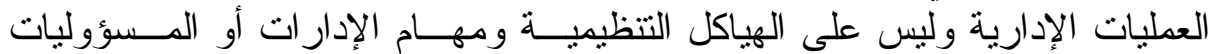

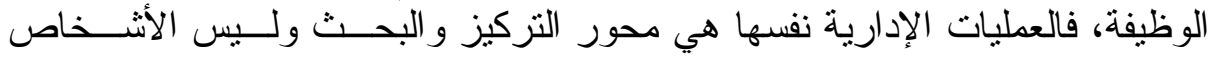

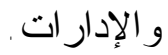

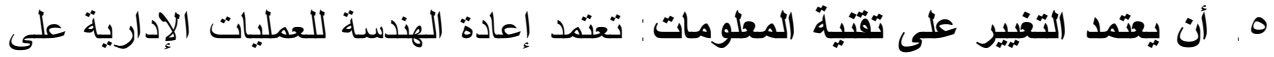

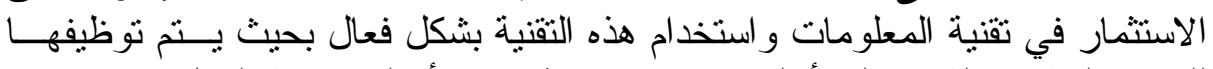

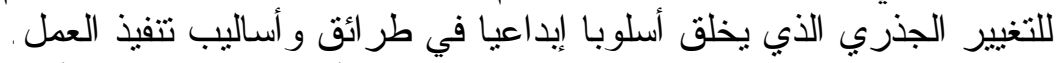

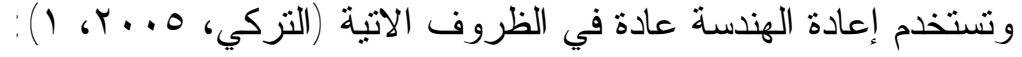

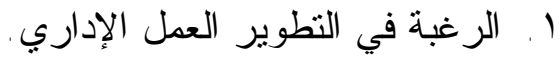

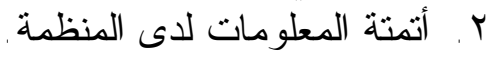

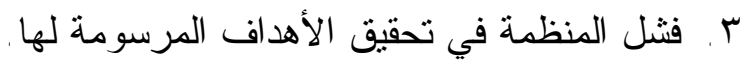

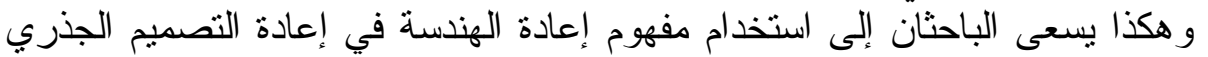

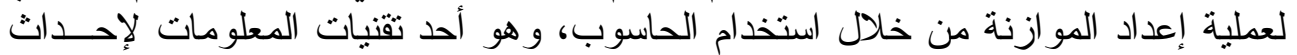

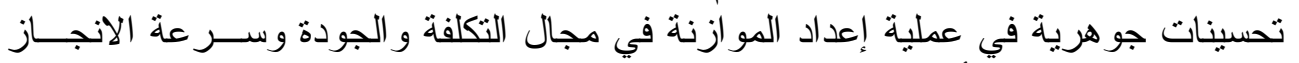
بوصفها خطة شاملة لأنشطة المنظمة معبر ا عنها بصورة في مالية الئة 


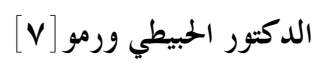

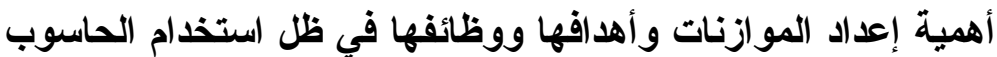

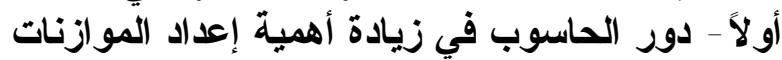

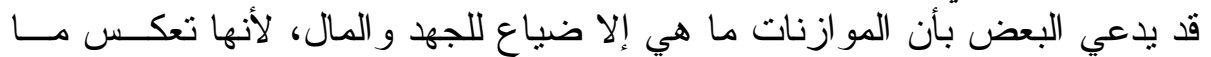

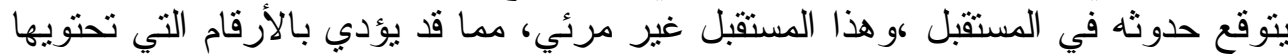

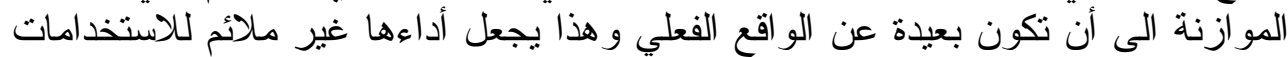

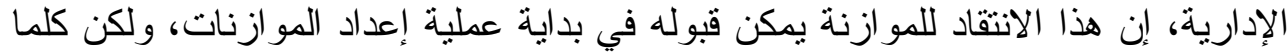

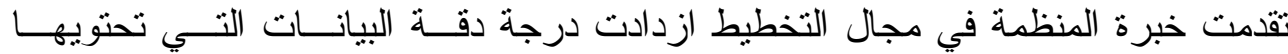

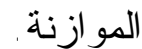

ولهذا فإن أهمية خصائص الموازنة تتضح من خلال: (إصدارات المجمع العربـي

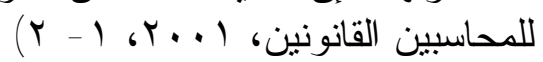

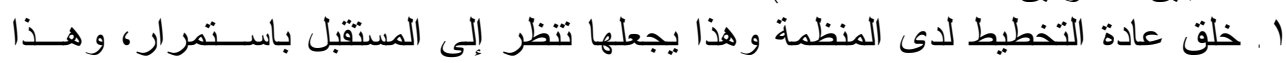

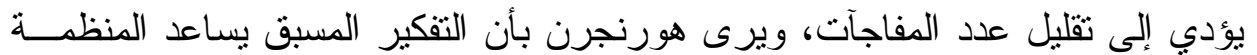

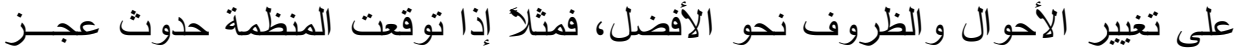

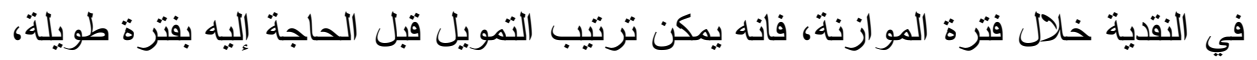

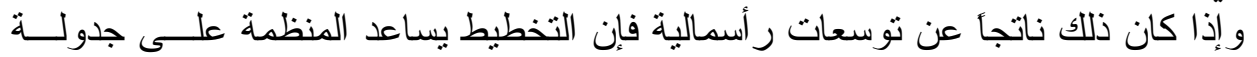

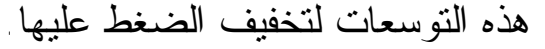

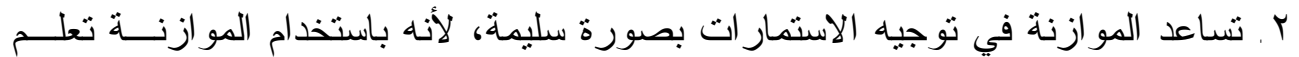

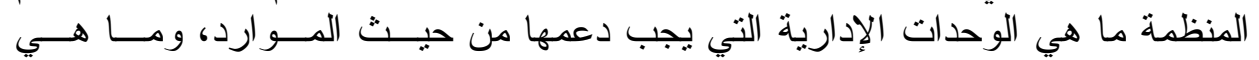

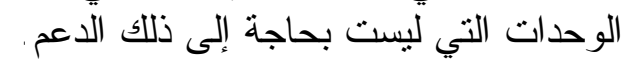

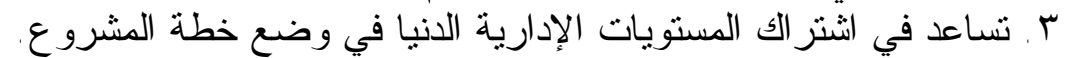

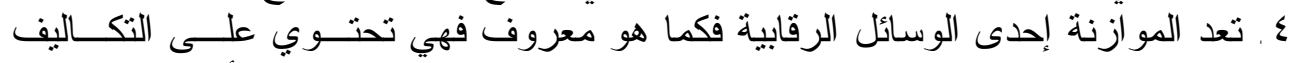

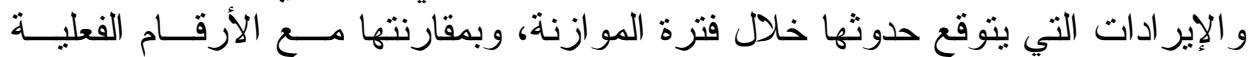

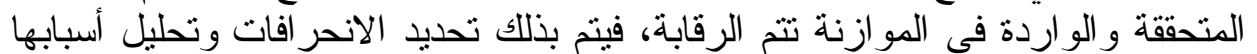

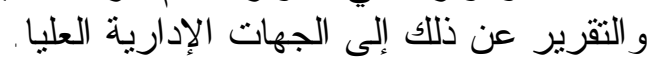
ه. التتسيق بين الإدار ات و الأقسام المختلفة في المنظمة الوالواحدة، الإلفعند معرفة حجم المبيعات

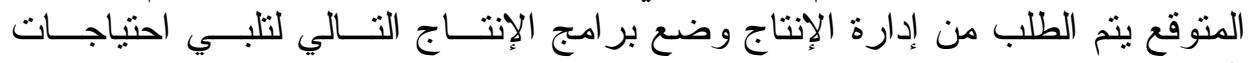

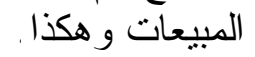
7 . المو ازنة تساعد في تحديد المسؤولية لمر اكز التكلفة والربحية و الاستثمارية.

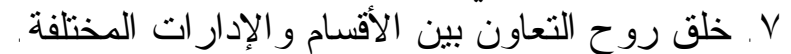

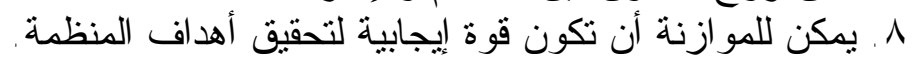

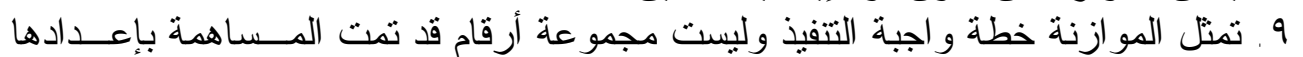
من قبل المدر اء و المو افقة عليها.

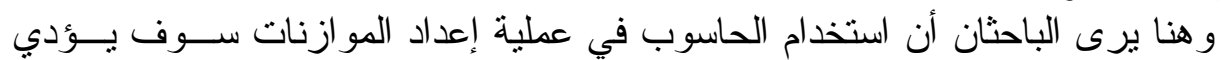

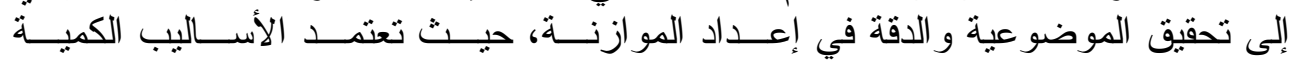

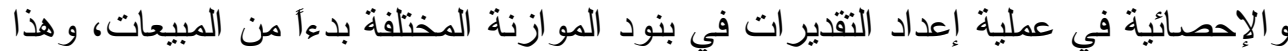

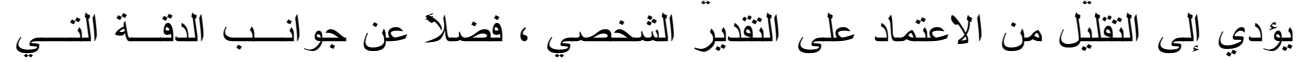
يوفرها الحاسوب من خلال العمليات الحسابية. 
يتم عادة إعداد الموازنات وذللك لتحقيق مجموعة من الأهداف، ويمكن تلخيص أهـــ التهـ

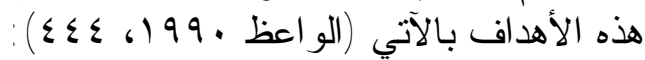

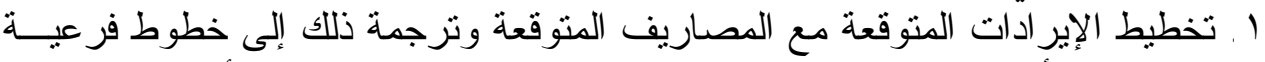

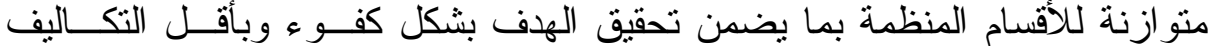
الممكنة.

r. تحديد معايير دقيقة تكون أساساً في تقييم الأداء وتحديد مسؤولية كل فرد عن النـشاط

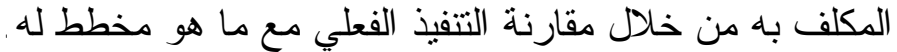

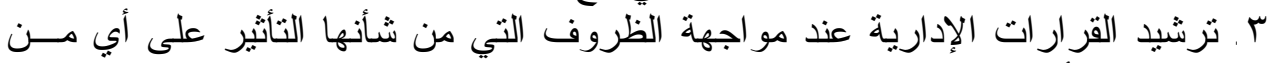

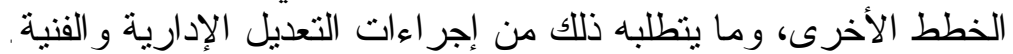

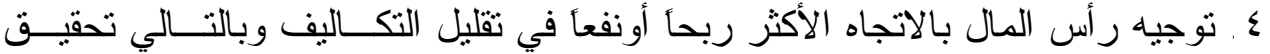

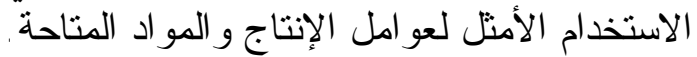

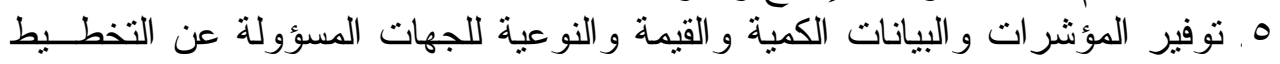
و المتابعة المركزية.

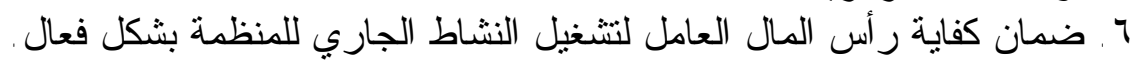

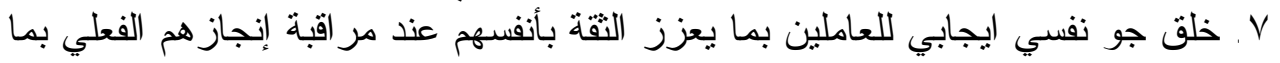

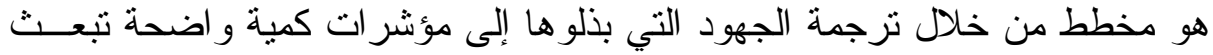

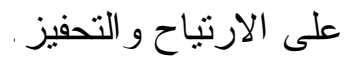

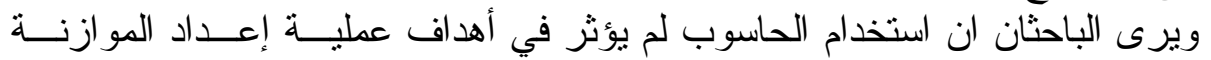
بشكل مباشر ، ولكنه أثر بالتأكيد على سهولة الوصول التهول إلى هذه الأهداف وتحقيقها.

\section{ثالثاً - وظائف الموازنة}

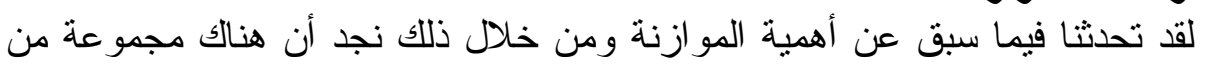

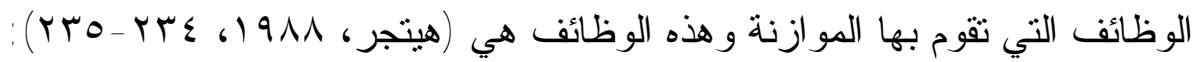

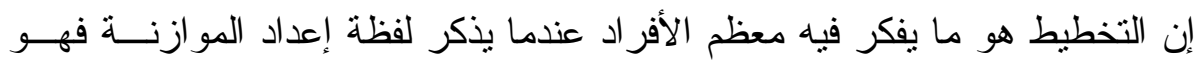

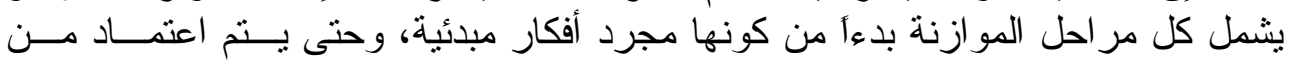

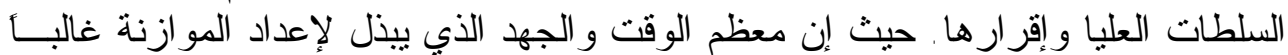

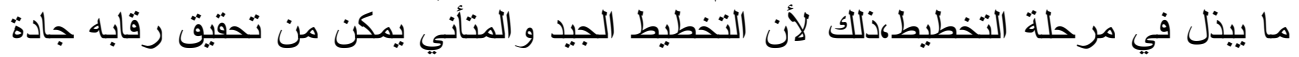
كوظيفة ثانية للمو ازنة.

ب الرقابة

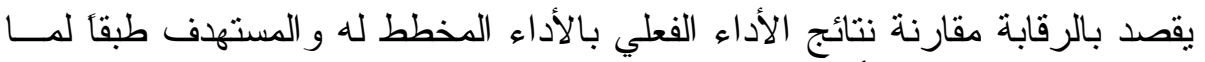

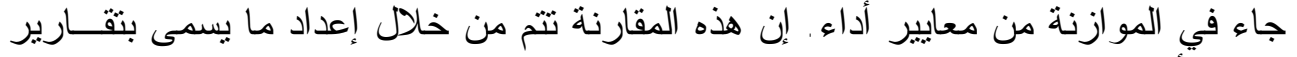

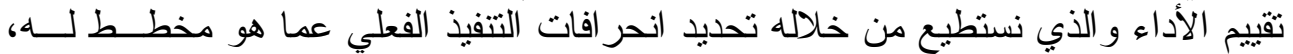

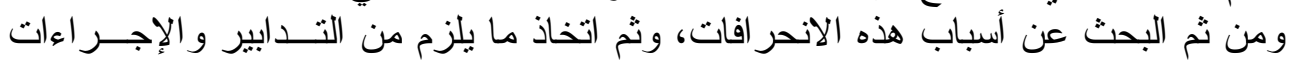

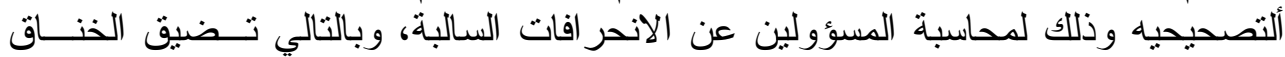
عليها حتى لا تتكرر مره أخرى، ومكافأة المسئولين عن الانحر افات الموجية وتطوير ها. 
الدكتور الحبيطي ورموب[9]

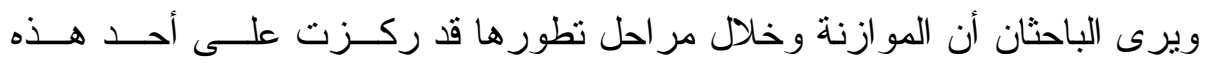

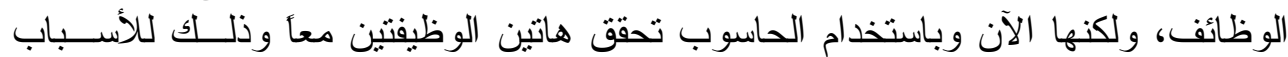

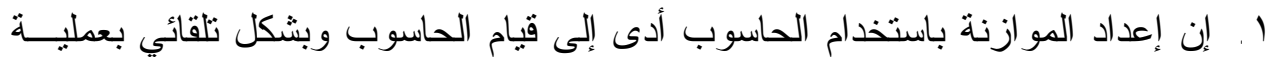
المقارنة بين الأداء الفعلي و المخطط بموجب المبات الموازنة و على مستويات نشاط مختلفة

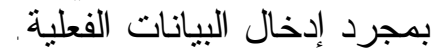

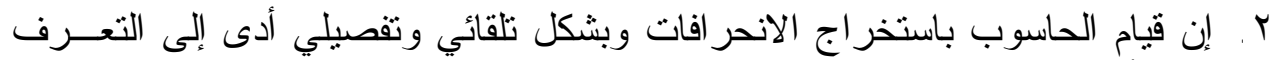

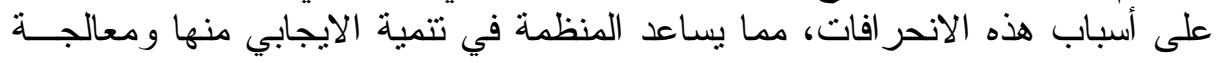

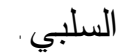

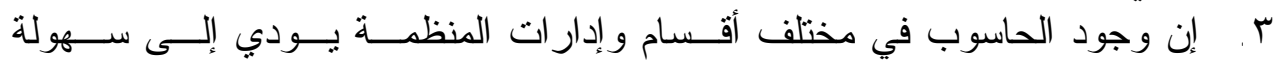

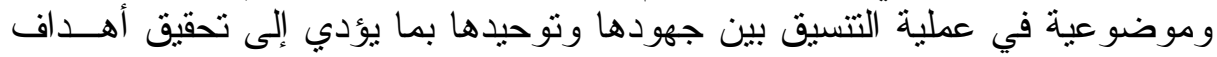

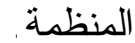

\section{مبادئ وقو اعد إعداد الموازنة

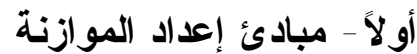

لكي يتم إعداد المو ازنة بصورة صحيحة ودئة ودقيقة فلابد من وجود مبادئ علمية تقـوم

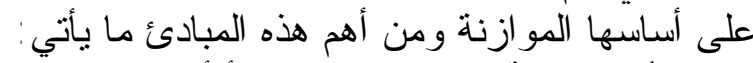

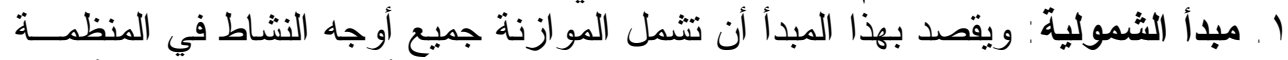

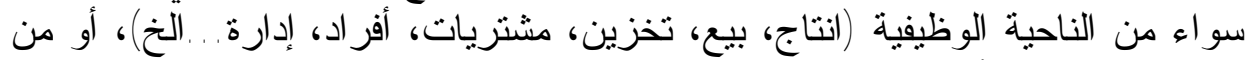

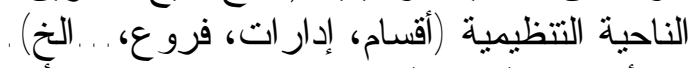

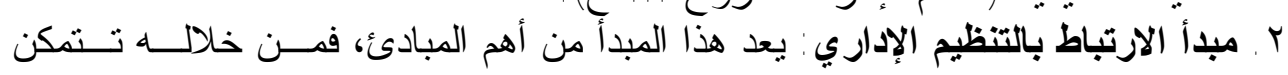

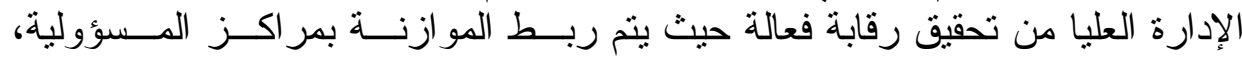

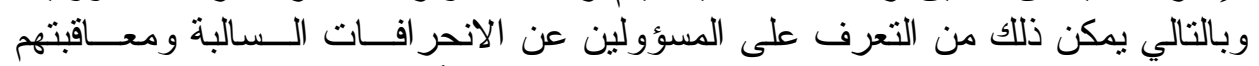

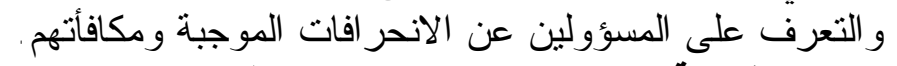

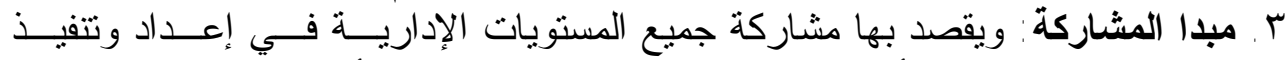

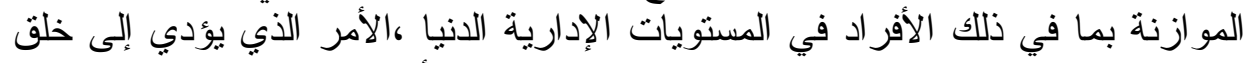

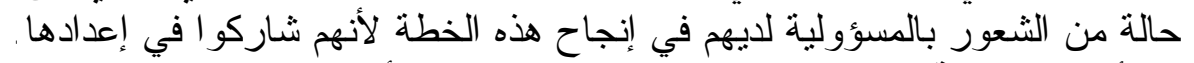

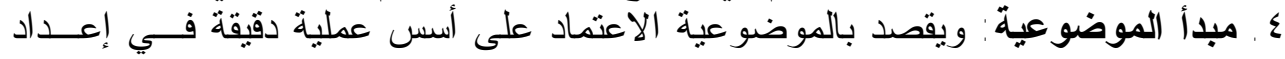

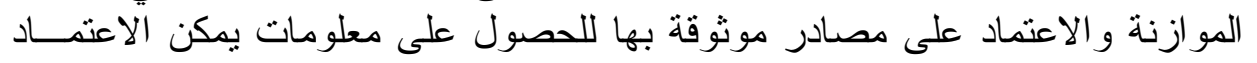
عليها.

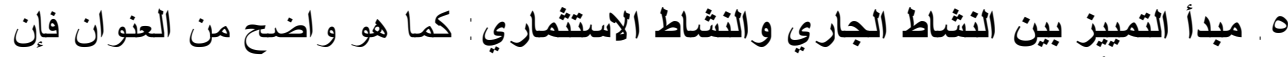

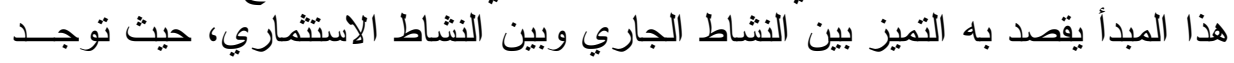

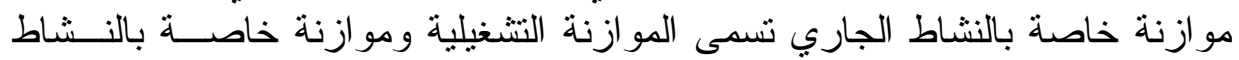

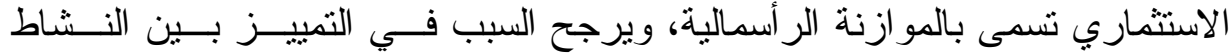

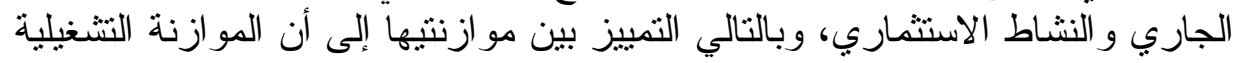

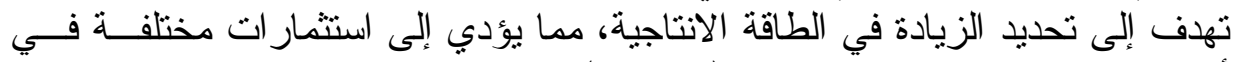

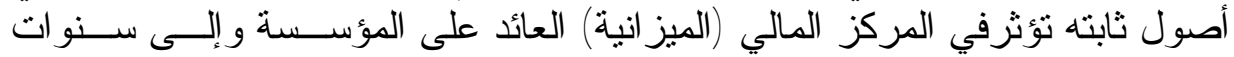
كثيرة قادمة. 


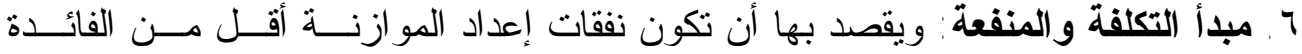

المرجوة من إعداد الموازنة، لأنه كلما كانت نفقات إعداد الموازنة أكبات أكبر من فائـــنها

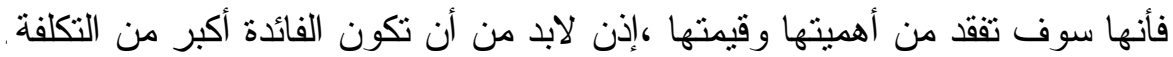

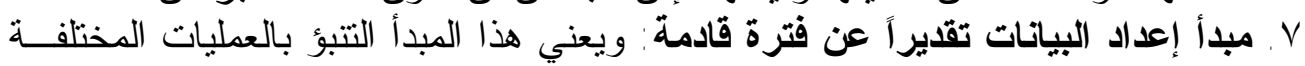

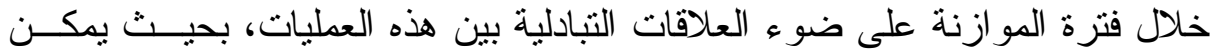

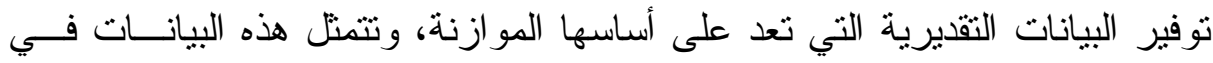

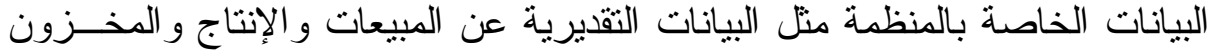

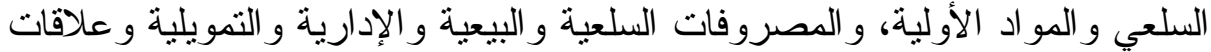

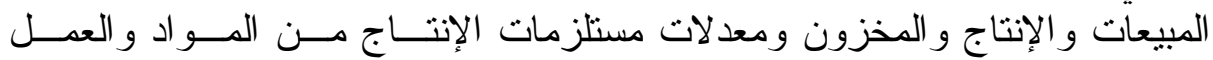

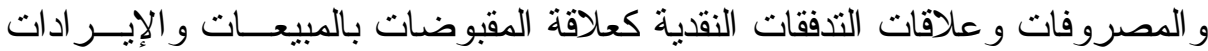

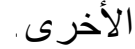

^. مبدأ التتــسيق: إن أهمية التتسيق تظهر في تحقيق التوازن بين العمليــات و والأنـشطة

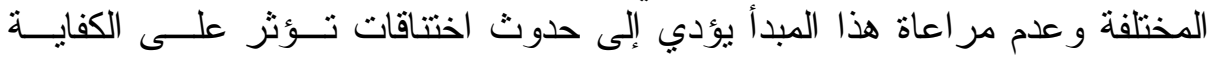
الإنتاجية للمنظمة، ويعني هذا المبدأ تحقيق التجنس بين الجداول التهائ الفرعية المشتقة من

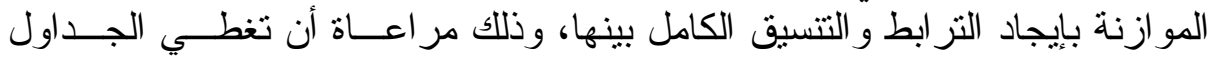

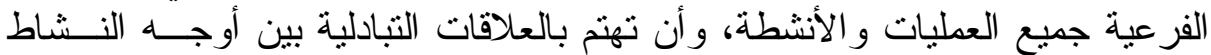

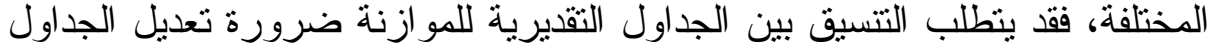

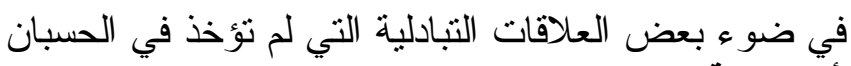

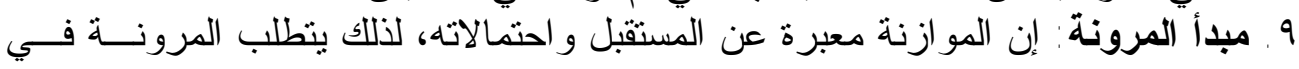

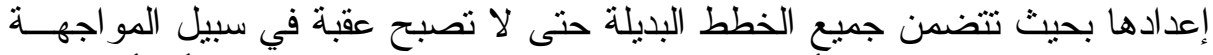

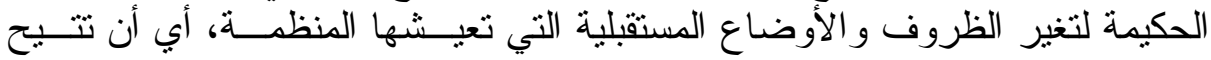

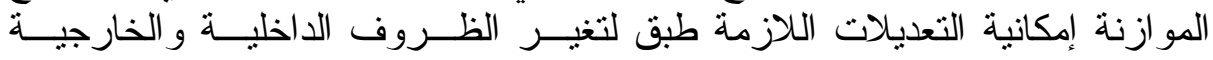
للمنظمة.

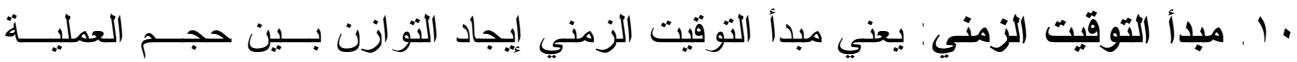

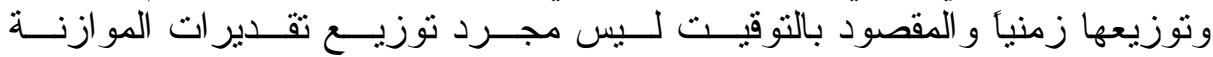

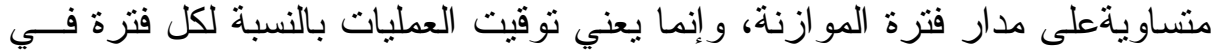

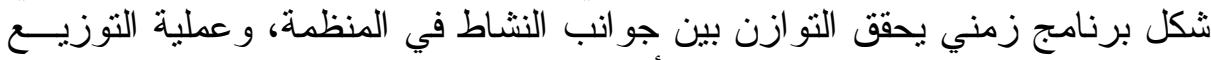

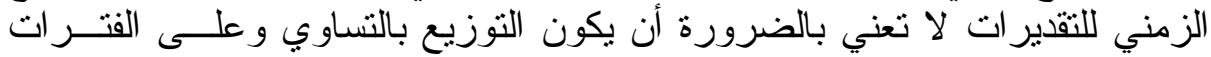

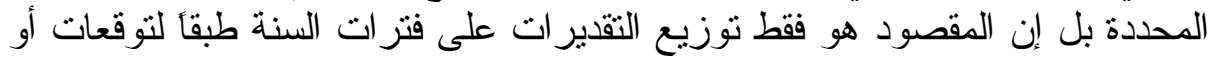

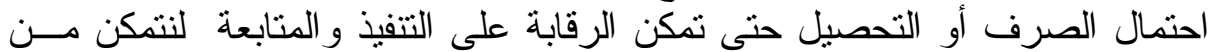
تجنب أي ارتباكات مالية.

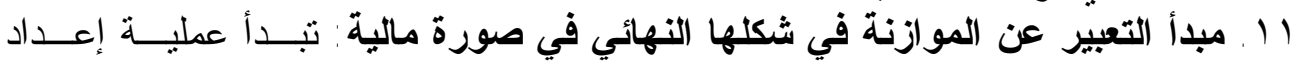

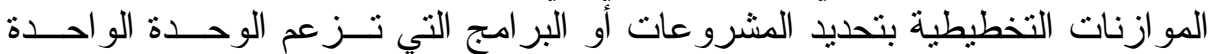

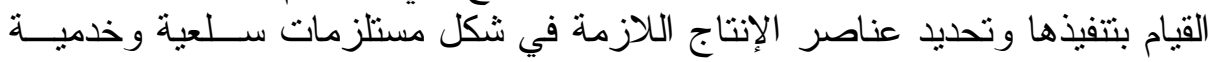

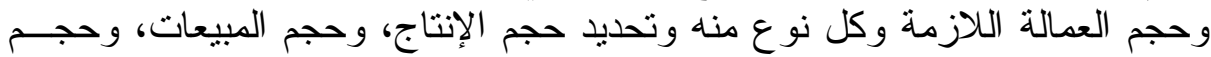

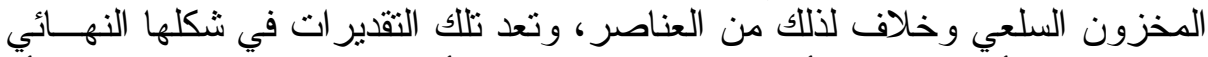

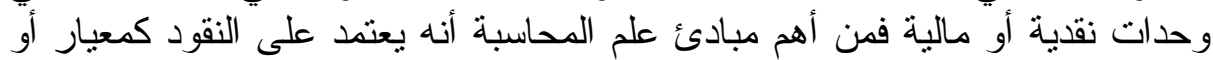

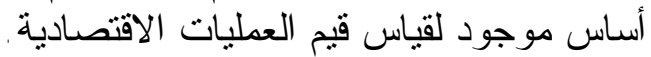




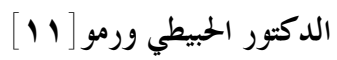

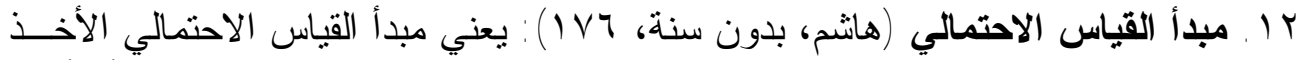

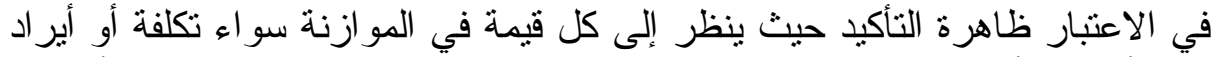

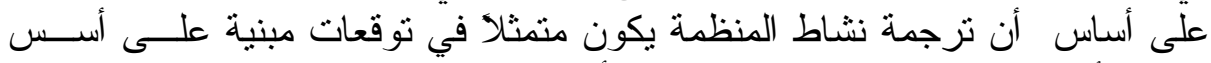

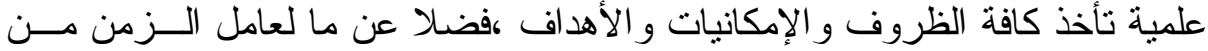

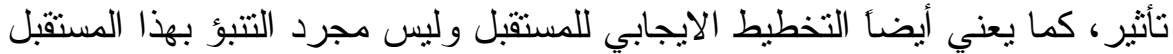

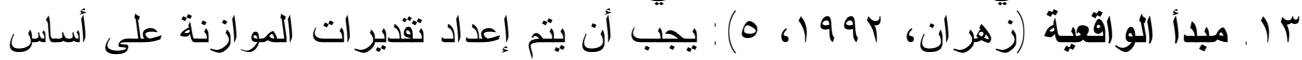

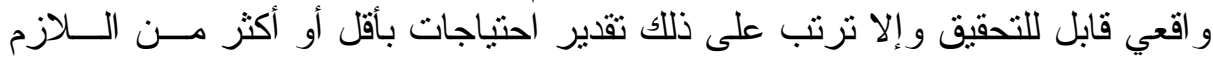

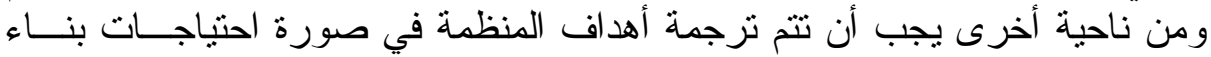

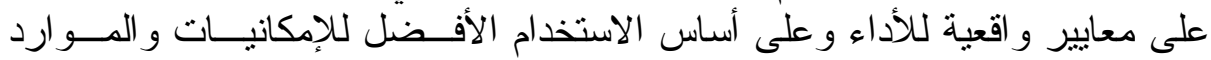

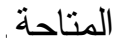

ـ ا ـ المبدأ السلوكي للموازنات: مما لاثك فيه أن نجاح أو فثل الموازنة التخطيطية كأداة

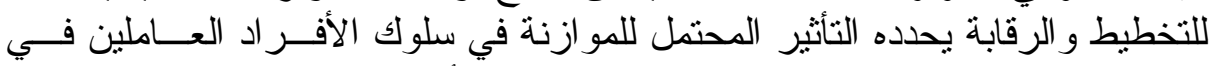

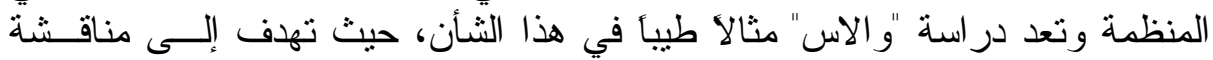

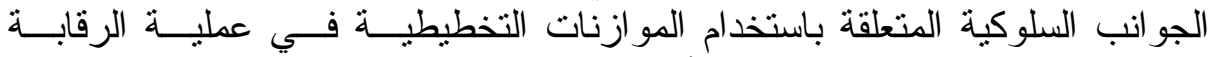

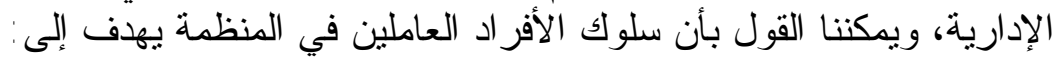
- ت تحقيق أهداف عامة المنظمة.

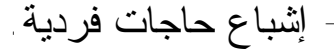
فيما ياتي المكملات السلوكية قد تنتج عن عدم التو افق بين هذين الهدفين:

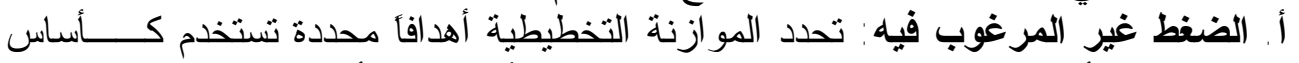

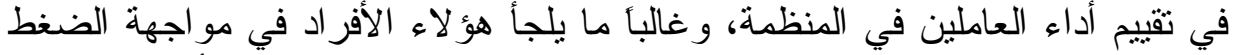

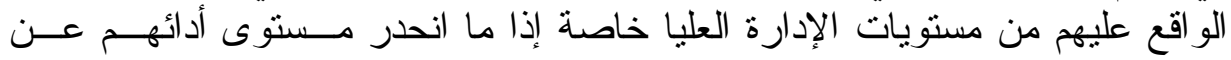

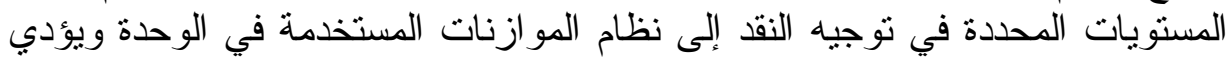

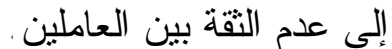

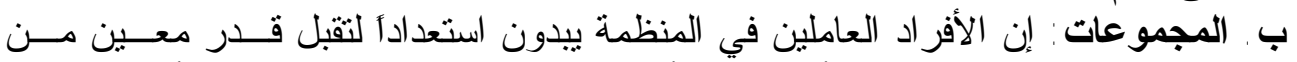

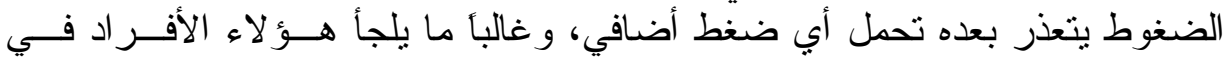

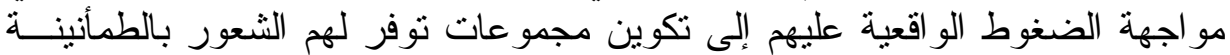

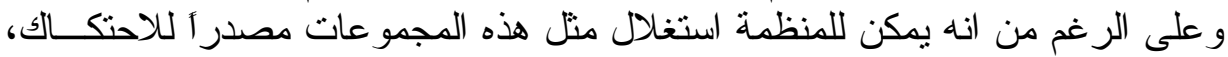

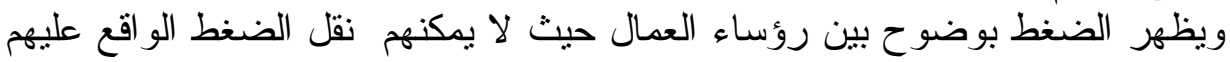

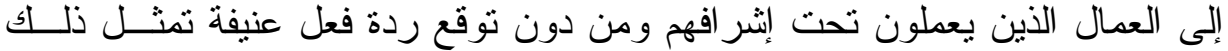

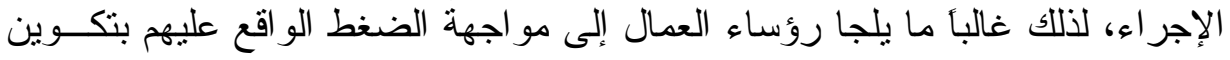
مجمو عات منهم.

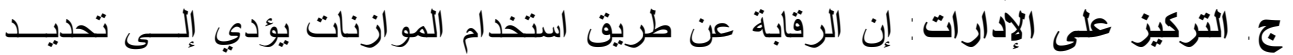

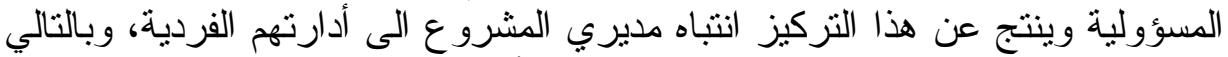

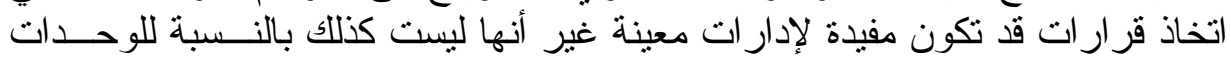

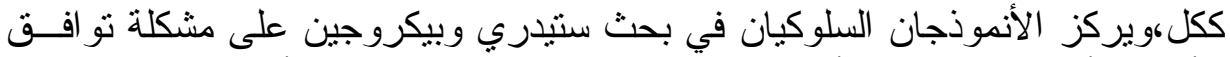

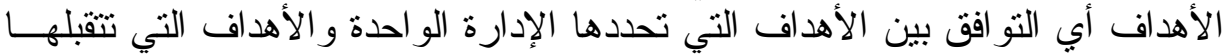

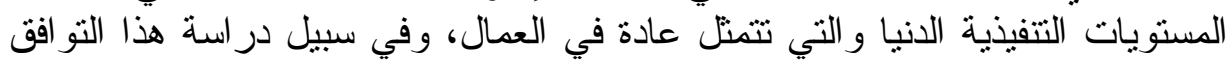

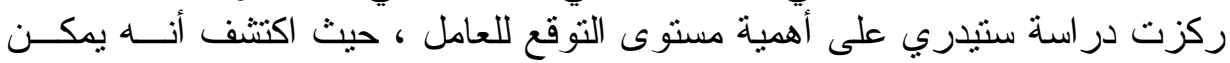


تحقيق مستويات أفضل للأداء إذا ما ارتبطت الموازنة التخطيطية بمسـتوي التوقـع

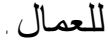

كما إنه تم التركيز على هذا المبدأ في تعريف الموازنة حيث عرفت الته على أنها: أنها:

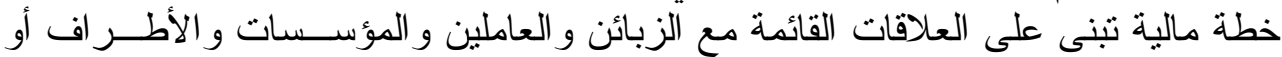

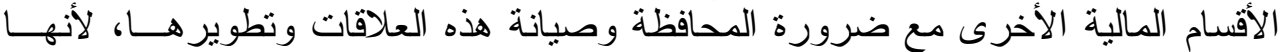

تانغير باستمر ار تغير الظروف (حسين، 10

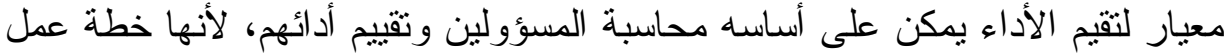

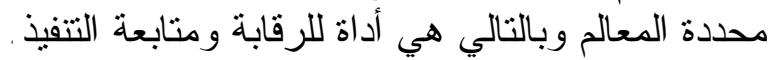

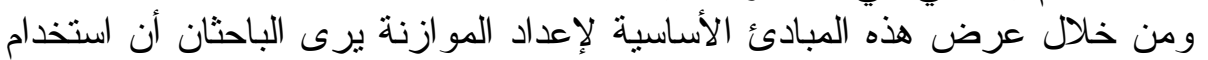

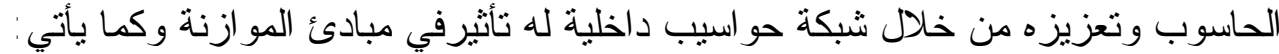

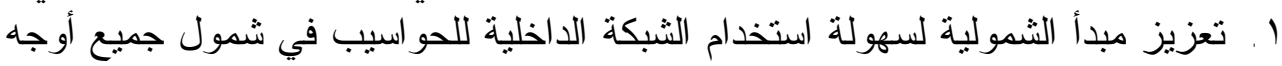

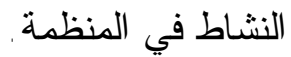

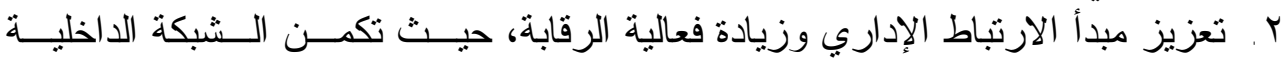

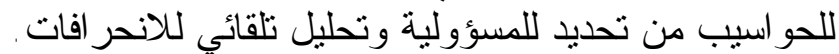

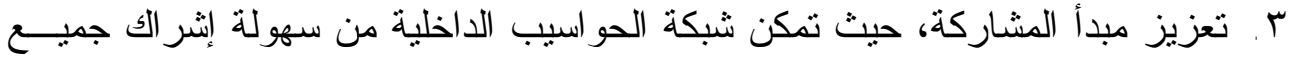

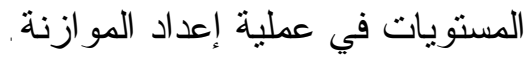

ع. . تعزيز مبدأ الموضوعية، حيث تتضح أهمية استخدام الحاسوب في تحقيق الموضو عية الهية

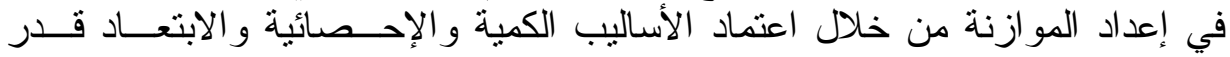

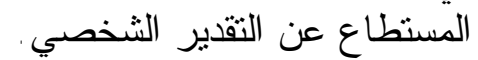
ه. تحقيق مبدأ الكلفة والمنفعة، حيث يؤدي استخدام الحاسوب إلى تقليل الكلف المستخدمة

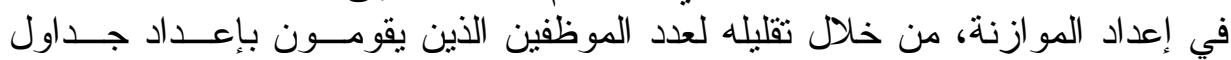

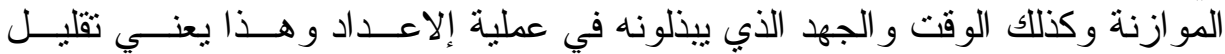
لتكاليف إعداد المو ازنة.

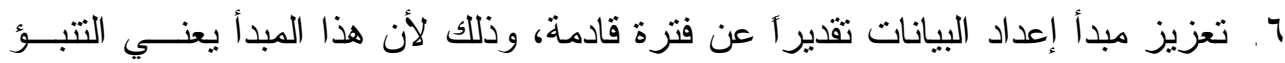

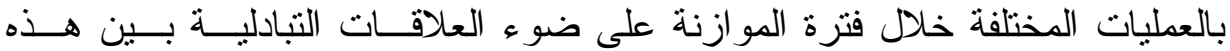

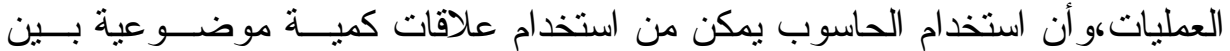

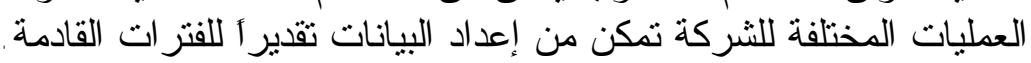

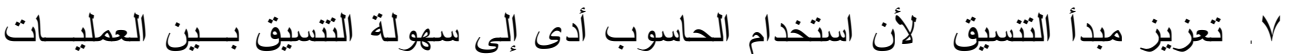
و الأنشطة المختلفة من خلال تحقيق التجنس بين الجداول الفرعية المشتقة من الموازنة لإنة بإيجاد التز ابط و النتسيق الكامل بينها.

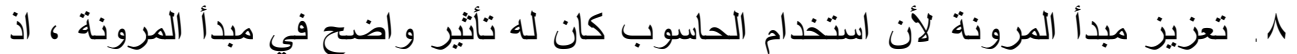

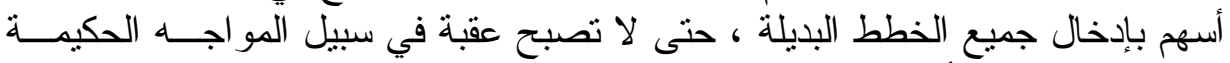

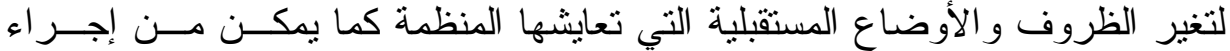
التعديلات اللازمة طبقاً لتغير الظروف الداخلية و الخارجية للمنظمة.

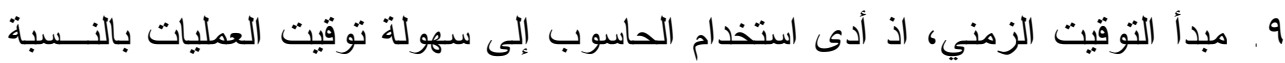
لكل فترة في شكل برنامج زمني يحقق التوازن بين جوانب النـشـاط فــي المنظمـــة 


\section{الدكتور الحبيطي ورمو[ب أ]}

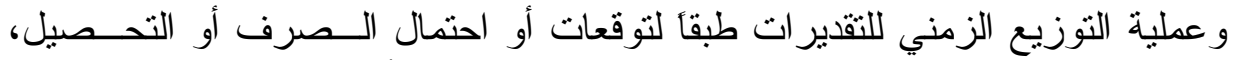
حتى يمكن الرقابة على التتفيذ ومتابعته وحتى يمكن تجنب أي الزئ ارتباكات مالية.

\section{ثثانياً - قو اعد وخطو اته إعداد الموازنة}

عند إعداد الدوازنة فأنه يؤخذ بنظر الاعتبار القواعد الاتية: (عبد العسال، ....؟،

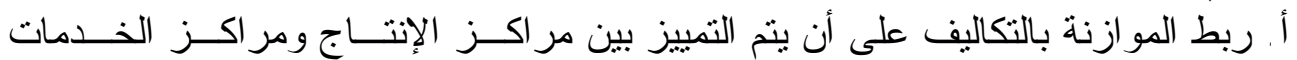

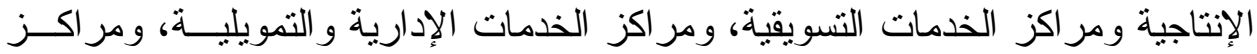

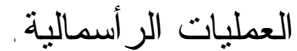

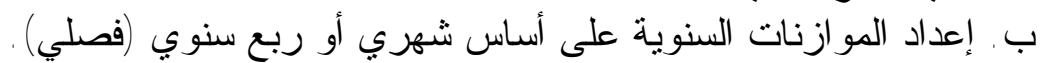

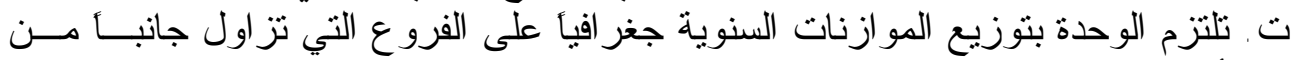
أنثطنها الاقتصادية الرئيسية.

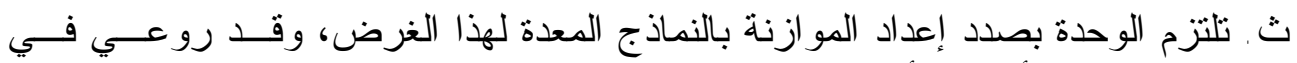

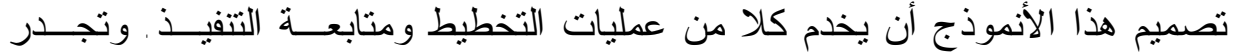

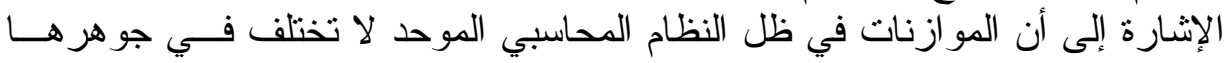

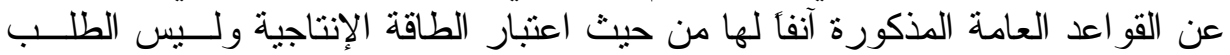

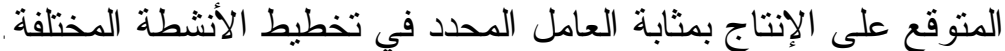

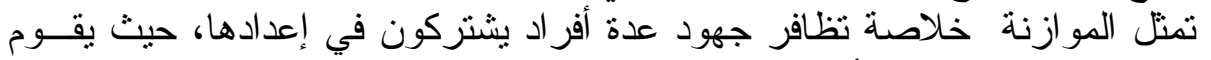

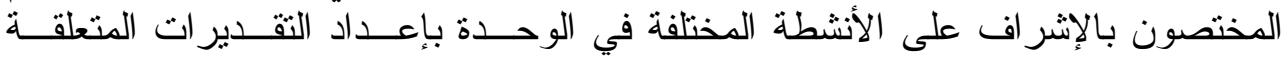

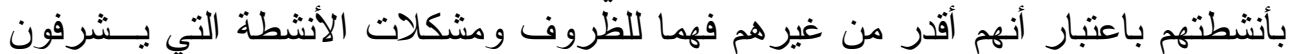

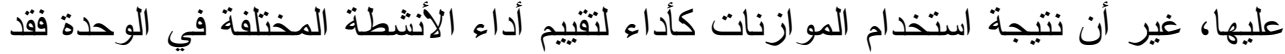

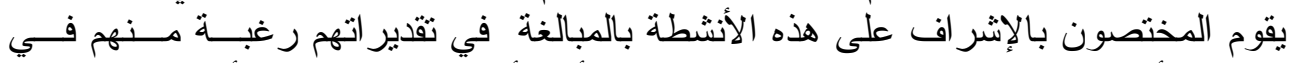

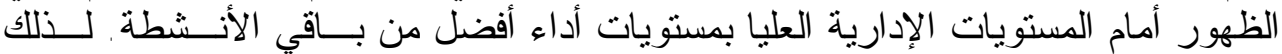

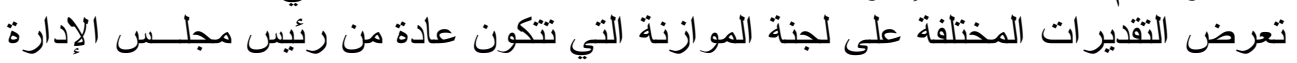

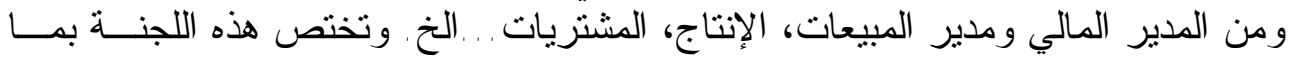

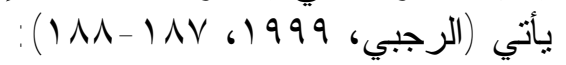

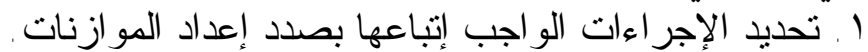

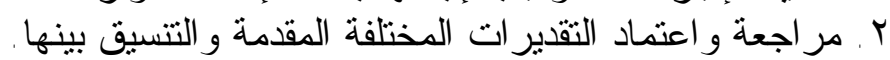

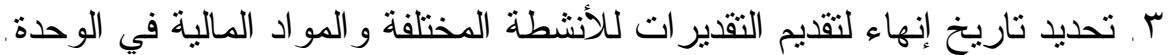

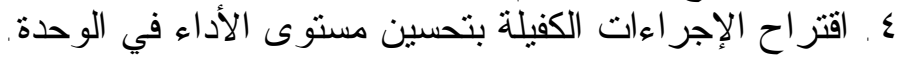

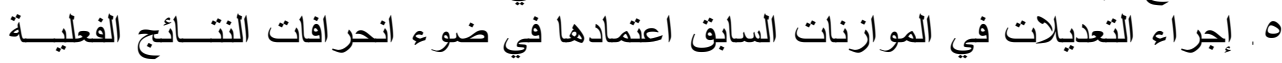

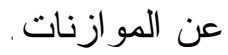
7. تحديد بداية ونهاية فترة إعداد الموازنات في ضوء المستجدات و الظروف التي تتـأثر

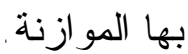

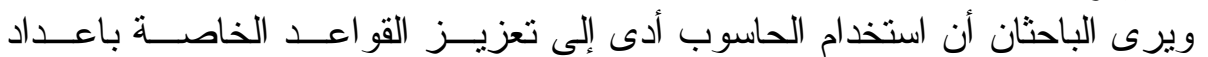
المو ازنة وسهولة تحقيقها من خلال :

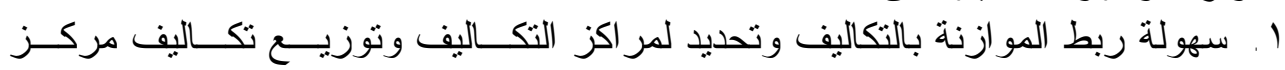
الخدمات على المر اكز الإنتاجية وبشكل تلقائي. 
r. إعداد الموازنة على أساس شهري أو فصلي أو نصف سنوي وبشكل تلقائي.

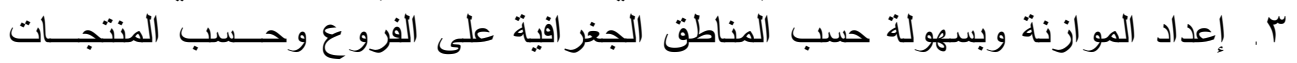
و على المستوى الكلي وبشكل تلقائي.

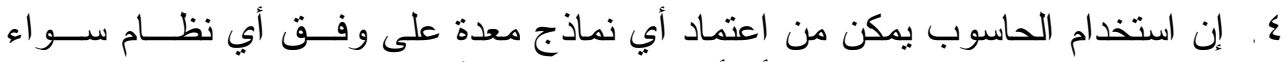

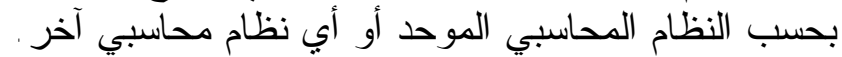

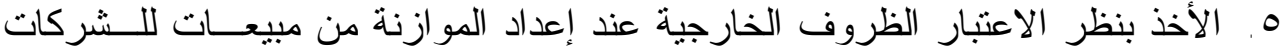

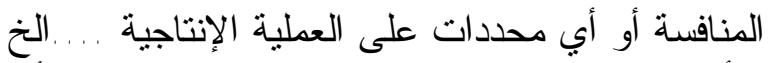

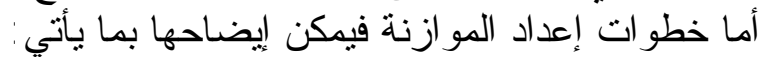

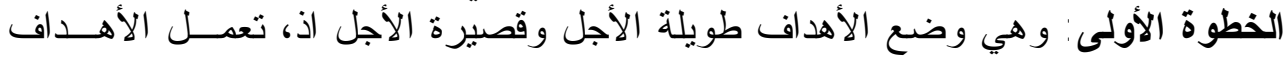

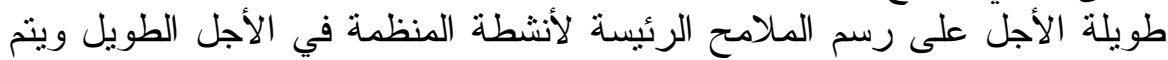

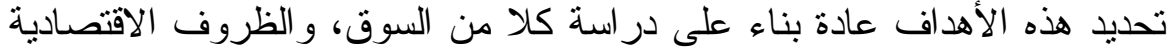

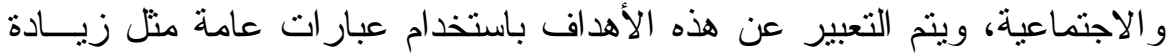

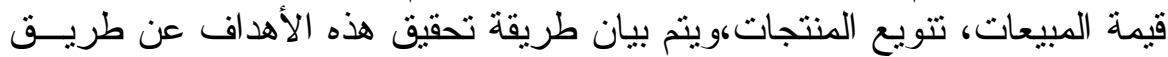

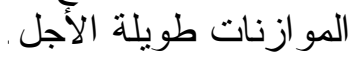

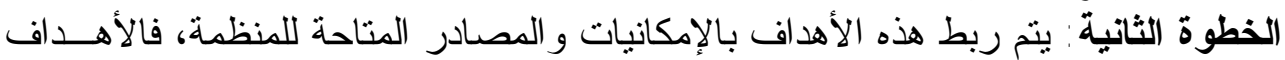

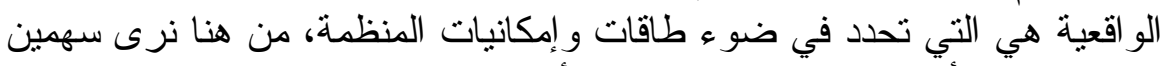

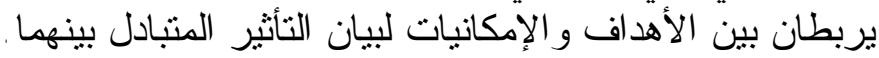

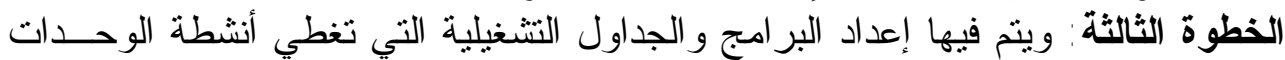

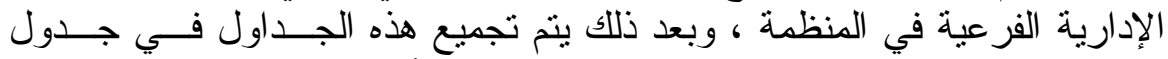

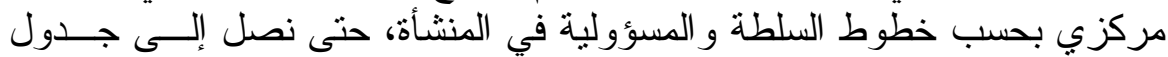

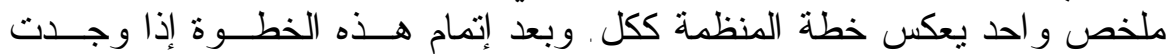

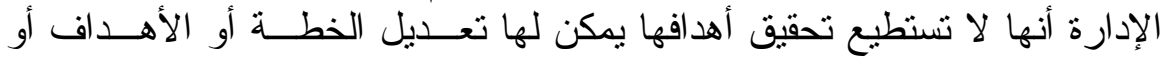

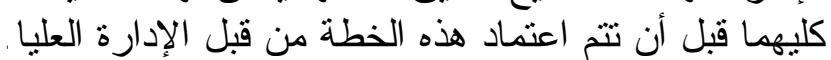

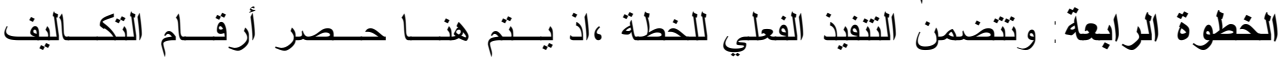

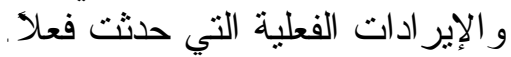

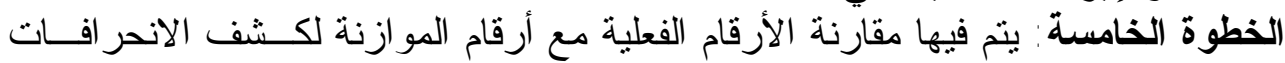

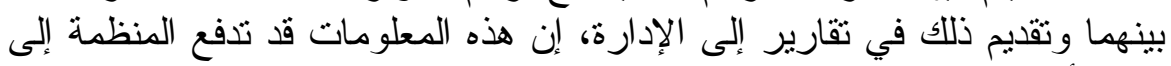

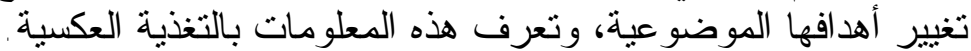

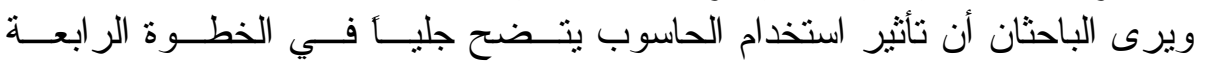

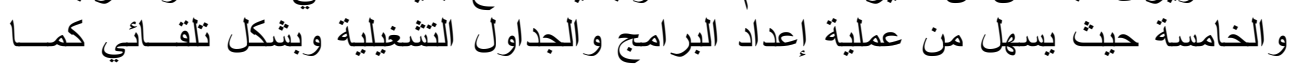

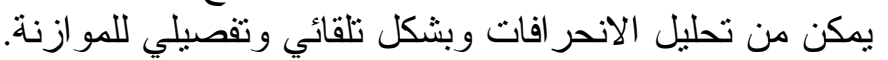

استخدام برنامج أكسل في إعداد الموازنة (حالة دراسية)

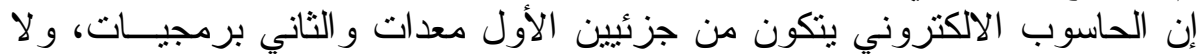

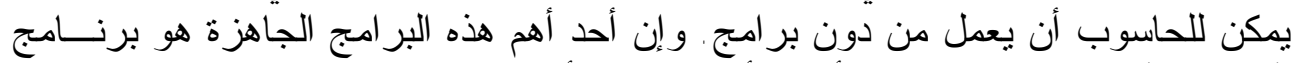
(EXCEL)

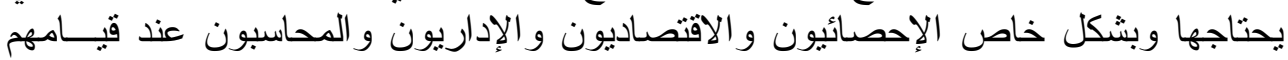

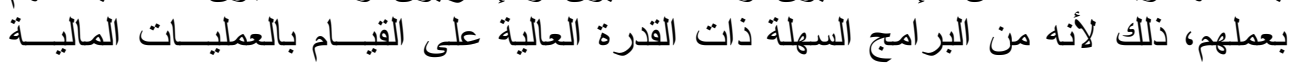




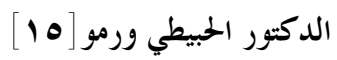

و الإحصائية و الاقتصادية سو اء في مجال المحاسبة المالية أو استخدام المحاسبة الإداريــة أو أي فرع من فروع الإنحاسبة بالمعنى الثنامل لعلم المحاسبة.

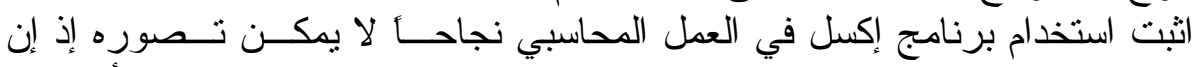

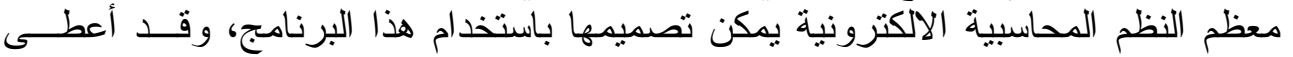

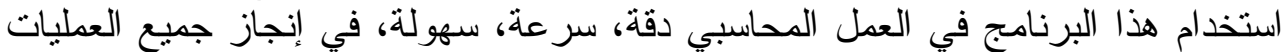
التي يمكن القيام بها داخل النظام المحاسبي.

\section{أولاً - حالة دراسية - مبية}

لبيان كيفية استخدام البرامج في إعداد الموازنة الثاملة نفترض الحالــة الدراســبة

تقوم شركة الموصل الصناعية بإنتاج نو عين من المنتجات أرب وتقوم بتسويقها فــي

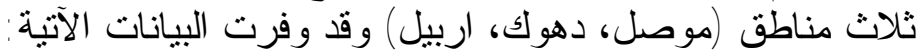

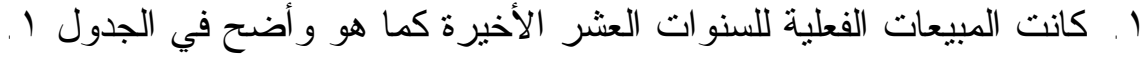

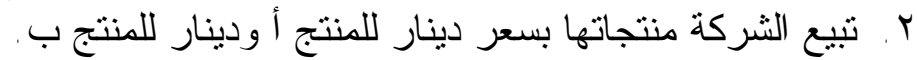

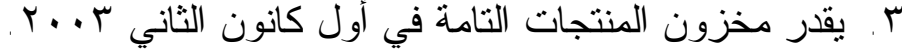

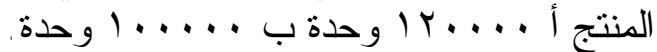

مخزون المنتجات تامة الصنع في نهابة الفترات الثهرية للربع الأول و الفترات ربع

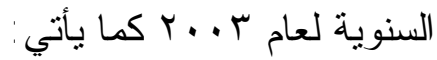

\begin{tabular}{|c|c|c|}
\hline المنتج ب & المنتج أ & الثشهر \\
\hline $9 \ldots$ & $11 \ldots$ & كانون الثاني \\
\hline$\wedge \ldots$ & $1 \ldots \ldots$ & شباط \\
\hline$v \ldots$ & $9 \ldots$ & اذذار \\
\hline$v \ldots$ & $9 \ldots$ & الربع الاول \\
\hline $7 \ldots$ & $\wedge \ldots$ & الربع الثاني \\
\hline $0 \ldots$ & $v \ldots$ & الربع الثالث \\
\hline$v \ldots$ & $9 \ldots$ & الربع الر ابع \\
\hline
\end{tabular}

ع. تستخدم الثركة ثلاثة أنواع من المو اد الأولية هي س ، ص ، ع ع ومعدلات استخدامها لإلتناج الوحدة الو احدة من المنتج كما يأتي:

\begin{tabular}{|c|c|c|}
\hline+ & $i$ & المادة الخام \\
\hline$r$ & - & $\omega$ \\
\hline- & 1 & $ص$ \\
\hline- & $r$ & $\varepsilon$ \\
\hline
\end{tabular}

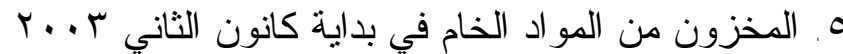




\begin{tabular}{|c|c|c|}
\hline سعر الوحدة & وحدة & المادة \\
\hline$\bullet, r .0$ & ro... & س - س \\
\hline$\bullet, \mu$ & vo... & ص ص \\
\hline$\because .90$ & $r \ldots$. & $\varepsilon$ \\
\hline
\end{tabular}

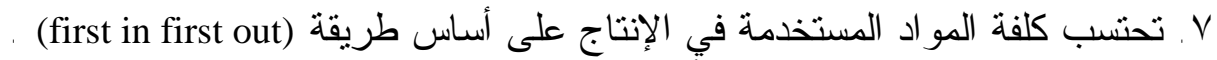

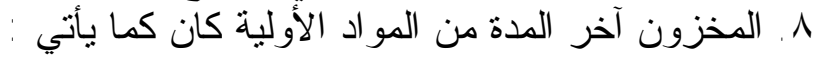

\begin{tabular}{|c|c|c|c|}
\hline المادة ع & المادة ص & المادة س & الثهر \\
\hline r & $\wedge \ldots$ & TRY... & كانون الثاني \\
\hline ro.... & $90 \ldots$ & $r \varepsilon \ldots$. & شباط \\
\hline$r \leq 0 \ldots$ & $\vee \wedge \ldots$ & $r \leq 0 \ldots$ & اذار \\
\hline$r \leqslant 0 \ldots$ & $\vee \wedge \ldots$ & $r \leqslant 0 .$. & الربع الاول \\
\hline ..... & NT... & rro... & الربع الثاني \\
\hline r..... & A $\vee .$. & $r \varepsilon \ldots$ & الربع الثالث \\
\hline ro.... & $9 \ldots$ & $r \leqslant 0 \ldots$ & الربع الر ابع \\
\hline
\end{tabular}

9 ـ تتوقع الثركة دفع الأسعار التقديرية للمواد الخام المشتر اة.

\begin{tabular}{|c|c|}
\hline سعر الوحدة & المادة \\
\hline$\cdot, r \ldots$ & س س \\
\hline •. & ص ص \\
\hline 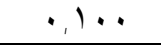 & $\varepsilon$ \\
\hline
\end{tabular}

• ا. معدل الوقت اللازم لإنتاج الوحدة من المنتج النهائي ومعدل الأجر في الساعة كمـا

\begin{tabular}{|c|c|c|}
\hline معدل الاجر & معدل الوقت & المنتج \\
\hline$\cdot, r \cdots$ & $\cdot, 0$. & أ \\
\hline - Y. & •, $\leqslant$. & ب \\
\hline
\end{tabular}

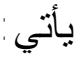


[iv] الدكتور الحبيطي ورمو

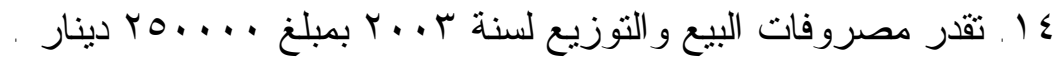

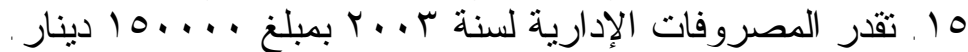

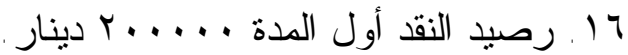

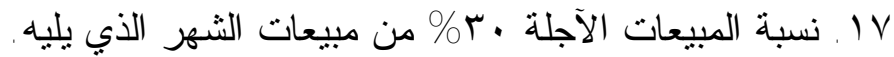

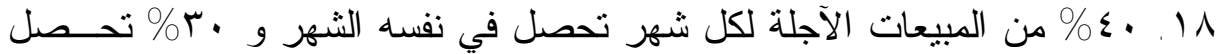

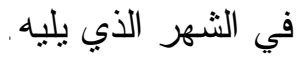
9 1 ـ تكون المدفوعات عن المواد المشتراة .0\% في نفسه الثهر و . \% في الثهر

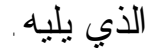
• r ـ تدفع جميع المدفو عات الأخرى نقداً خلال نفسه الثهر .

ثانياً - تنفيذ البرنامج

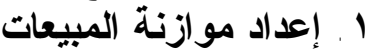

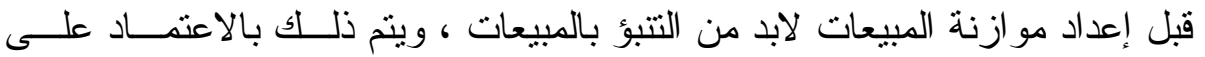

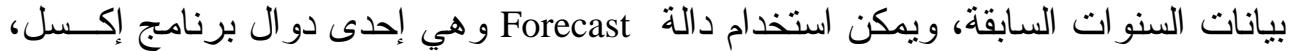
وكما هو واضح في الشكل الآتي:

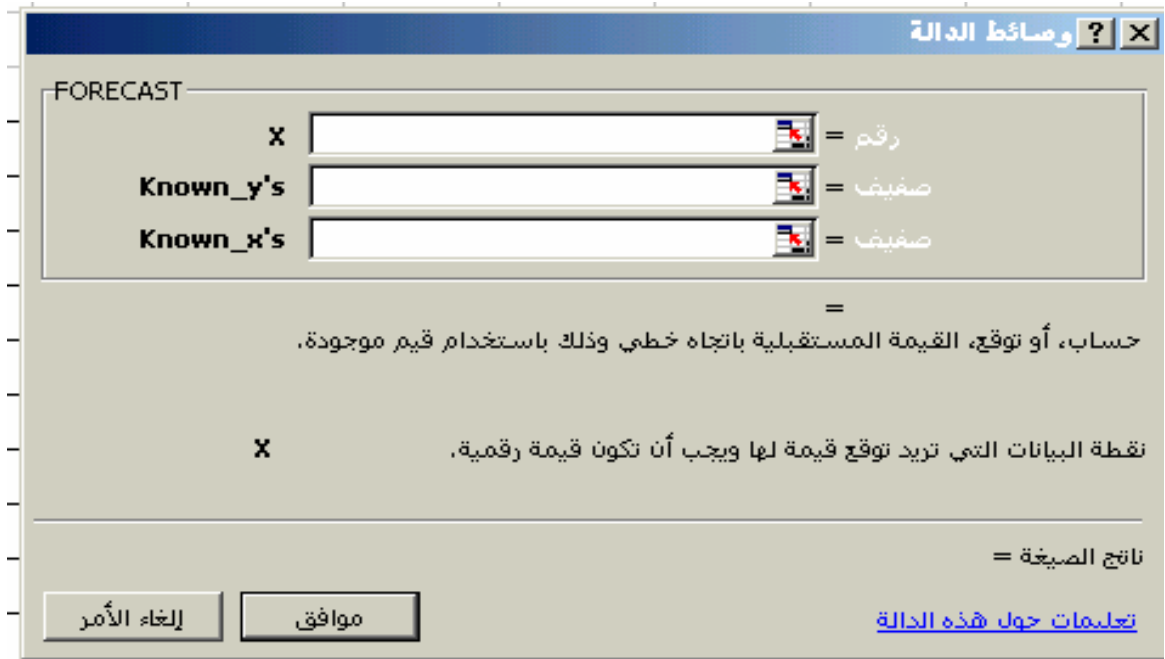

وتستخدم هذه الدالة لحساب أو التتبؤ بقيمة مستقبلية باستخدام قيم موجــودة، تكــون

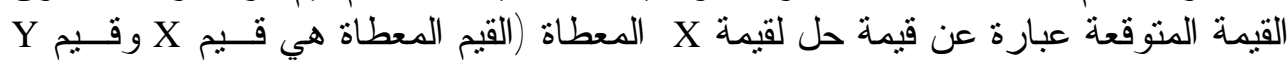
الموجودة، وقيم التتبؤ بالقيمة الجديدة باستخدام الانحدار الخطي) ويمكن استخدام هذه الدالة الذية للتتبؤ بالمبيعات ومتطلبات المخزون و اتجاهات السوق المستقبلية.

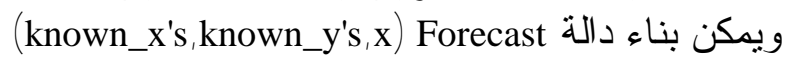
X $x$ Known_y's Known_x's وتكون معادلة Forecast هي 


$$
B=\frac{N \sum X Y-\left(\sum X\right)\left(\sum Y\right)}{N \sum X^{2}-\left(\sum X\right)^{2}}
$$

وتم استخدام هذه الدالة للتنبؤ بمبيعات شركة الموصل الصناعية من خلال البيانـات

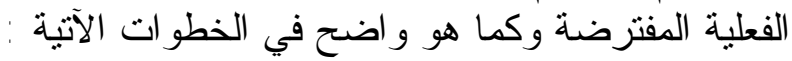

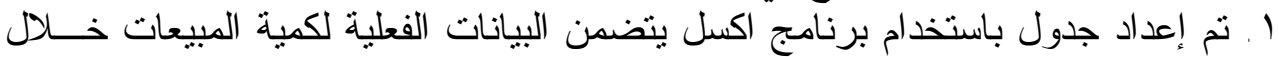

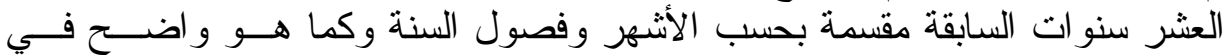

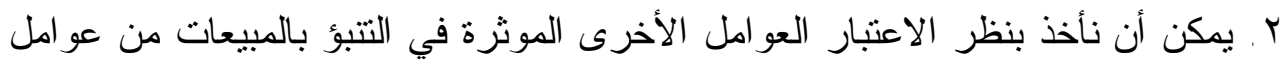

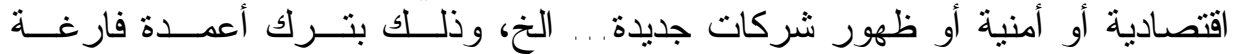

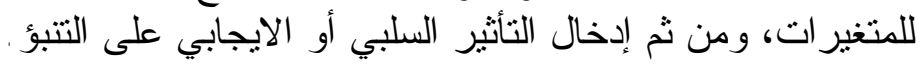

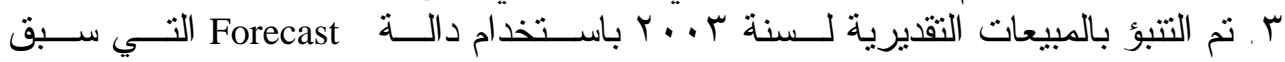
توضيحها.

و الثكل الآتي بيبن انه تم استخدام دالة Forecast في التتبؤ بالمبيعات التقديرية لسنة . r. r

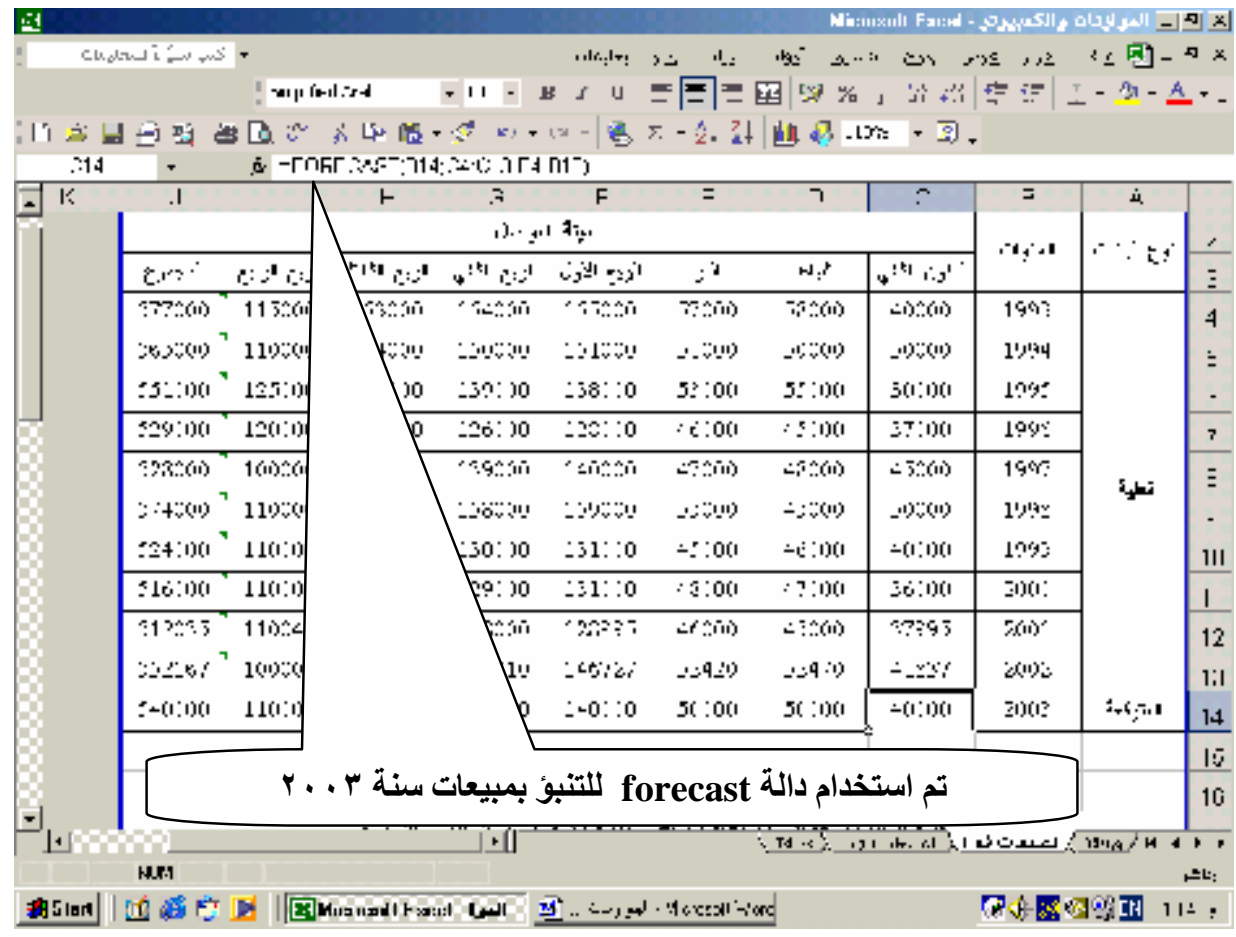

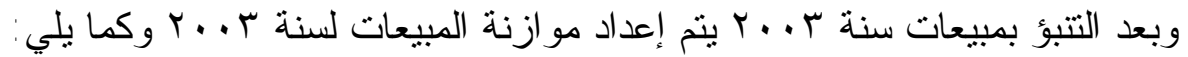


الدكتور الحبيطي ورمو[9]

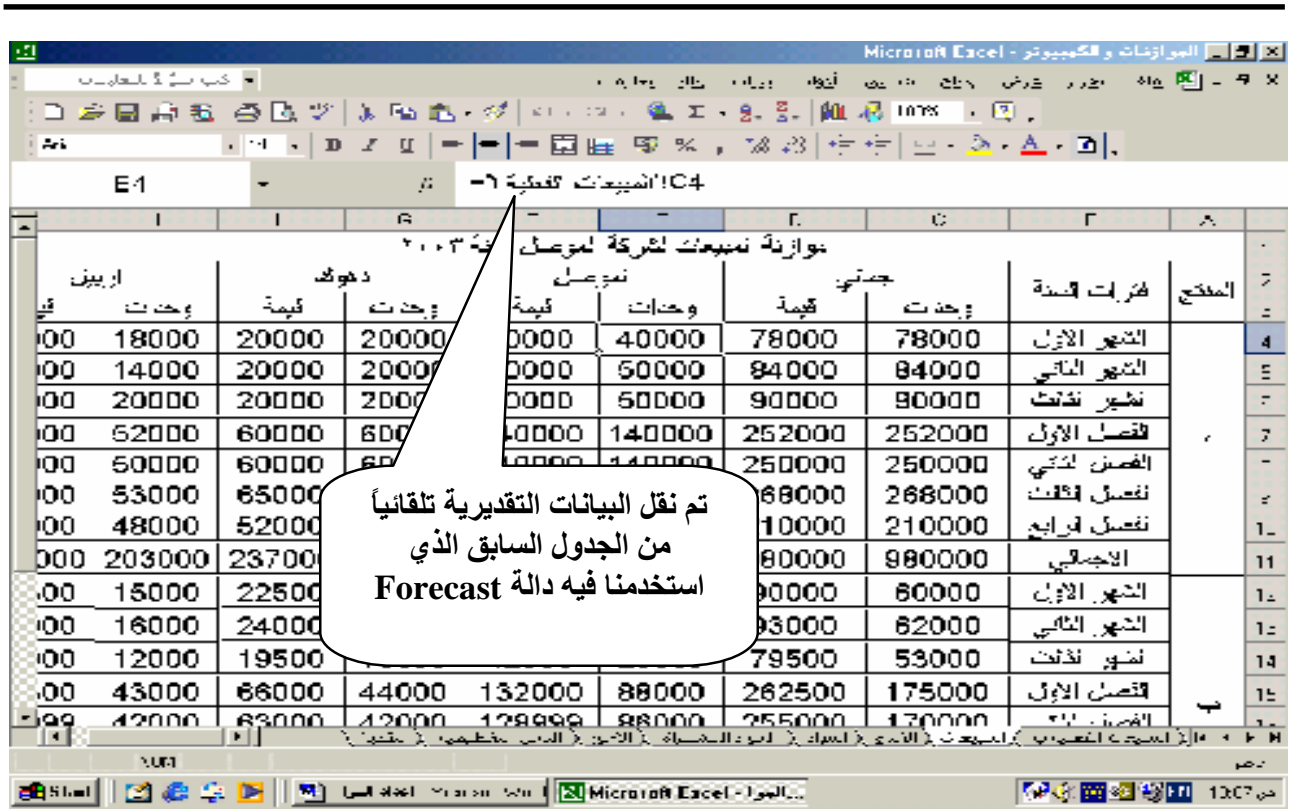

$$
\text { و اضح فما تم إجر آه جميع العمليات الحسابية بشكل تلقائي من جمع وضرب وكمــا هــو }
$$

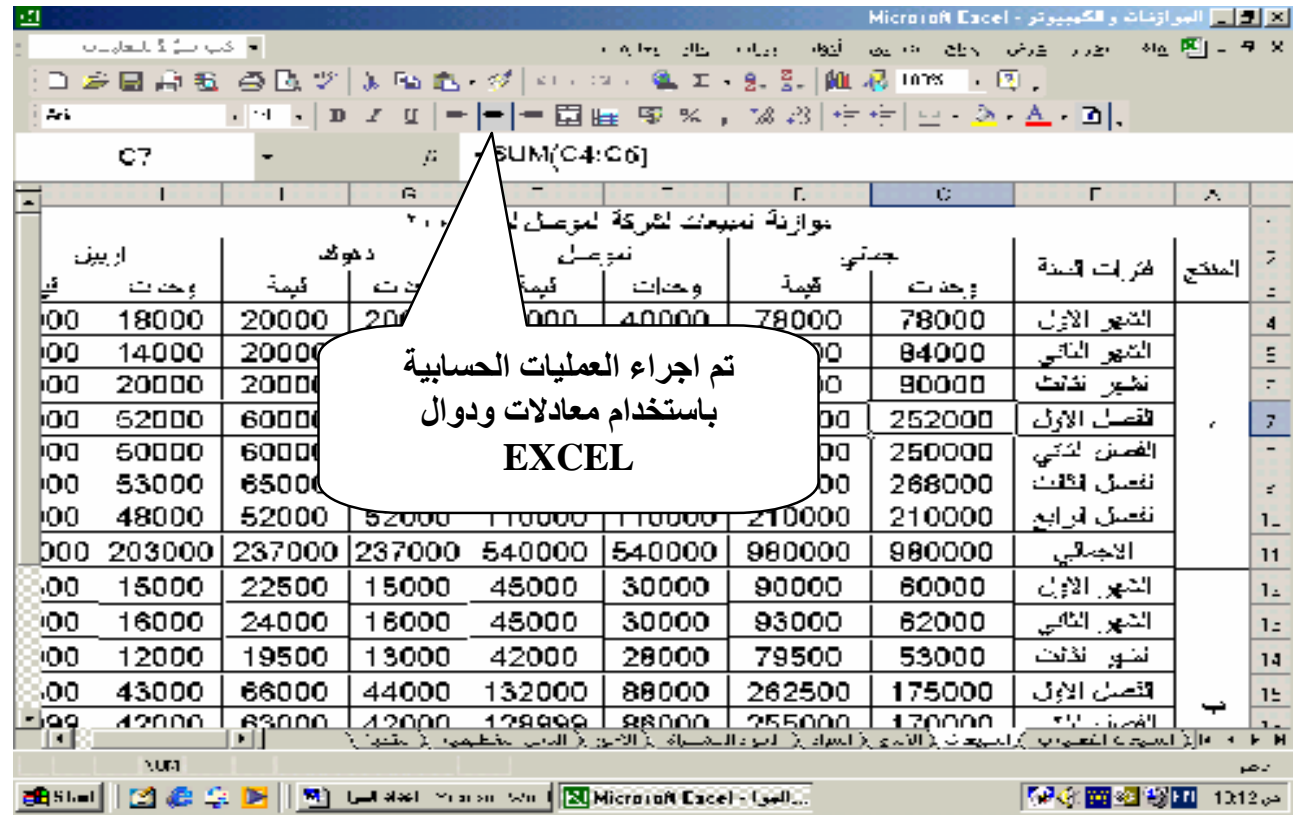

كما تم استخر اج قيمة المبيعات تلقائياً بضرب وحدات المنتج أ بدينار و احد وضرب عدد وحدات المنتج ب بدينار ونصف، و هو سعر الوحدة الو احدة . 


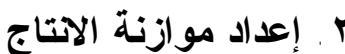

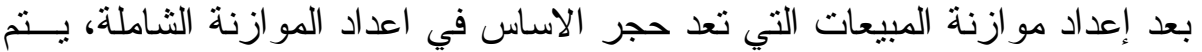
إعداد مو ازنة الانتاج بالاستتاد الى بيانات موازنة العئة المبيعات وباستخدام المعادلة الآتية :

المبيعات + مخزون آخر المدة = (إجمالي الاحتياجات) - مخزون أول المدة = الوحدات المطلوب إنتاجها

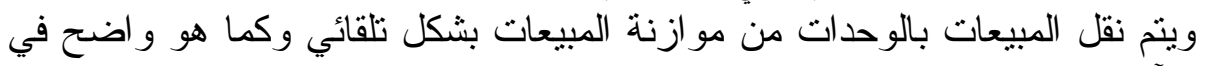

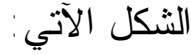

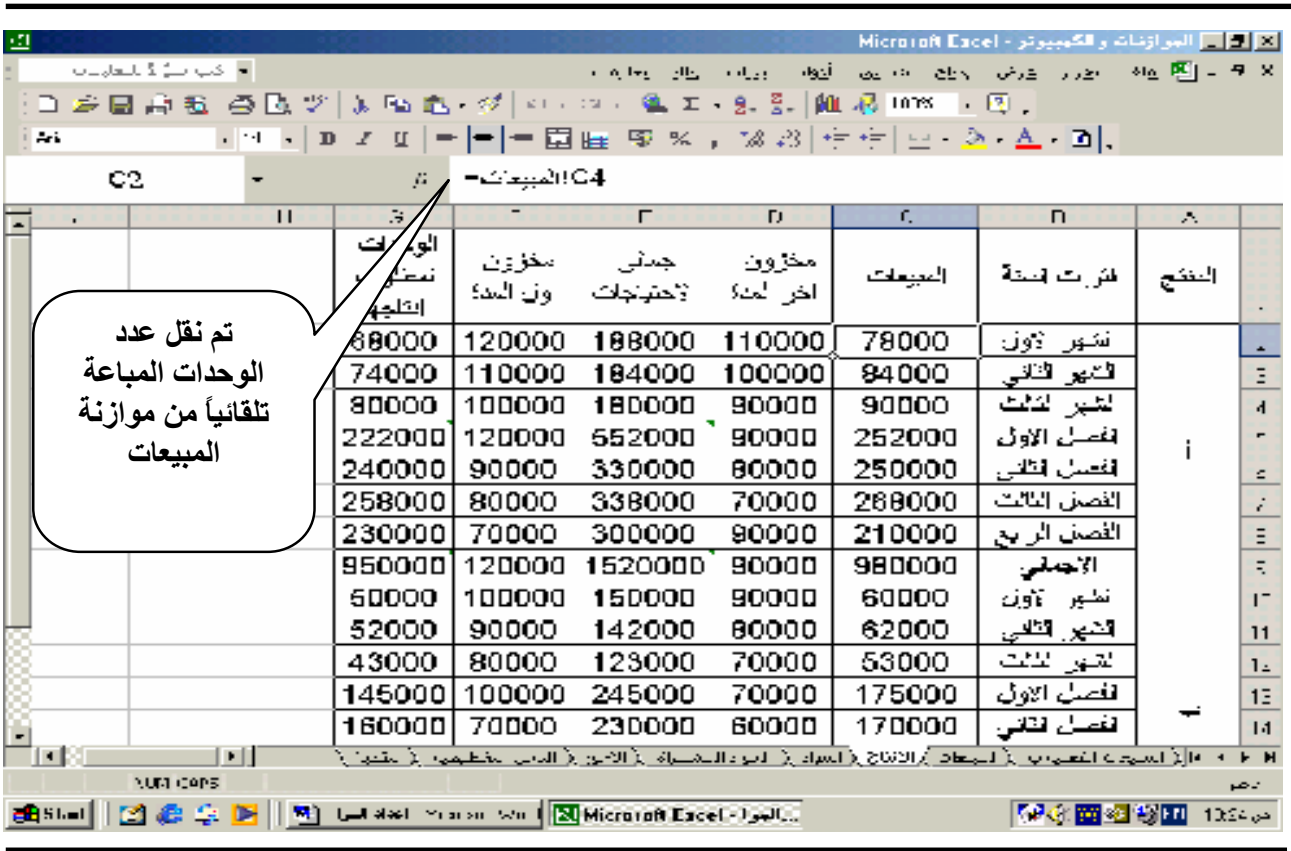

ويتم إجر اء العمليات الحسابية في موازنة الإنتاج بشكل تلقائي باستخدام المعسادلات

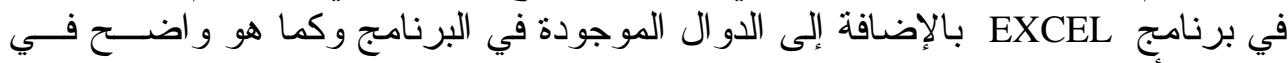
الثّكل الأتي:

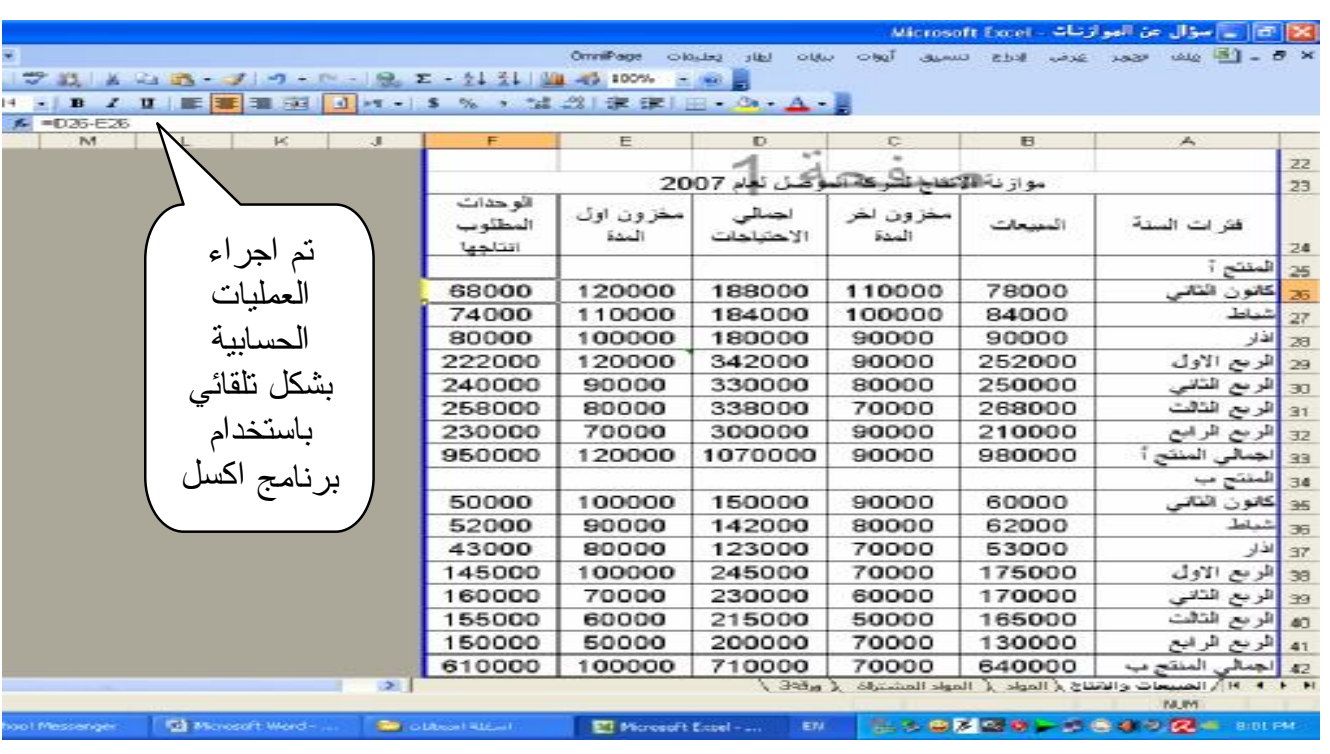




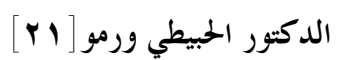

r ب إعداد موازنة المواد بعد الانتهاء من إعداد موازنة الإنتاج ينم إعداد موازنة المواد التي نحتاجها لإنتاج

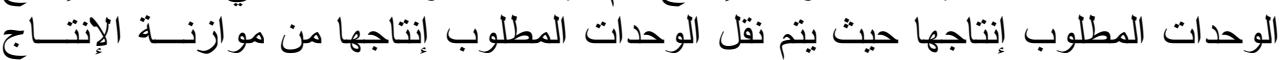
بشكل تلقائي وكما هو و اضح في الثكل الآتي :

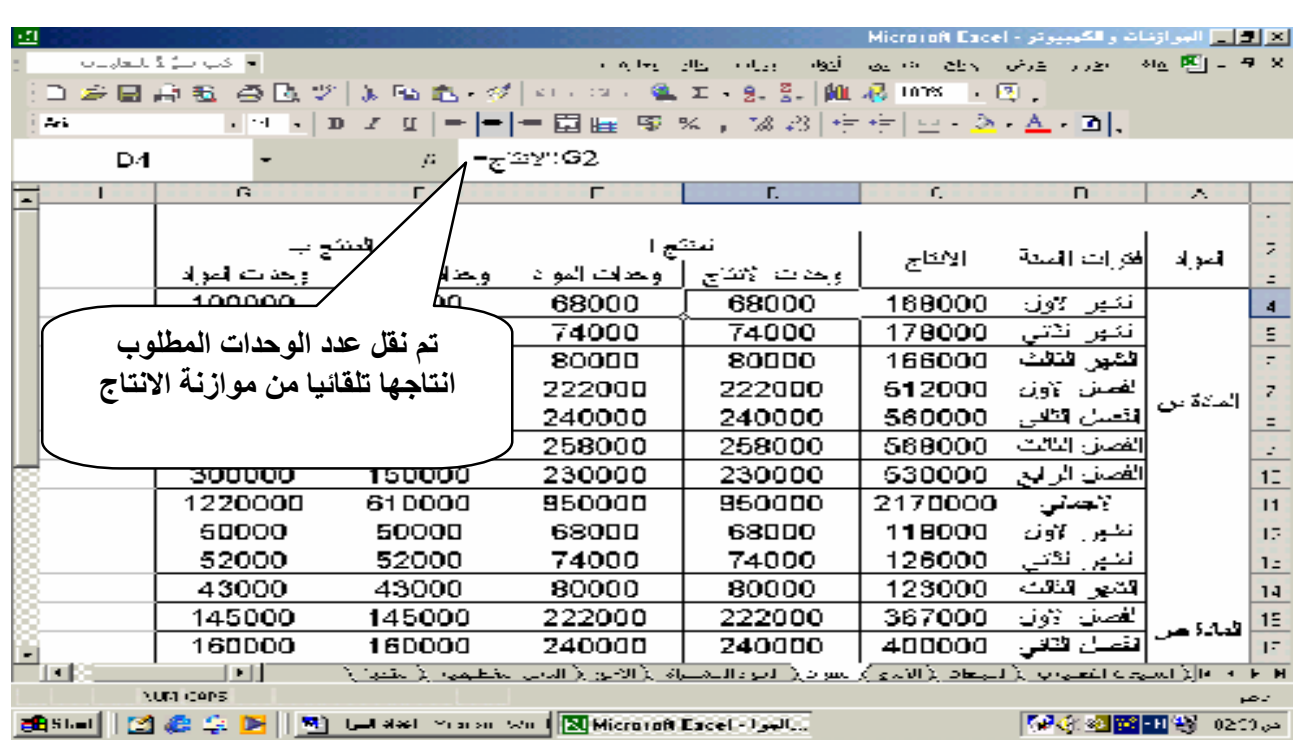

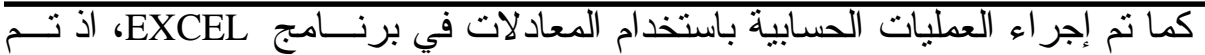

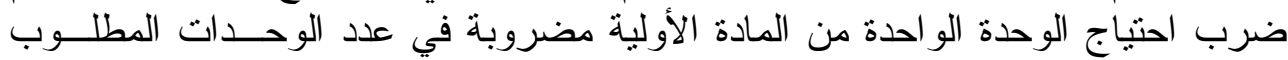

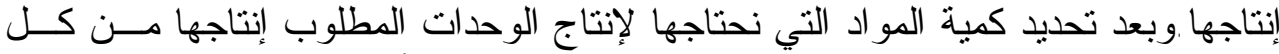

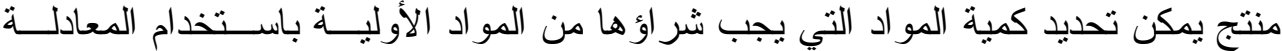
الآتية :

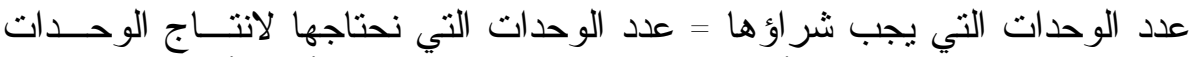

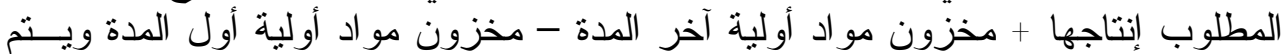

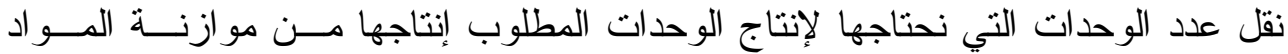

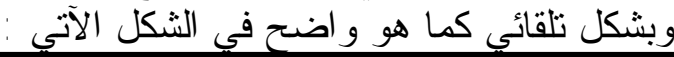

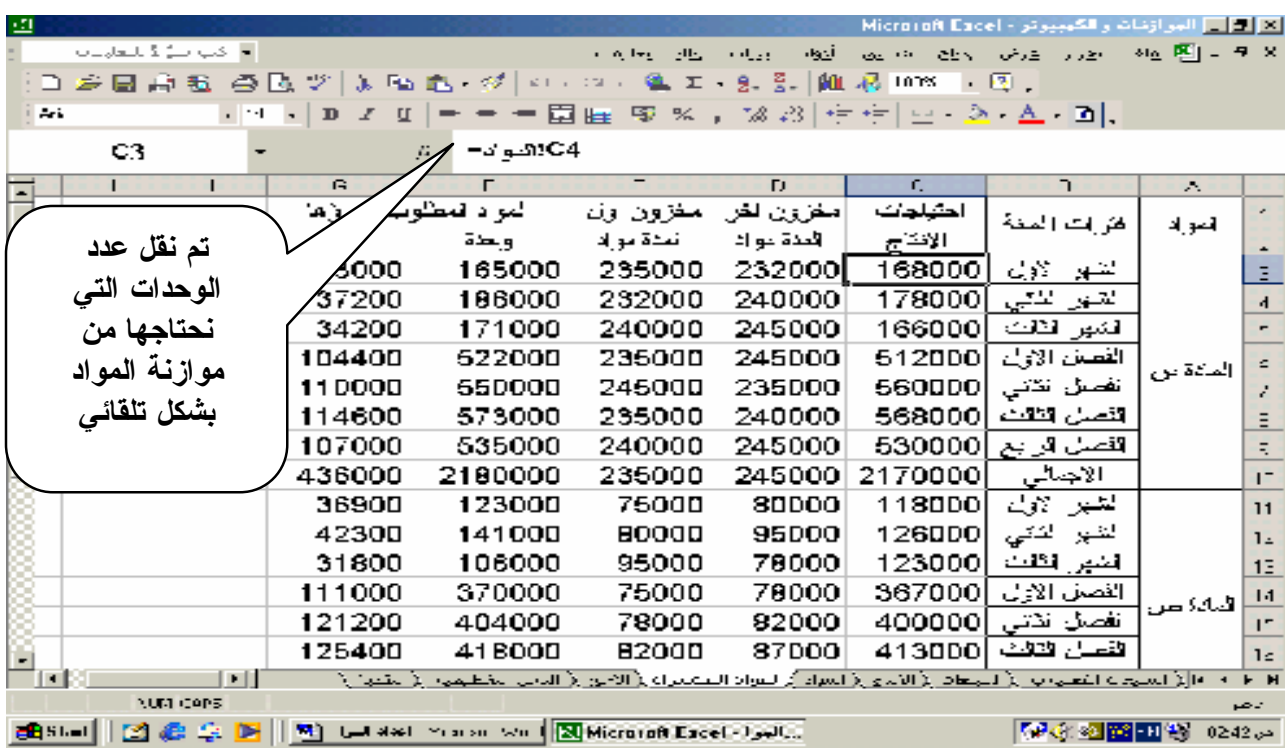




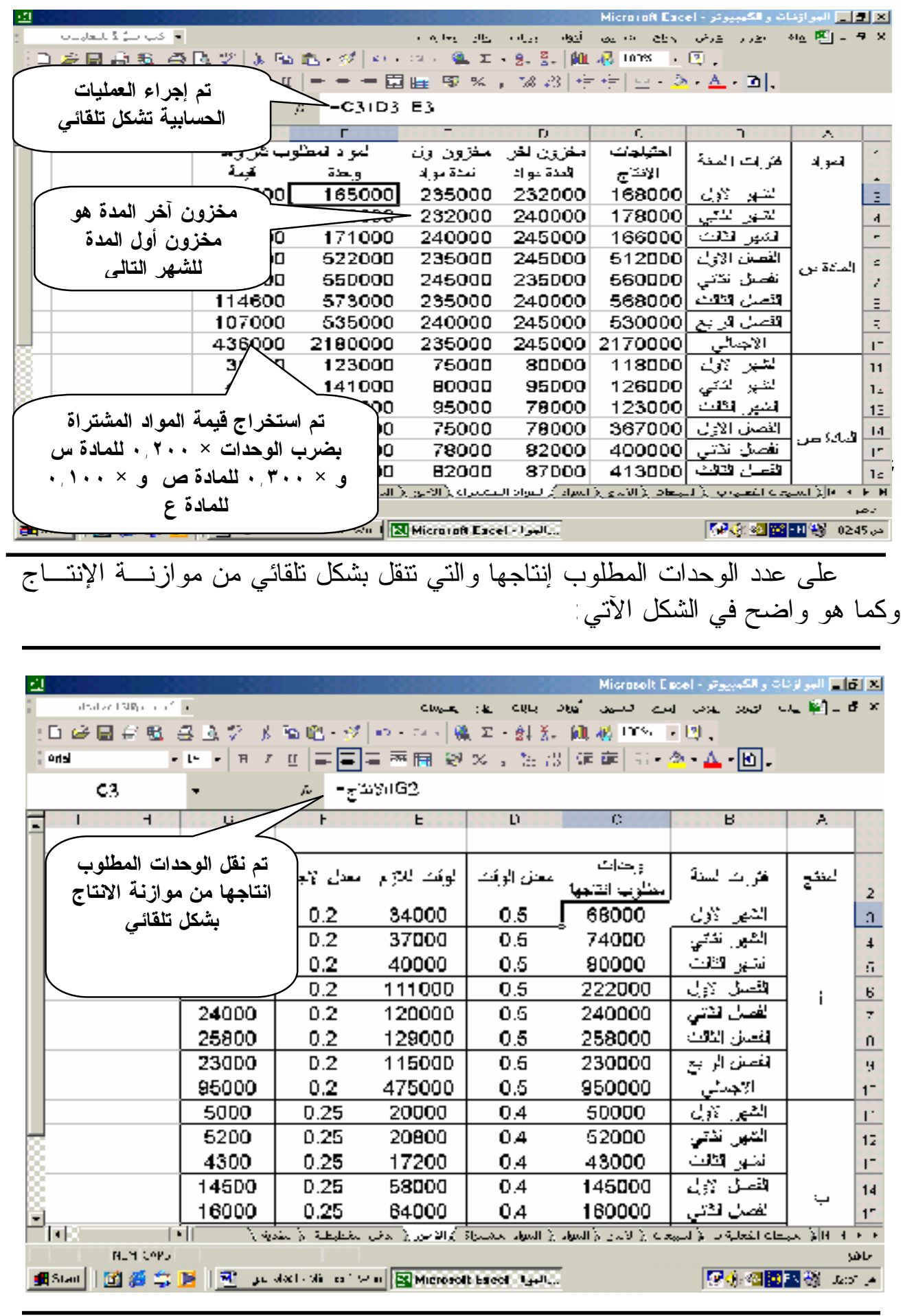




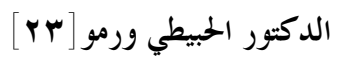

كما تم إجر اء العمليات الحسابية باستخدام المعادلات في البرنامج فضلاعن الــدوال

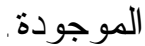

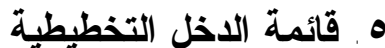

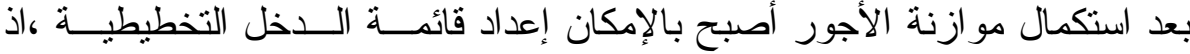

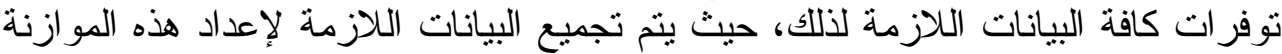

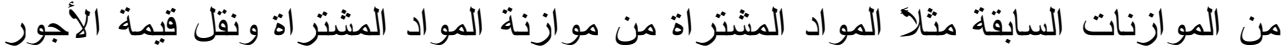
من موازنة الأجور وكما هو واضح في الثنكل الآتي :

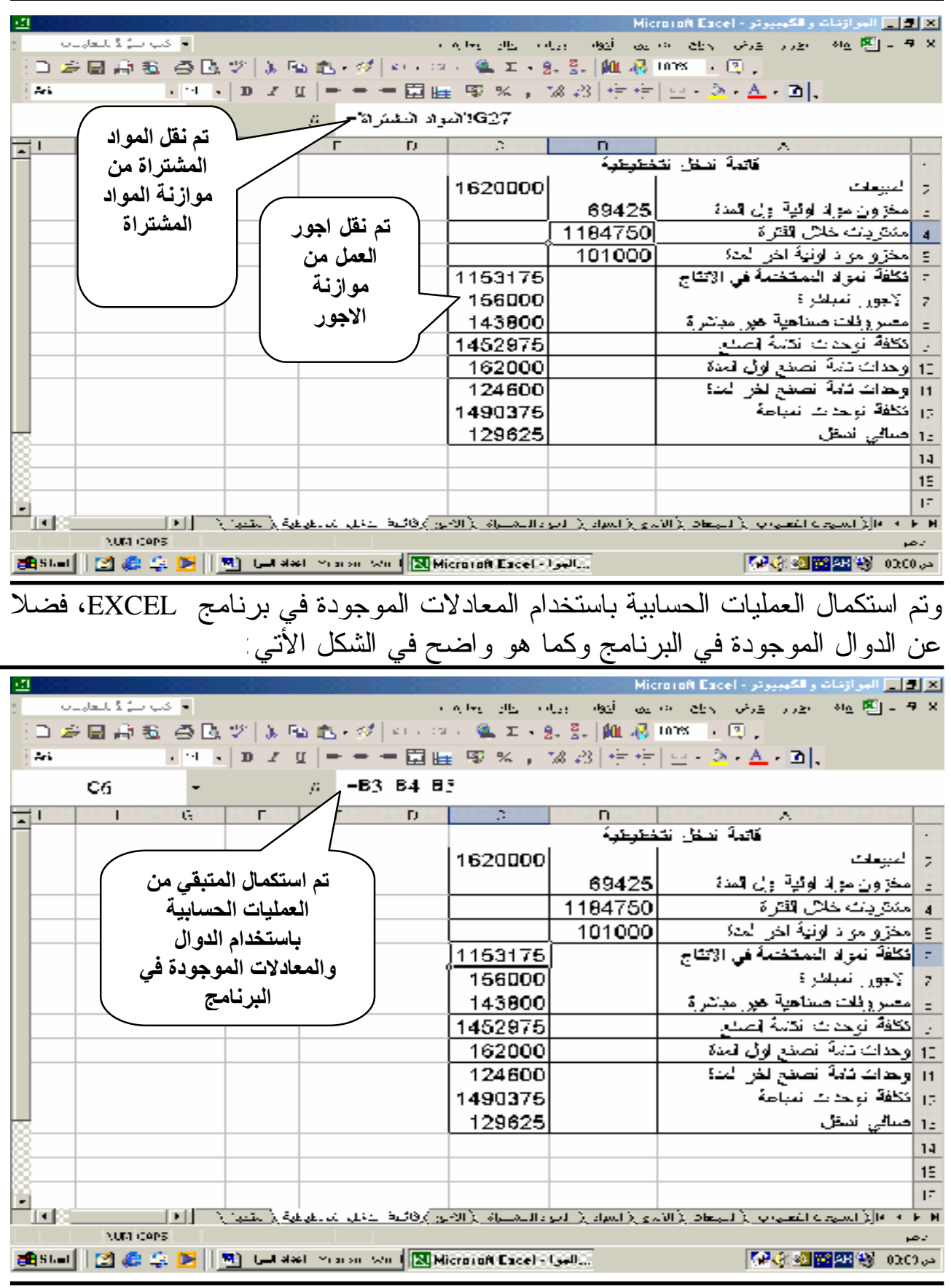




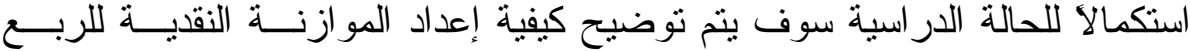

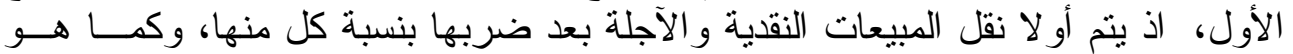

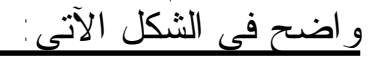

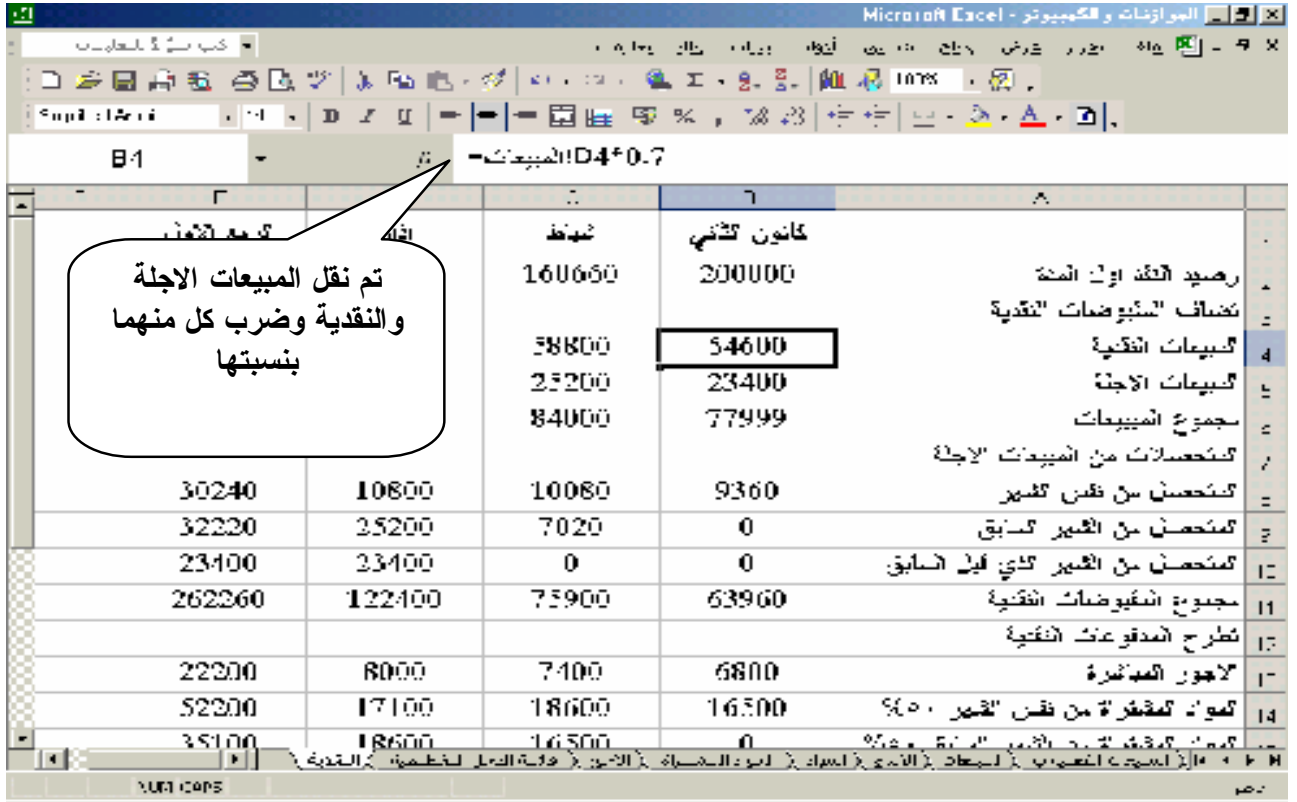

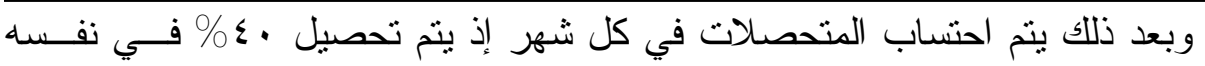

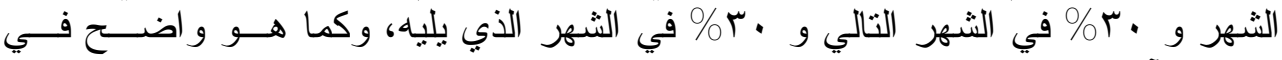
الشكل الآتي : (x)

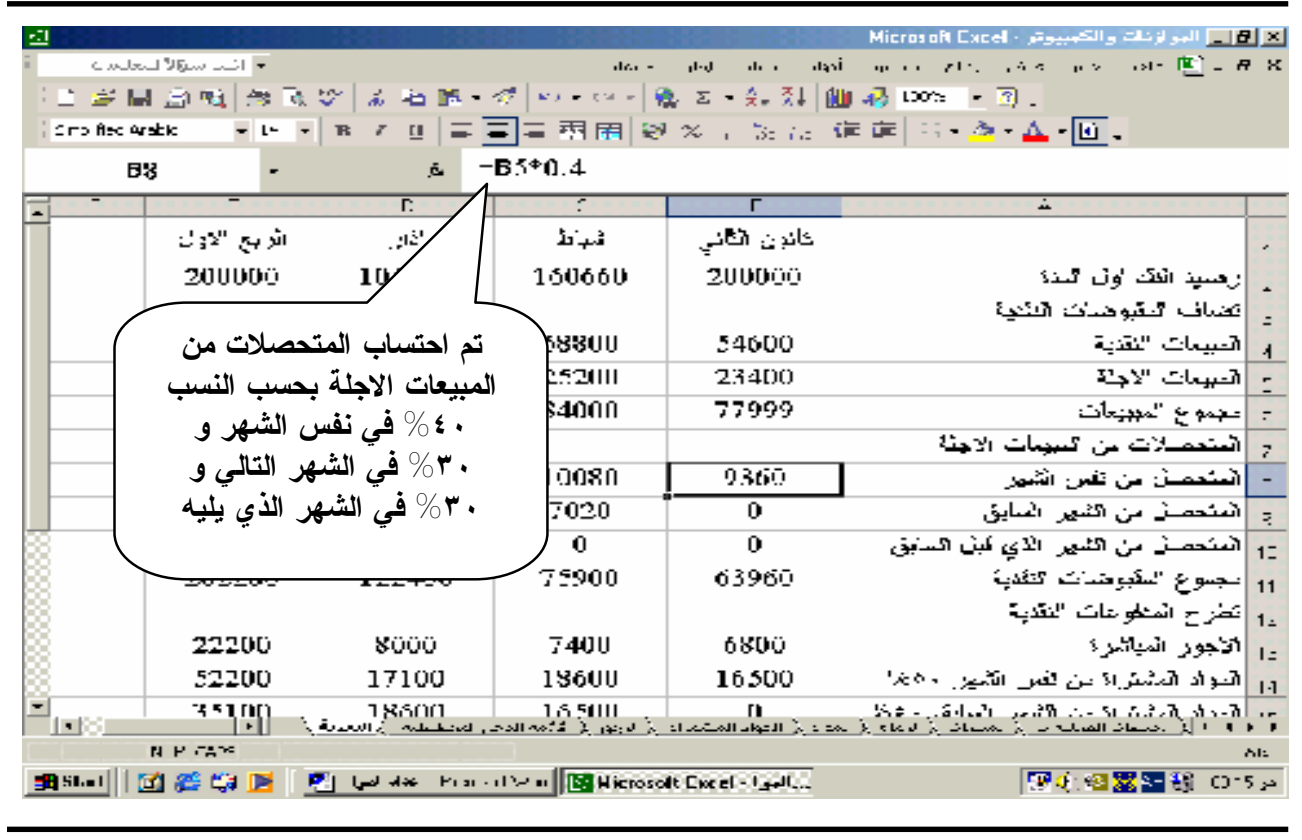




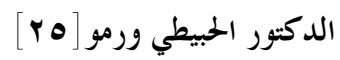

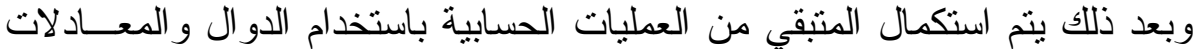

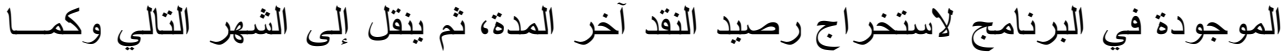

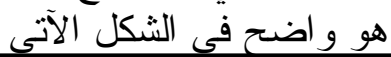

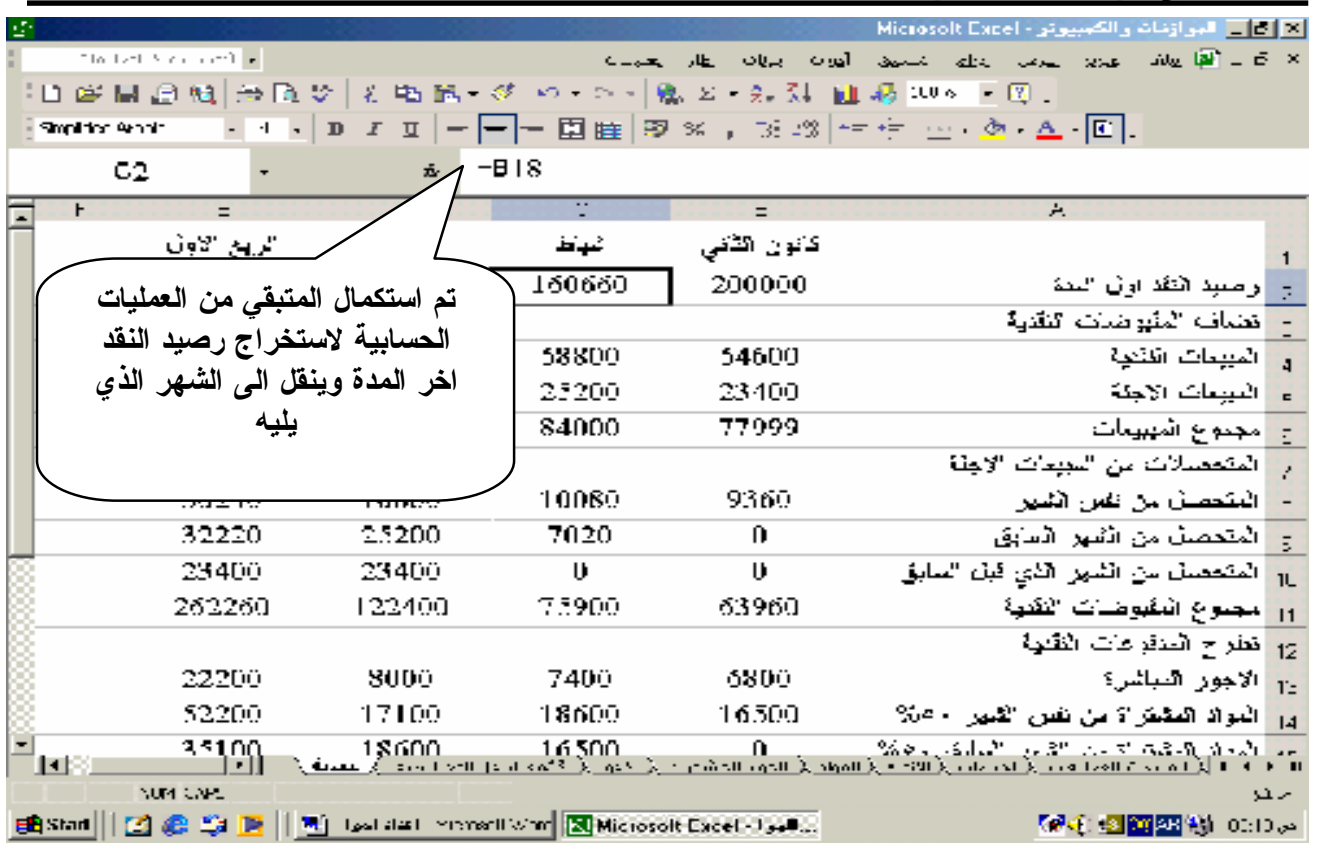

وبعد نوضيح وبيان كيفية إعداد الموازنة الثاملة فإنه يمكن طباعتها و إظهار بياناتها

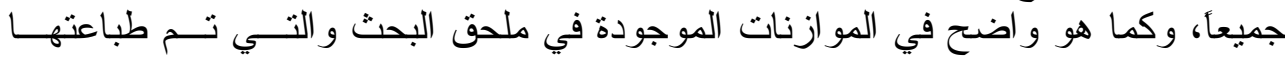

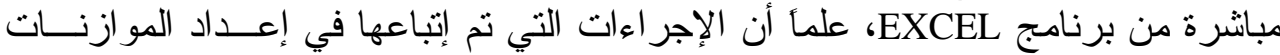

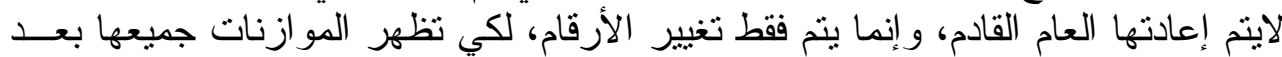

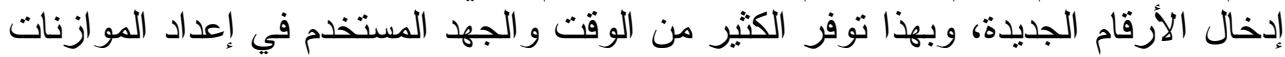

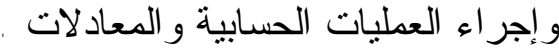

الخلاصة من خلال در اسة مشكلة البحث تم التوصل إلى مايأتي :

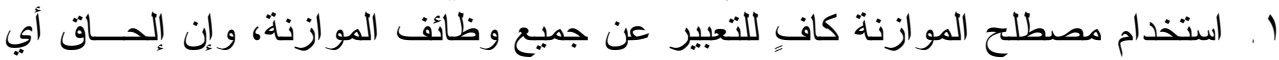

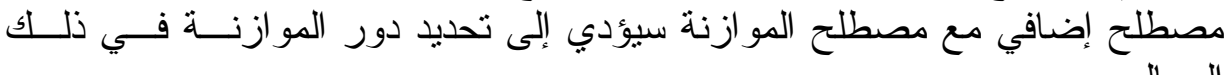

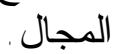
r. إن استخدام الحاسوب في عملية إعداد الموازنة لم يكن له تأثير فــي تغييــر مفهـوم

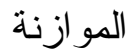

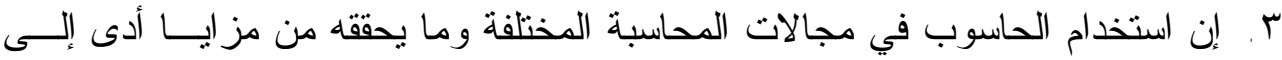

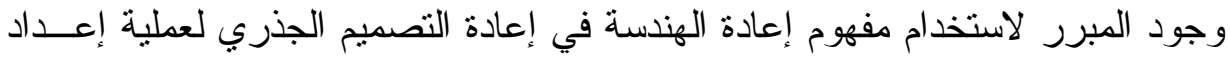

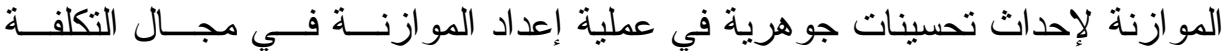


و الجودة وسر عة الانجاز بوصفها خطة شاملة لأنشطة المشروع معبر ا عنها بـصورة مالية.

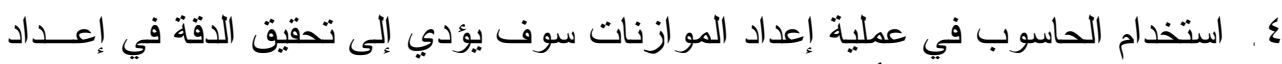

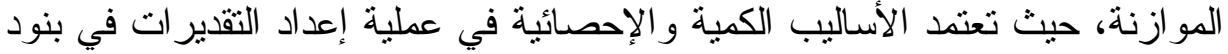

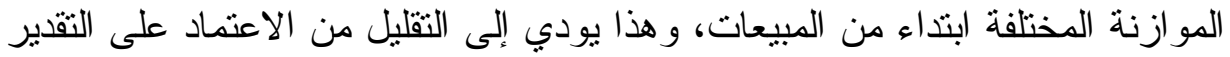

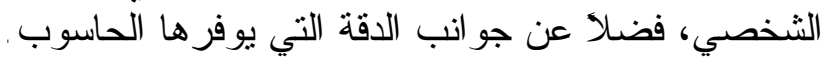
0. استخدام الحاسوب لم يؤثر على أهداف عملية إعداد الموازنة بشكل مباشر ، ولكنه أثز

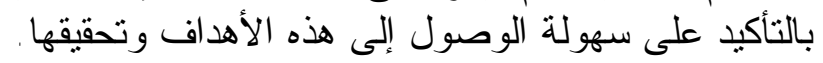

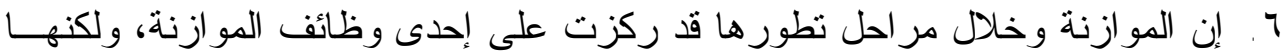

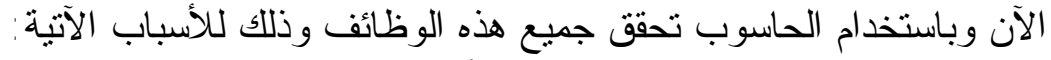

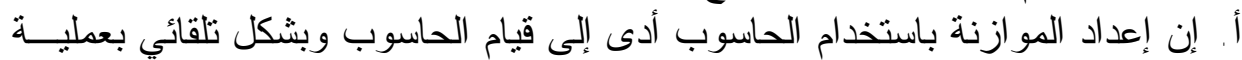

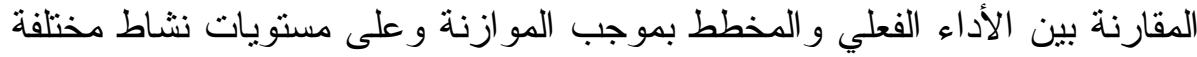
بمجرد إدخال البيانات الفعلية.

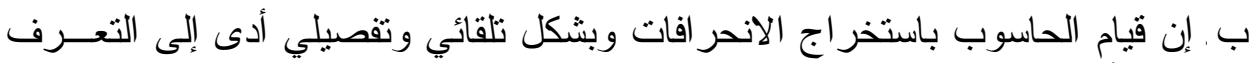

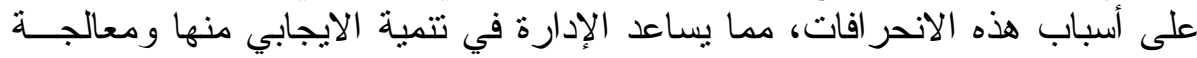
السلبي.

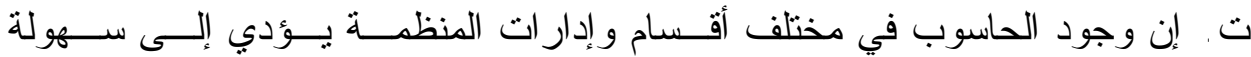

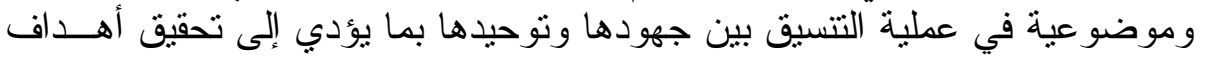
المنظمة من خلال تحقيق أهدافها.

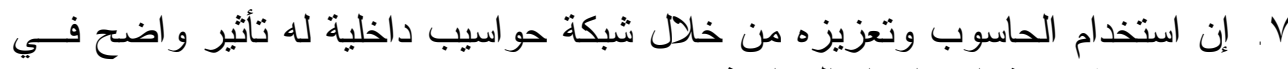

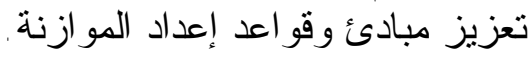

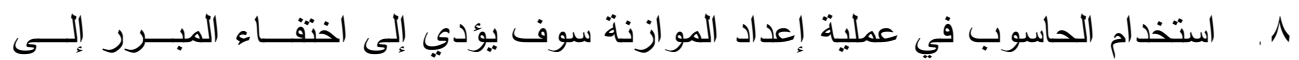

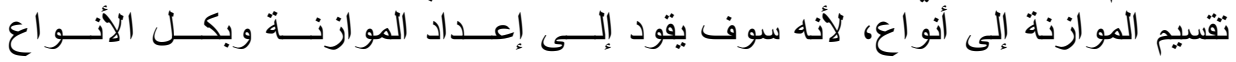
المتعارف عليها.

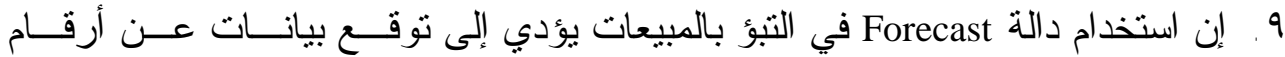

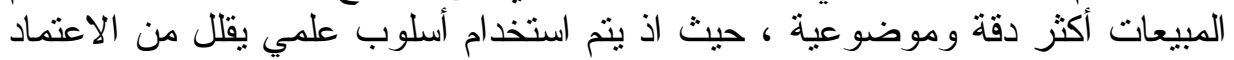

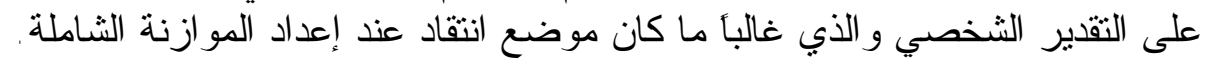

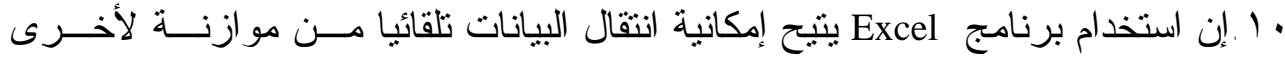

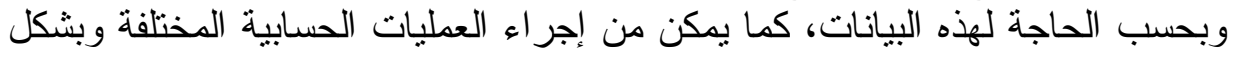

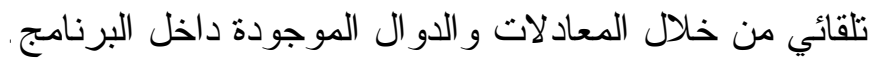

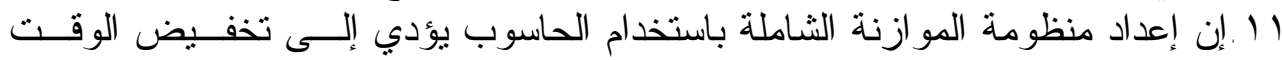

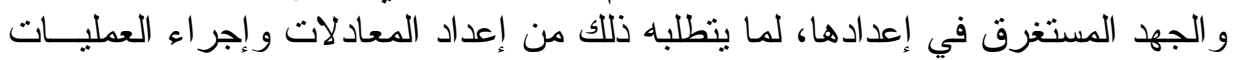
الحسابية سنويأ و التي تستغرق معظم الوقت المستخدم في إعداد الموازنة .

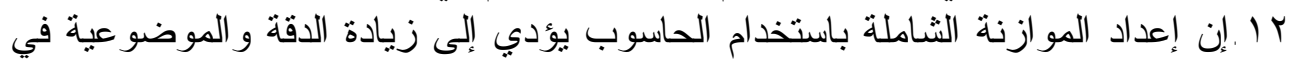

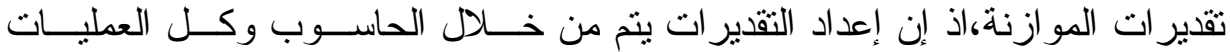

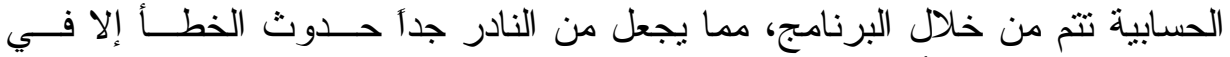




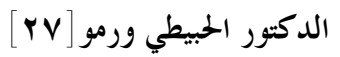

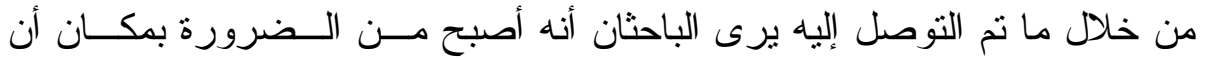

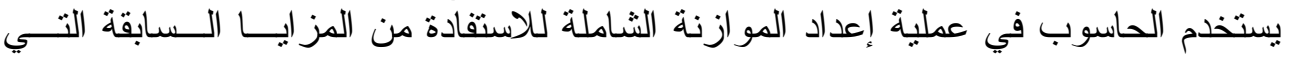

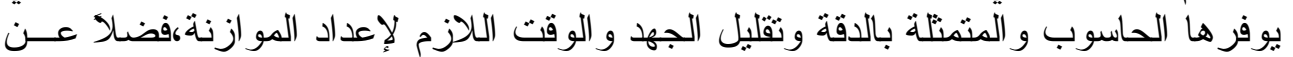

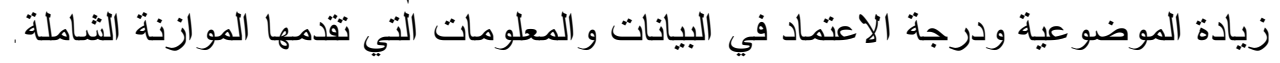

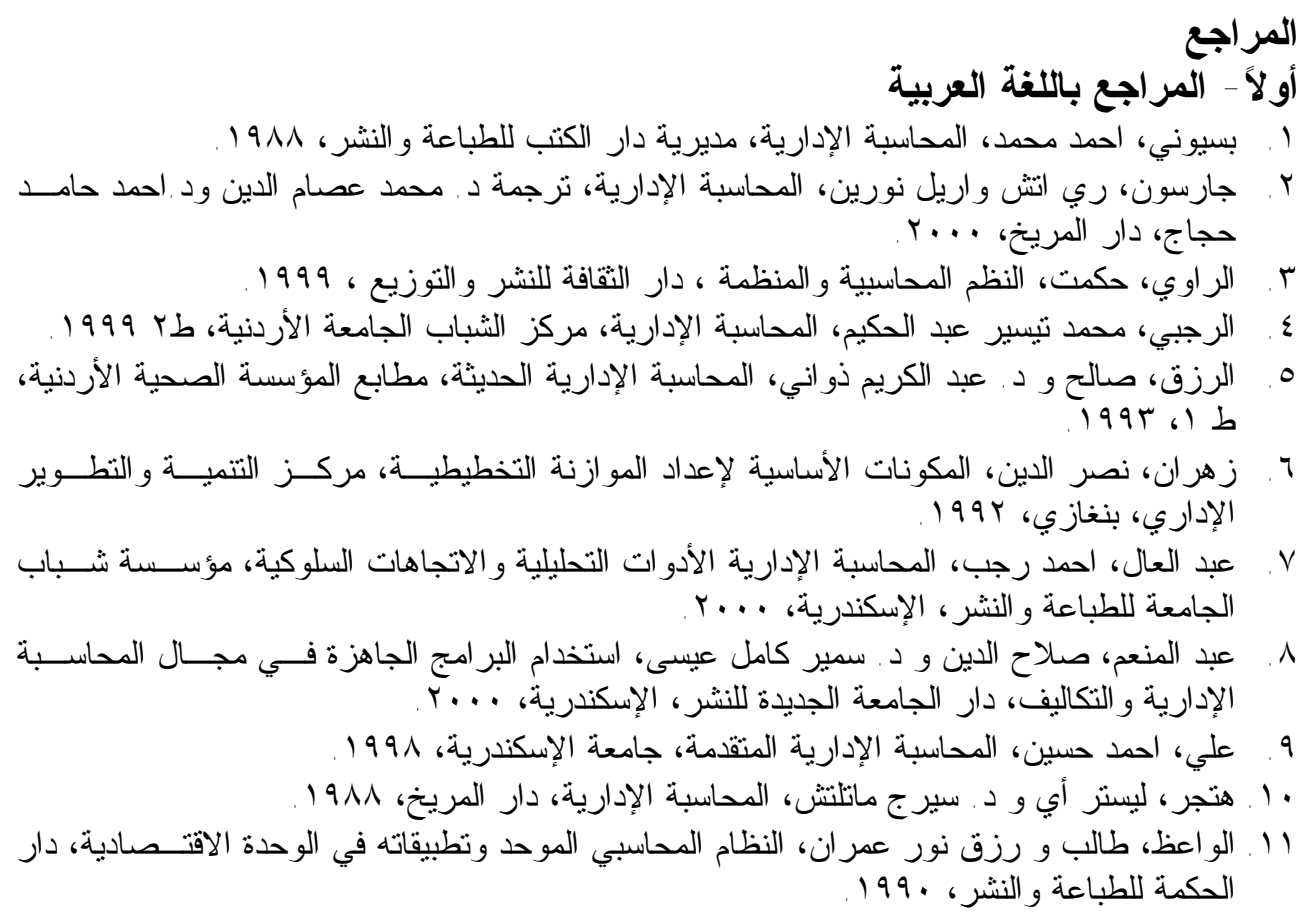

ثانياً - المر اجع باللغة الاجنبية

1. Hammer And Champy, Reengineering The Corporation: A manifesto For Business Revolution, 1993 .

2. Horngron ,Cost Accounting and Managerial , 10 th , macro Hill , 2002 .

3. Neill And Sohal, Business Process Reengineering Areviw Of Recent Literature, 1999.

4. Raymond L. Manganelli, The Reengineering Hand book, A macom, 1edition, 2003. 
ص ص[

\author{
استخدام الحاسوب في إعادة هندسة إعادة المادة

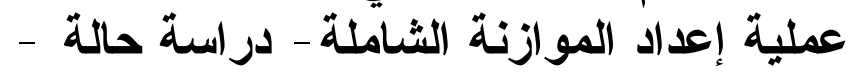

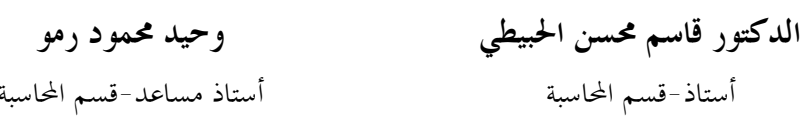 \\ كلية الإدارة والاقتصاد -جامعة الموصل
}

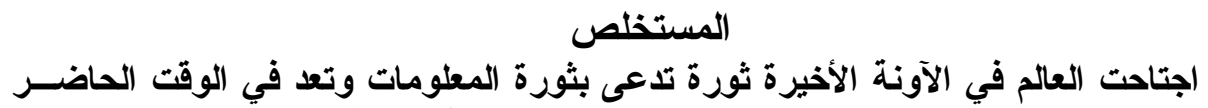

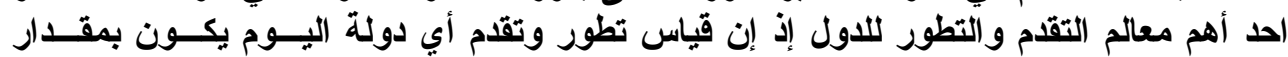

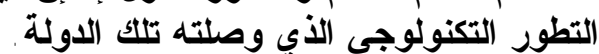

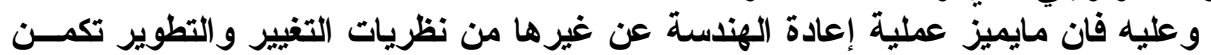

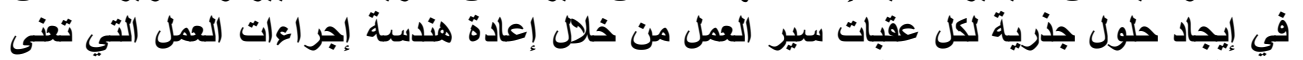

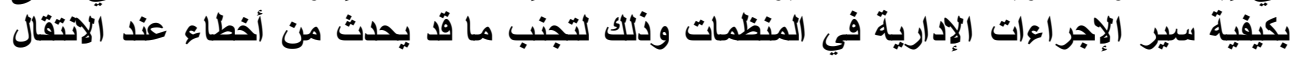

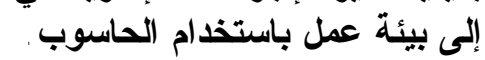

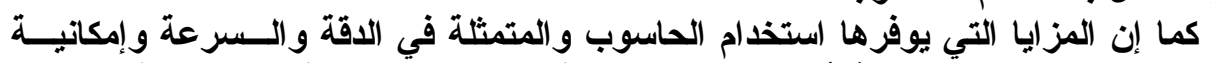

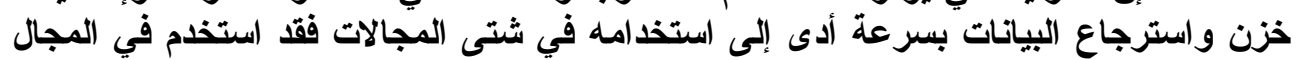

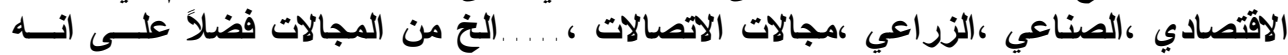
اوجد المبرر لعملية إعادة هندسة العمليات لغرض التئية التطوير والتحسين.

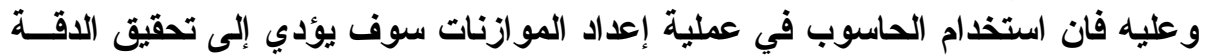

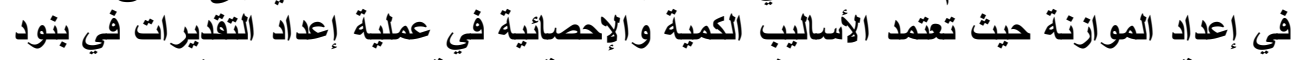

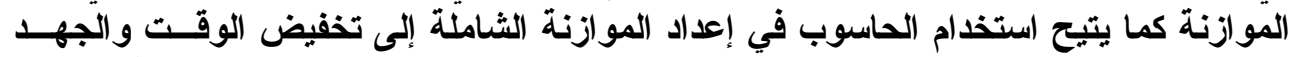

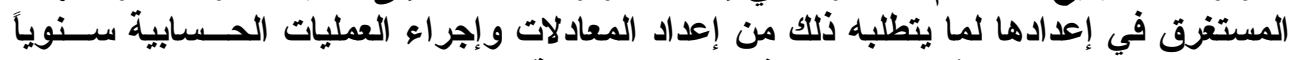

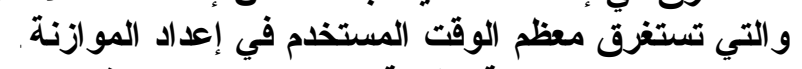

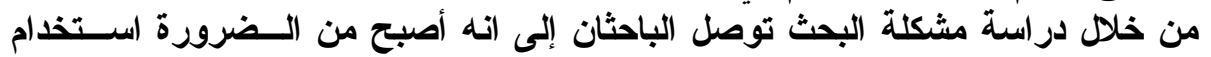

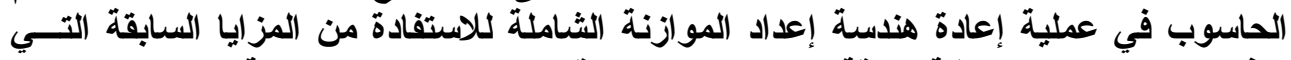

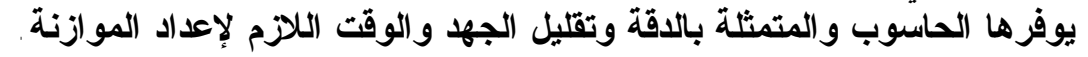




\title{
Using Computers in Reengineering in the Preparation of Balance Budget Sheet
}

\author{
Qasim M. Al-Hubaiti (PhD) \\ Professor \\ Department of Accountancy \\ University of Mosul
}

\author{
Wahid M. Rammo \\ Assistant Professor \\ Department of Accountancy \\ University of Mosul
}

\begin{abstract}
A revolution called information revolution has recently invaded the world. It is currently considered one of the most important properties of development to the countries of the world. Hence, the recognition of reengineering among other theories of innovation may be posited in finding radical procedures to overcome all obstacles in framework operations. This can be seen in reengineering the framework operations of management procedures in the organizations to avoid errors of transferring into computerized environment. The criteria provided by computers such as accuracy, speed, time saving storage and restore have led them to be widely used in economy, industry, agriculture, communications, etc, as well as being the major finder of reengineering the operations of innovation. The use of computers in the preparation of budgets will lead to achieve accuracy. Since, the operation draws upon the statistic and quantity estimations about budget items, the computerized balance sheet may save time and effort of preparing mathematical equations annually. According to the problem of study, the researchers concluded that it is necessary to use computers in reengineering the budget of balance sheet to save time and effort of preparation.
\end{abstract}

المقدمة

يعد الحاسوب في الوقت الحاضر أحد أهم معالم التقدم و التطور للاول، اذ إن قيــاس

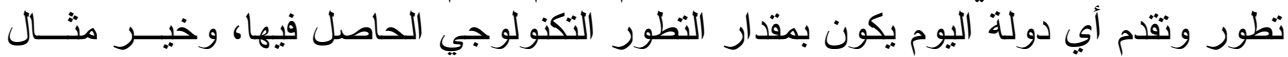

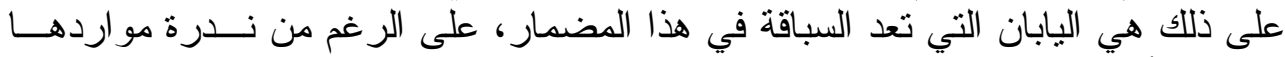

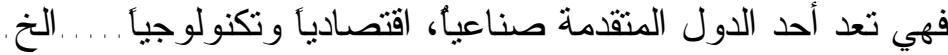

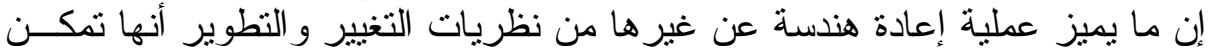

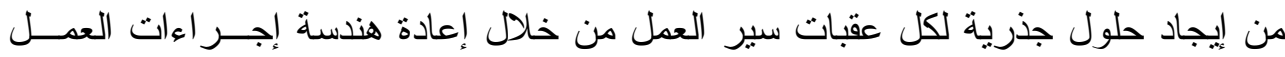

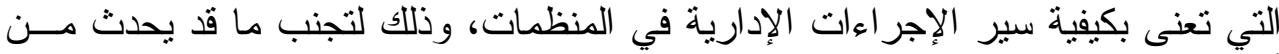

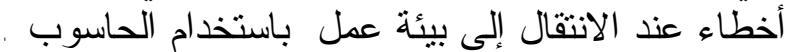

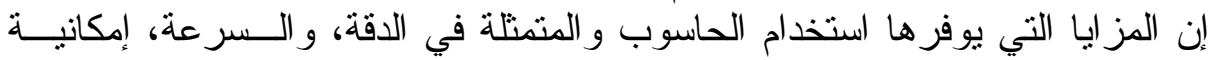

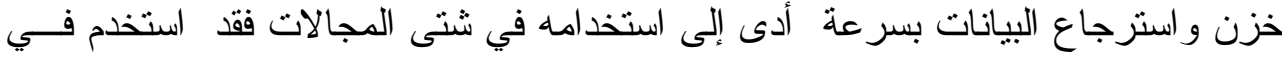

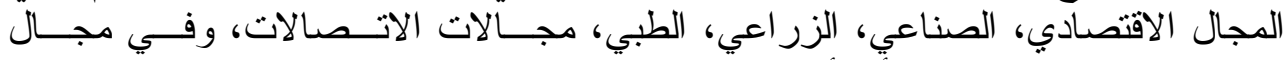

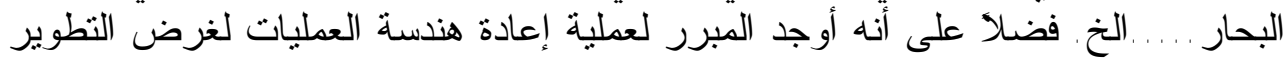

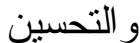

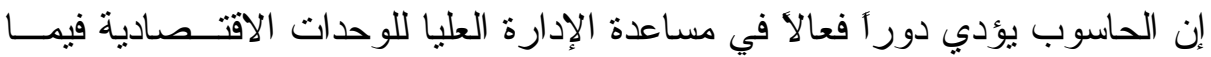

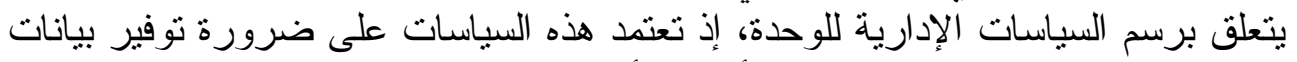

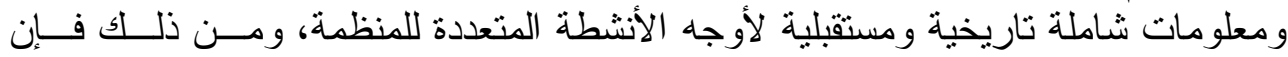

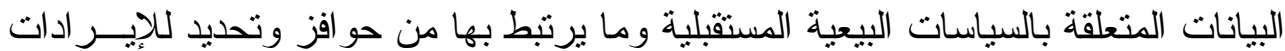




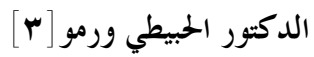

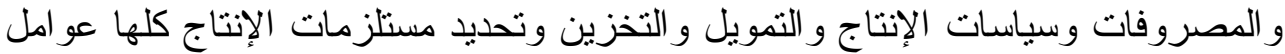

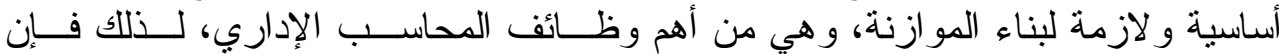

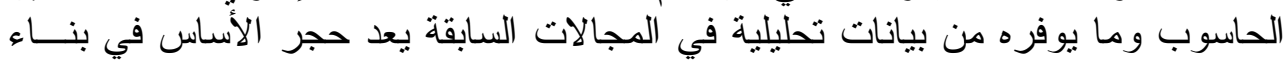
الموازنة بوصفها خطة مالية لأنشطة المنظمة المختلفة معبر أ عنها بصور مالية.

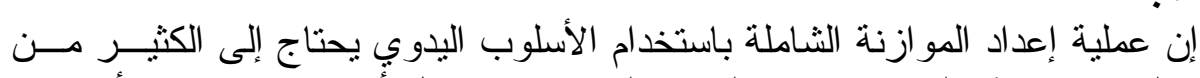
مشكلة البحث

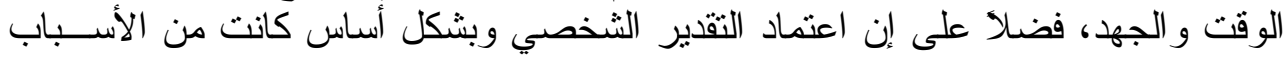

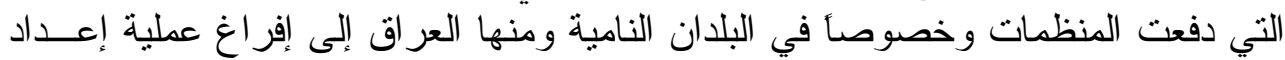

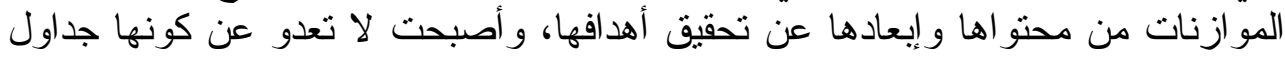

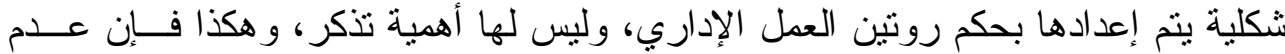

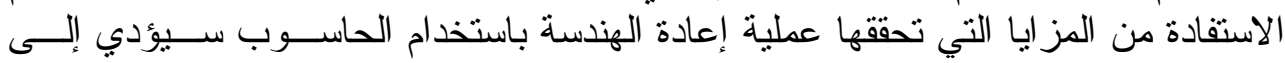

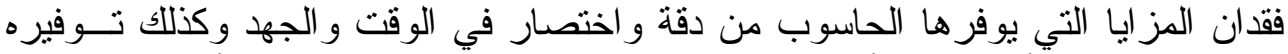

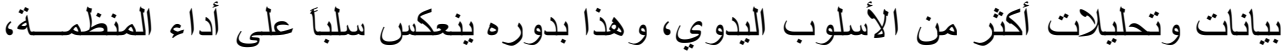
لأن الموازنة هي ترجمة لنشاط المنظمة لسنة قادمة معبر أ عنها بصورة مالية.

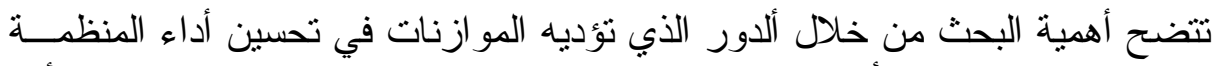
أهمية البحث

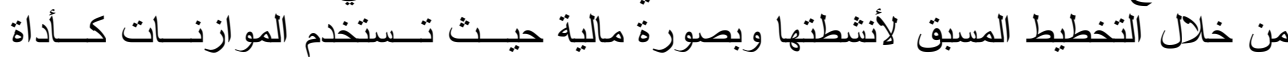

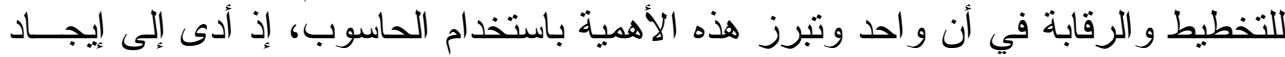

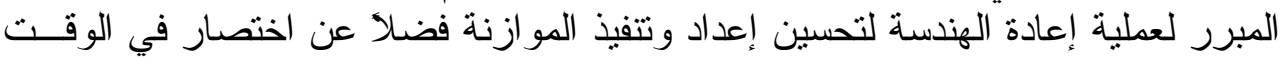

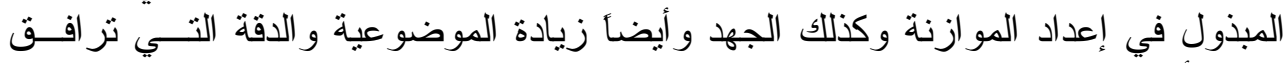

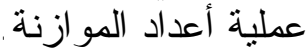

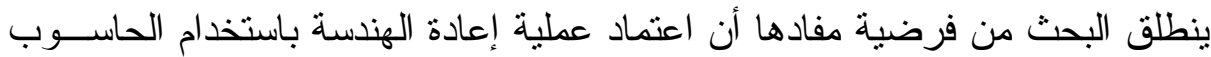
فرضية البحث

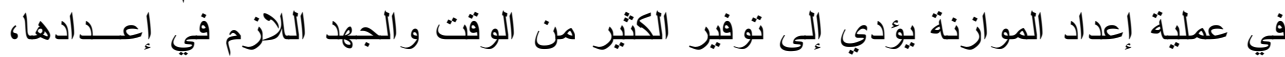

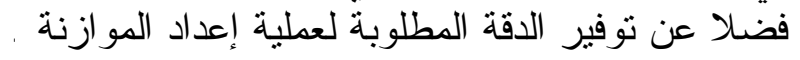

\section{مفهوم الموازنات وأنواعها

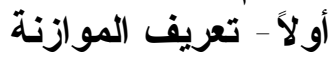

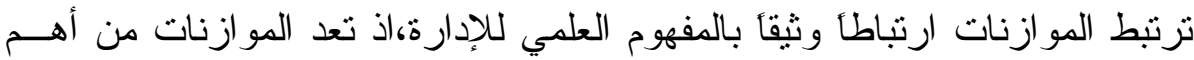

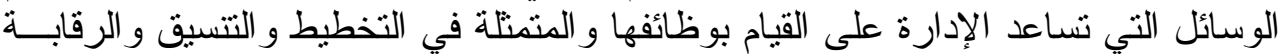

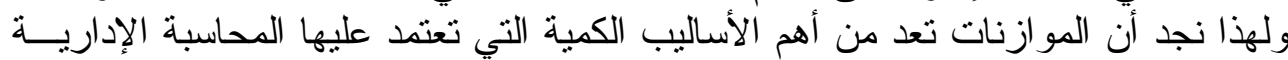
لمساعدة الإدارة لاتخاذ مختلف القر ارار ات في مختلف المسنويات الإن الإدارية.

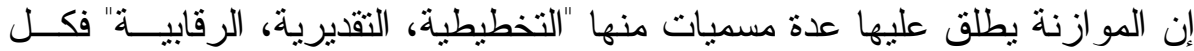

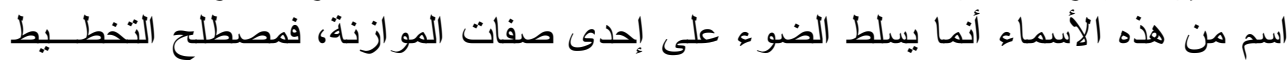

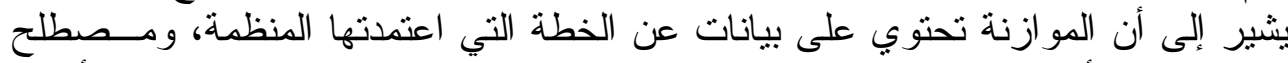

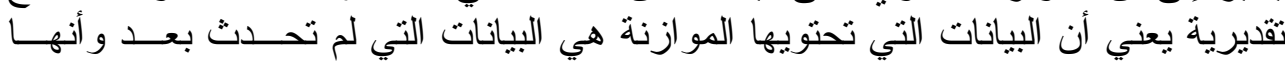




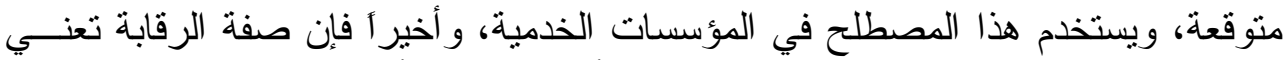

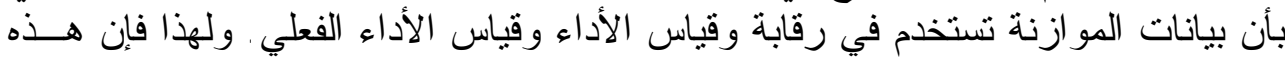

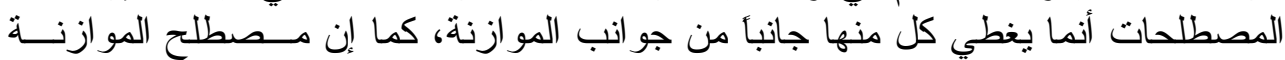

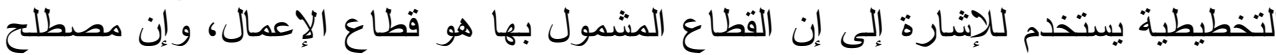

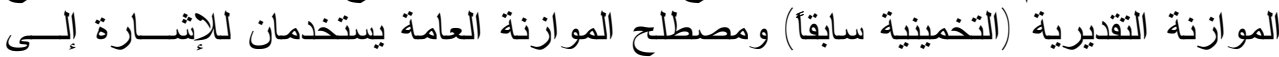

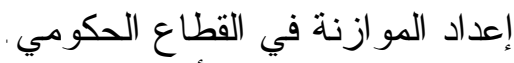

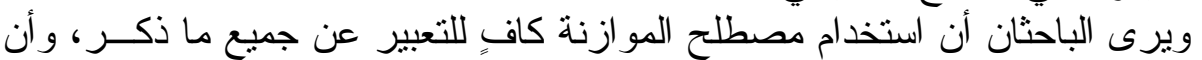

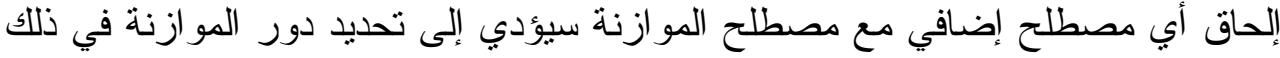

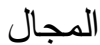

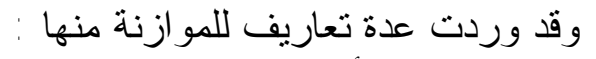

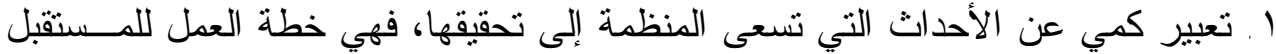

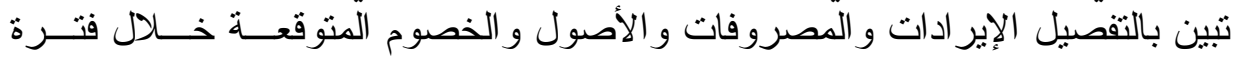

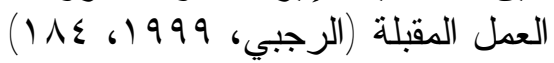
r . خطة معبر عنها بالاصطلاحات المالية و الكمية، أي إنها تعبير مالي وكمي عن الخطة

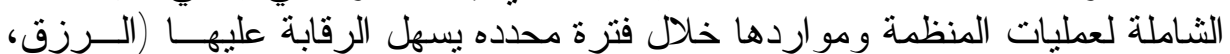
(r.人 ، 1994 r. التعبير الكمي لخطة موضوعة عن أنشطة المنظمة لفترة محددة وتساعد بناءً على ذلك الكا

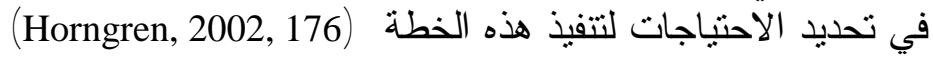

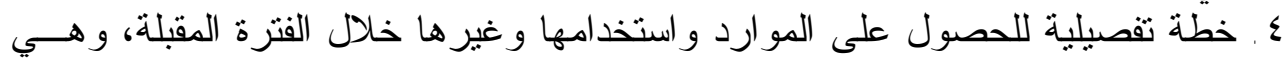

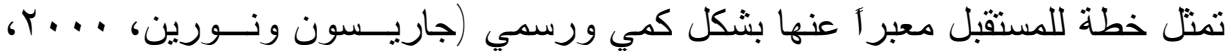

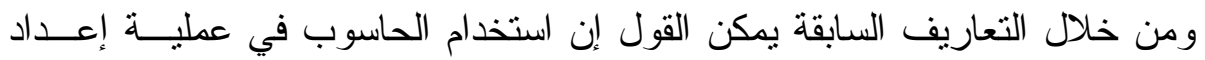

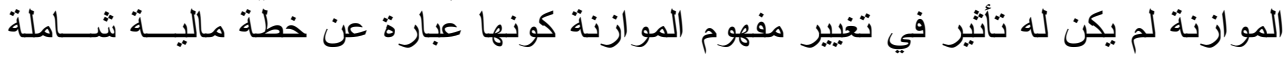

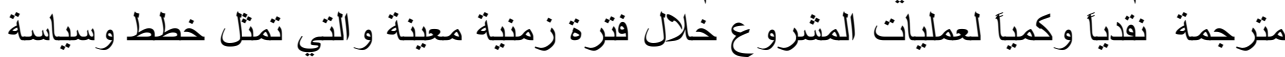

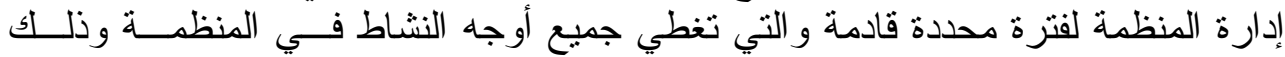

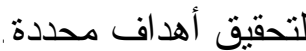

$$
\text { ثانياً - أنواع الموازنة }
$$

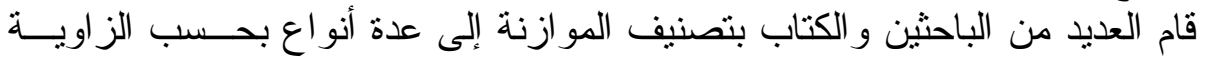

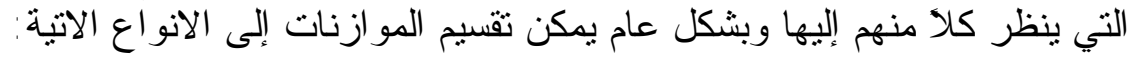

$$
\begin{aligned}
& \text { أولاً - من حيث الفترة التي تغطيها الموازنة }
\end{aligned}
$$

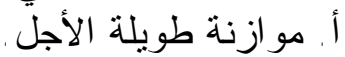

$$
\begin{aligned}
& \text { ب. ب. موازنة قصيرة الأجل. } \\
& \text { ثانياً - من حيث المرونة أنة المبرة } \\
& \text { أ. الموازنة المرنة. } \\
& \text { ب. الموازنة الثابتة. }
\end{aligned}
$$

ثالثاً - من حيث طبيعة العمليات و النشاط الأي تغطية الموازنة

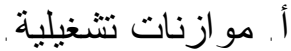




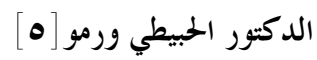

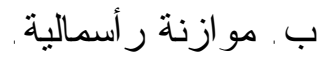

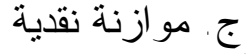

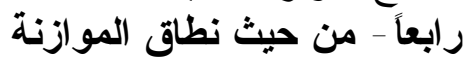

$$
\begin{aligned}
& \text { أ. ألموازنة الوظيفية (الفرعية) } \\
& \text { ب. الم الموازنات الثناملة (الرئيسة) }
\end{aligned}
$$

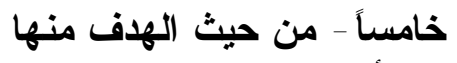

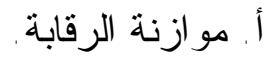

$$
\begin{aligned}
& \text { ب. ب. موازنة البر امج و الأداء (مو ازنة الأداء). }
\end{aligned}
$$

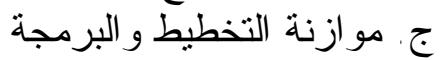

$$
\begin{aligned}
& \text { سادسأ - من حيث الموضنوع الثيط الذي تغطيه }
\end{aligned}
$$

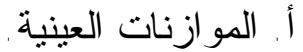

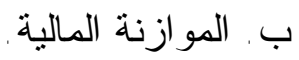

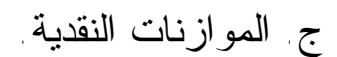

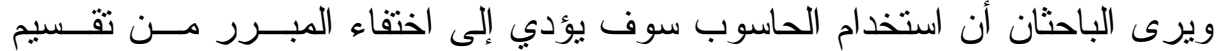

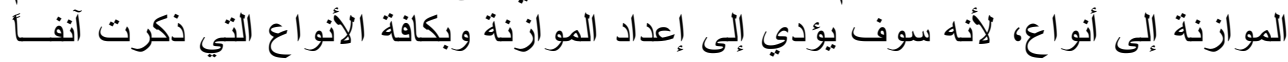

\section{مفهوم عملية إعادة الهندسة وأهميتها}

يعد استخدام الحاسوب في معظم المنظمات الحكومية أو الأهلية من أكثر المو اضـئيع

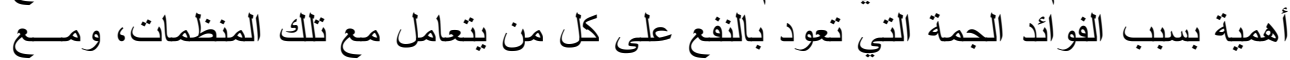

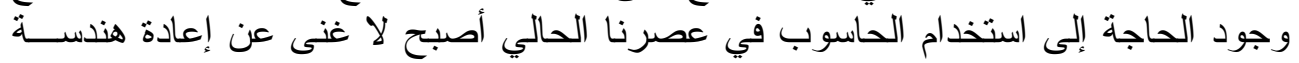

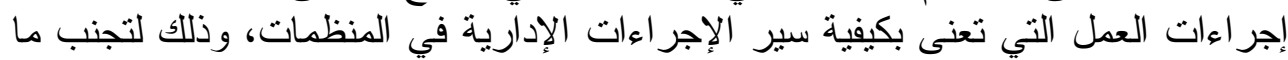

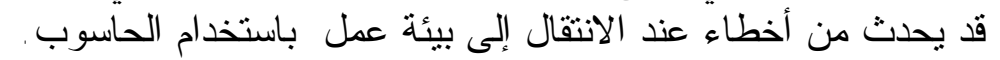

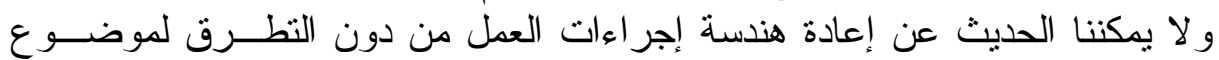

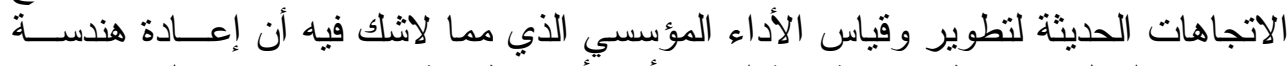

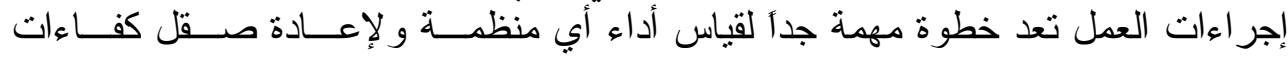

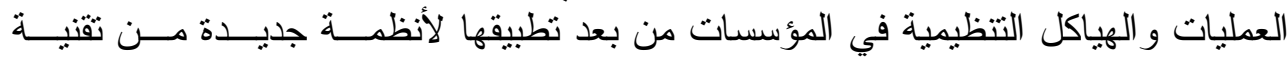

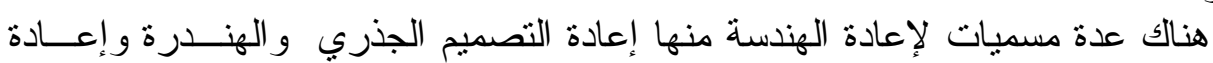
الهنسة التتظيمية و إعادة هيكلة العملية، وقد وردت العديد من التعــاريف لعمليــة إعـادة العادة

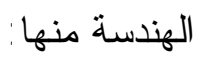


( . تحليل و إعادة تصميم تتابع العمل و عمليات التشغيل داخل المنظمات وبينهــا Neill) and Sohal , 1999, 573 )

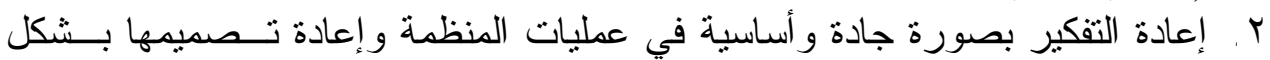

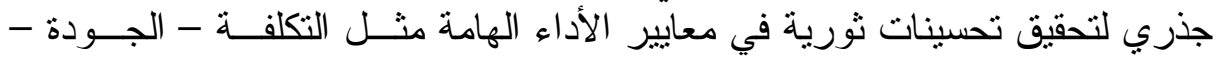
الخدمة - سر عة الانجاز (Hammer and Champy, 1993, 24)

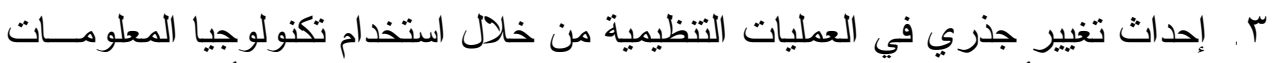

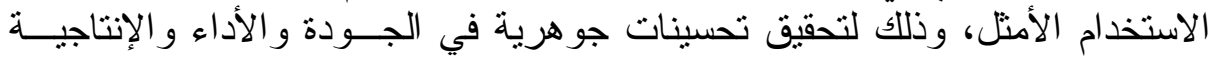

(Raymond, et al ., 2003, 72)

ويرى الباحثان أنه يمكن تعريف إعادة الهندسة بأنها قيام الشركة بإعادة التـصميم

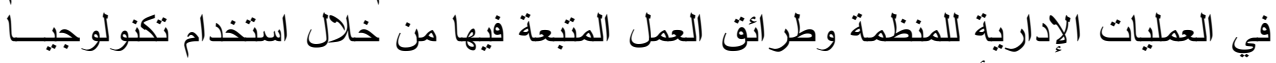

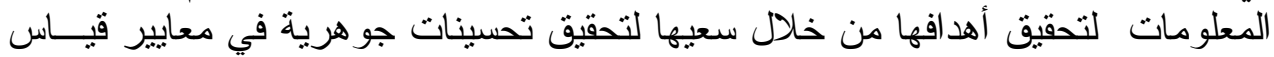

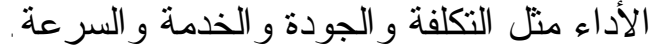

من خلال التعاريف السابقة يتبين أن جميعها تشنتركة في في عدد من العناصر و أهمها

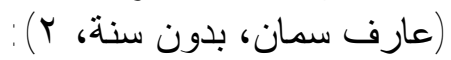

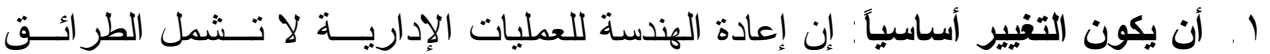

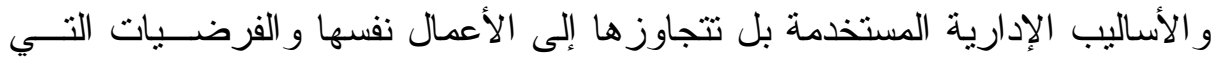
تقوم عليها . الاسبا الإن

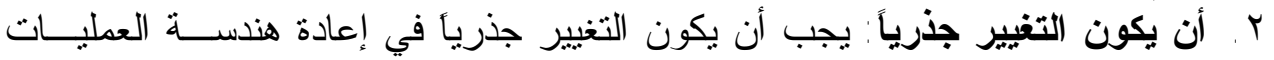

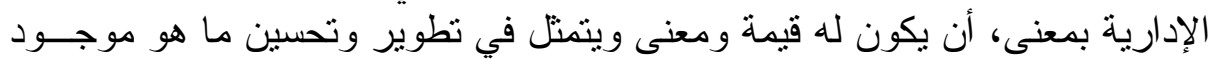

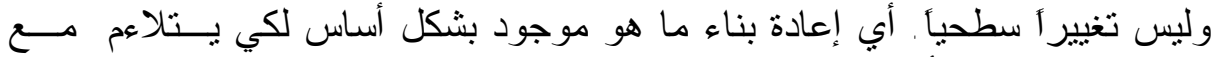

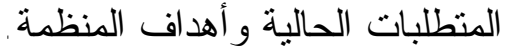

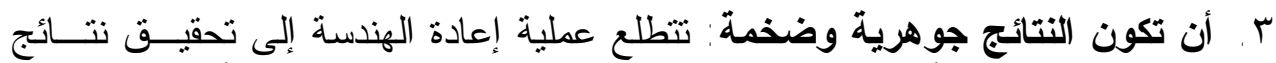

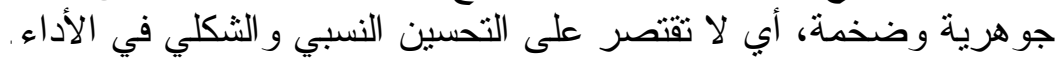

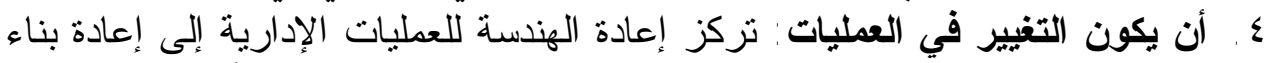

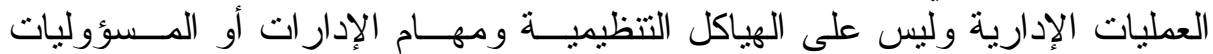

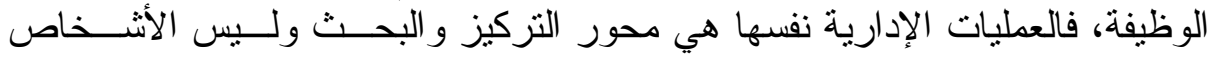

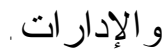

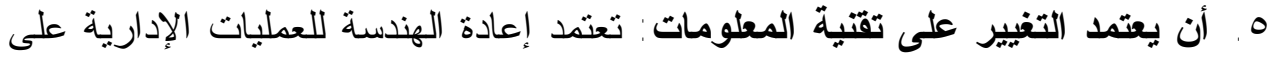

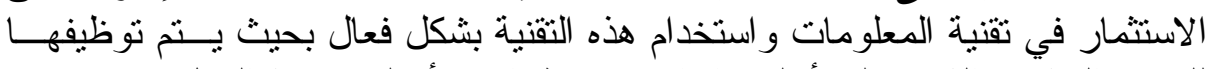

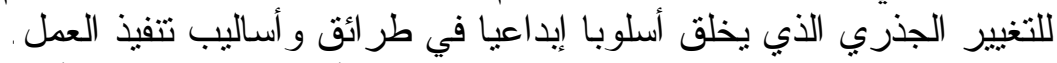

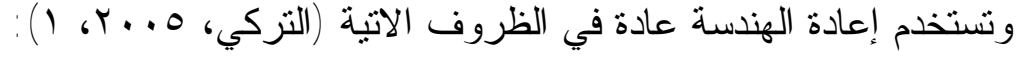

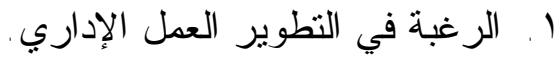

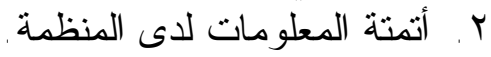

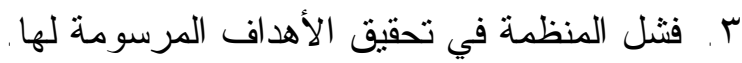

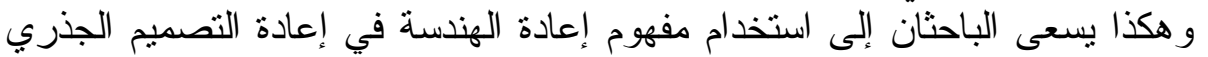

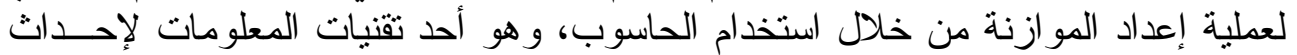

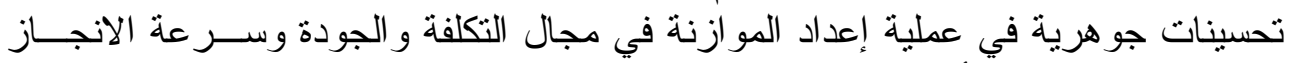
بوصفها خطة شاملة لأنشطة المنظمة معبر ا عنها بصورة في مالية الئة 


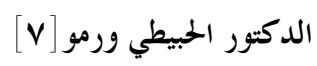

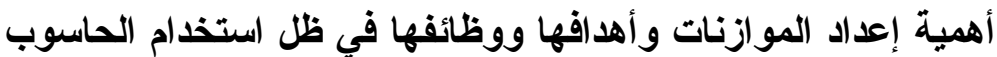

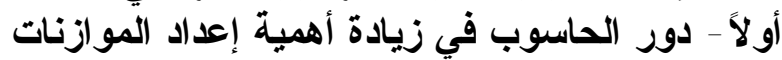

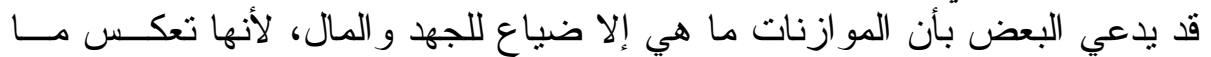

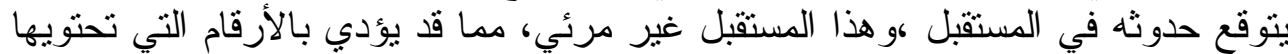

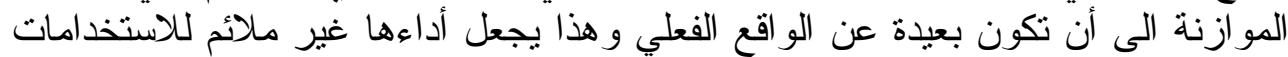

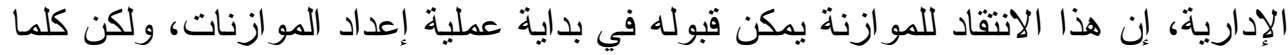

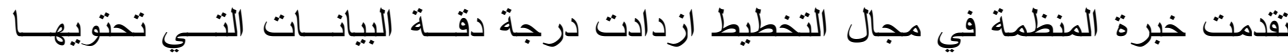

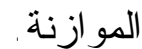

ولهذا فإن أهمية خصائص الموازنة تتضح من خلال: (إصدارات المجمع العربـي

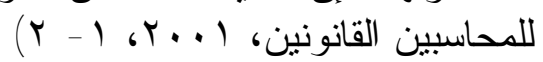

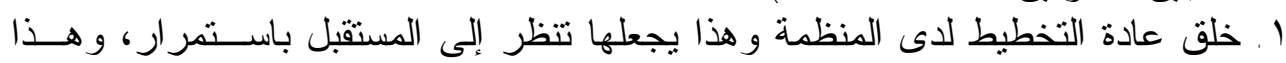

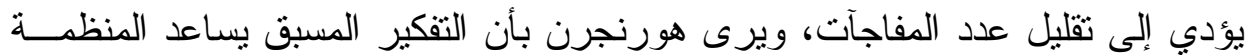

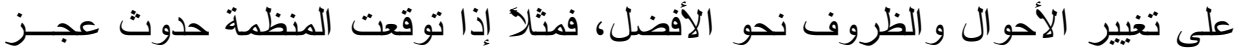

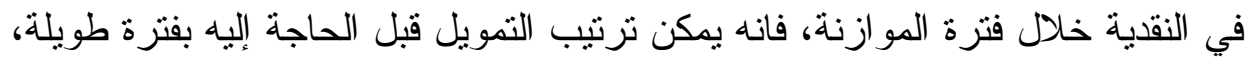

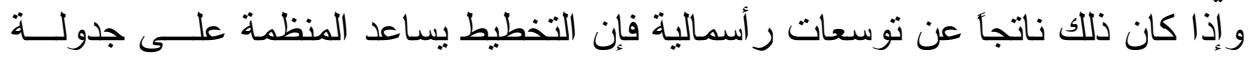

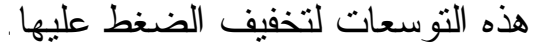

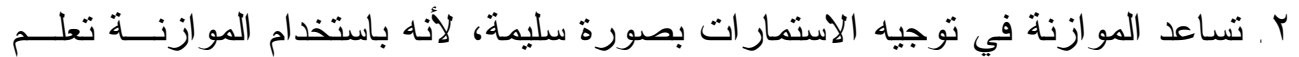

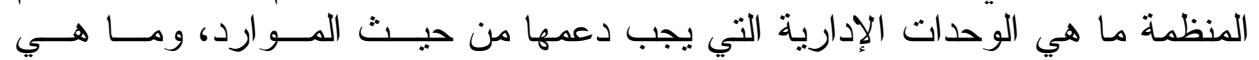

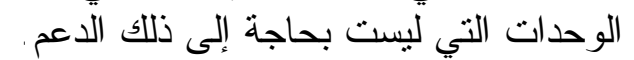

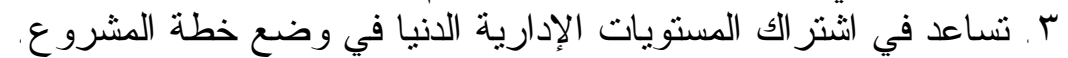

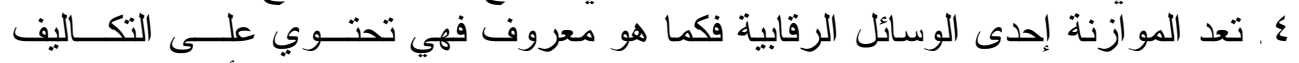

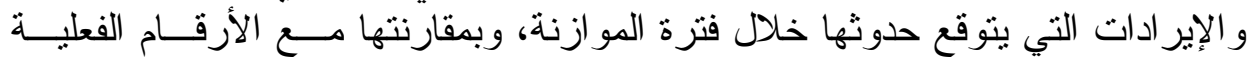

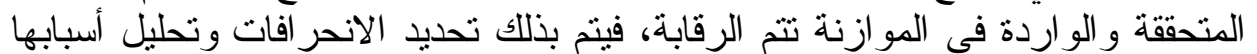

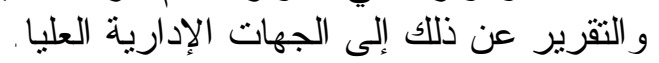
ه. التتسيق بين الإدار ات و الأقسام المختلفة في المنظمة الوالواحدة، الإلفعند معرفة حجم المبيعات

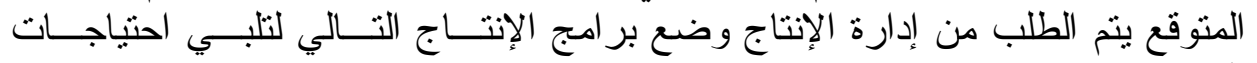

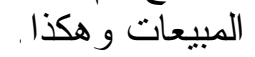
7 . المو ازنة تساعد في تحديد المسؤولية لمر اكز التكلفة والربحية و الاستثمارية.

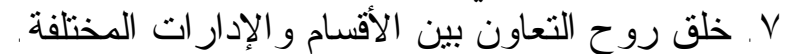

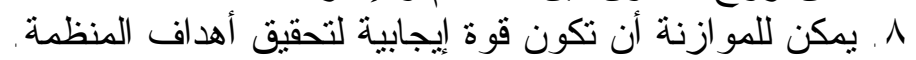

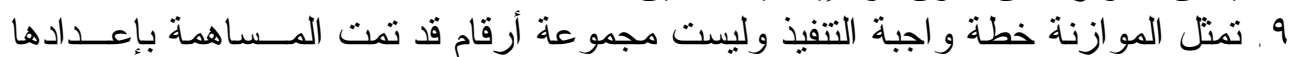
من قبل المدر اء و المو افقة عليها.

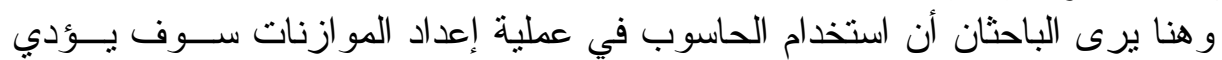

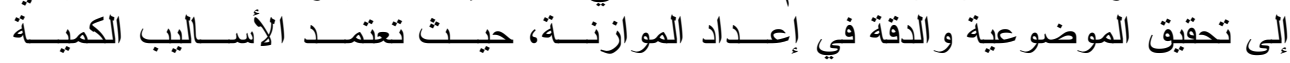

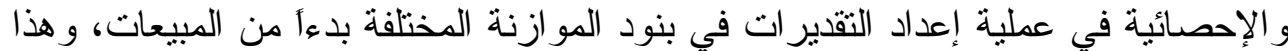

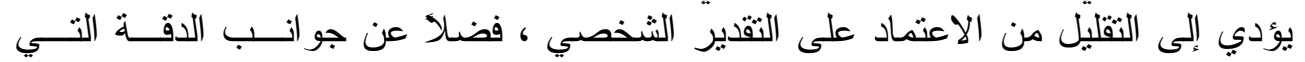
يوفرها الحاسوب من خلال العمليات الحسابية. 
يتم عادة إعداد الموازنات وذللك لتحقيق مجموعة من الأهداف، ويمكن تلخيص أهـــ التهـ

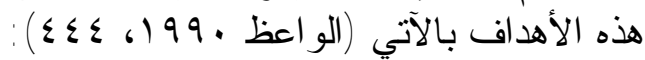

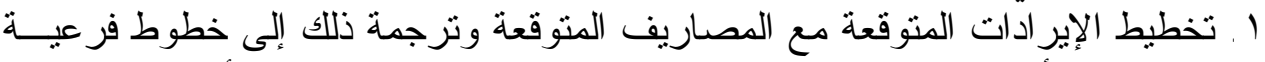

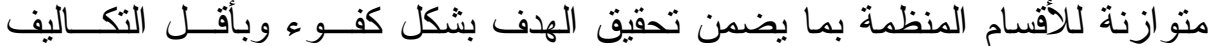
الممكنة.

r. تحديد معايير دقيقة تكون أساساً في تقييم الأداء وتحديد مسؤولية كل فرد عن النـشاط

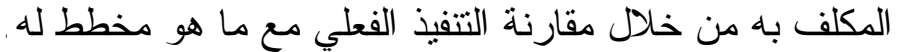

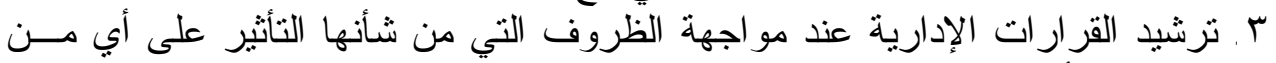

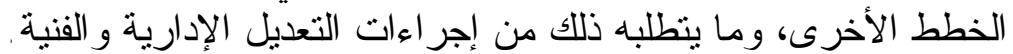

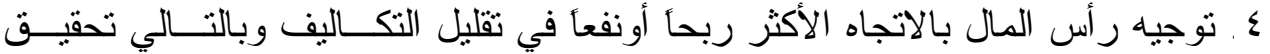

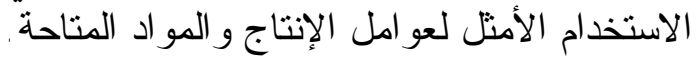

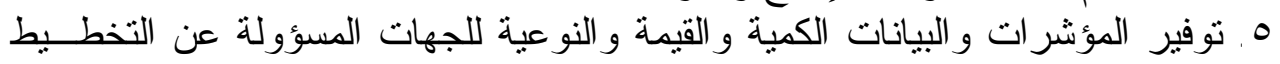
و المتابعة المركزية.

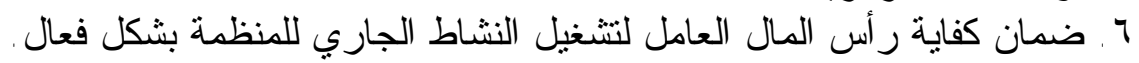

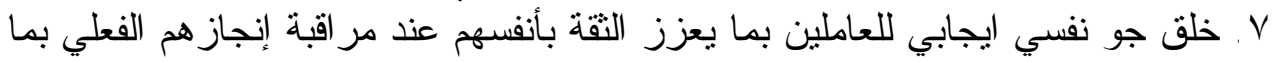

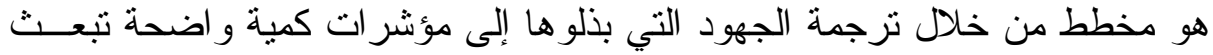

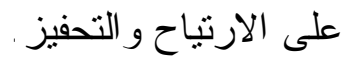

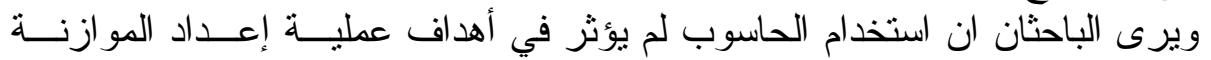
بشكل مباشر ، ولكنه أثر بالتأكيد على سهولة الوصول التهول إلى هذه الأهداف وتحقيقها.

\section{ثالثاً - وظائف الموازنة}

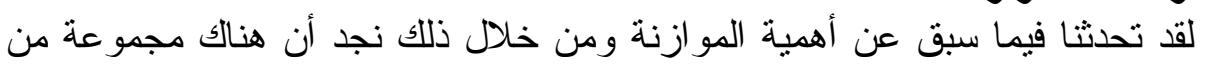

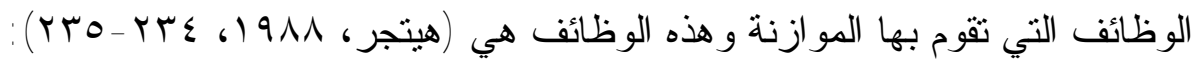

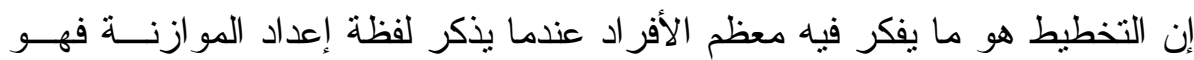

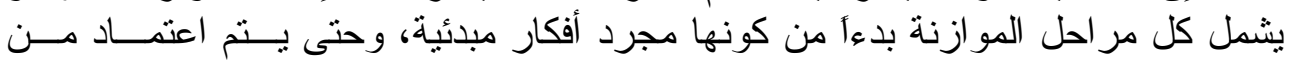

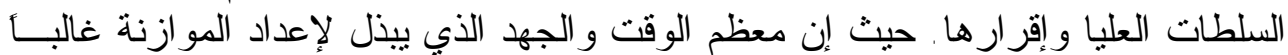

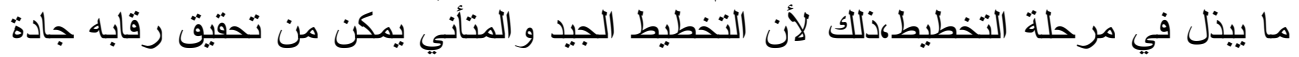
كوظيفة ثانية للمو ازنة.

ب الرقابة

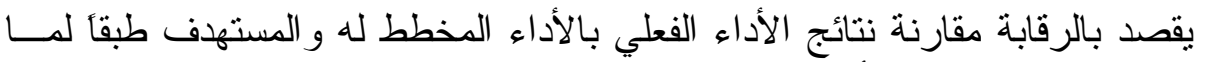

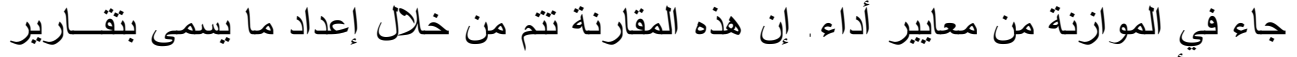

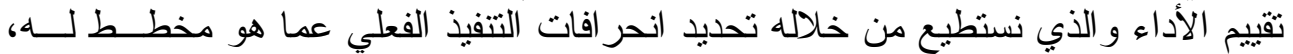

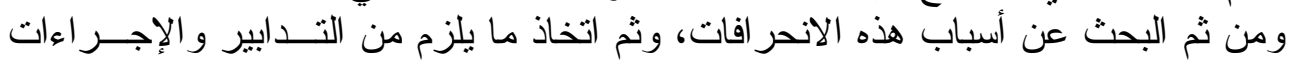

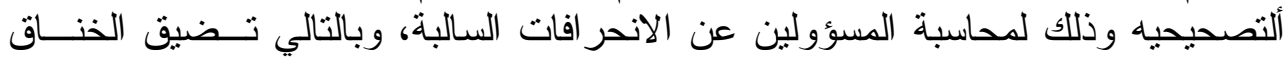
عليها حتى لا تتكرر مره أخرى، ومكافأة المسئولين عن الانحر افات الموجية وتطوير ها. 
الدكتور الحبيطي ورموب[9]

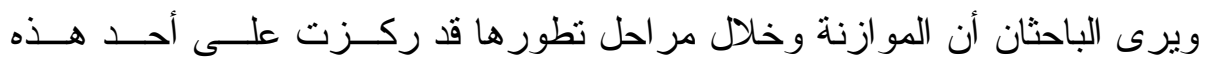

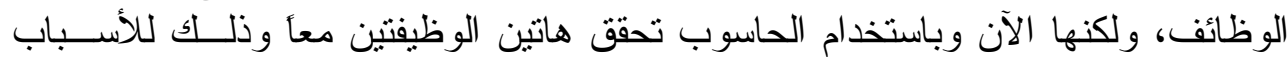

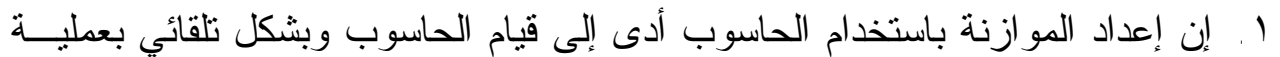
المقارنة بين الأداء الفعلي و المخطط بموجب المبات الموازنة و على مستويات نشاط مختلفة

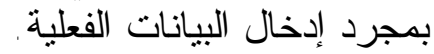

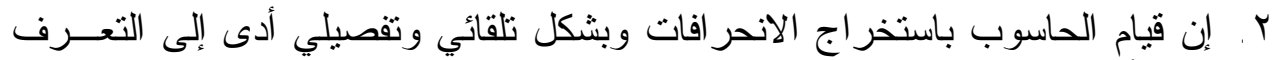

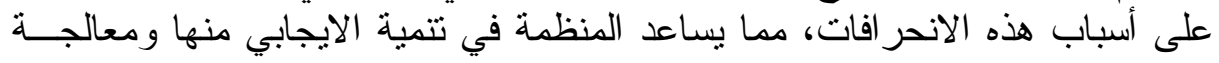

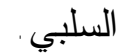

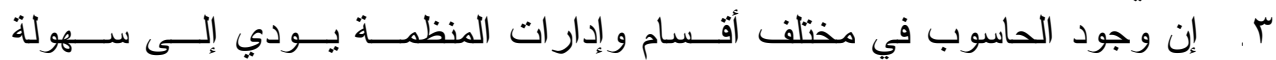

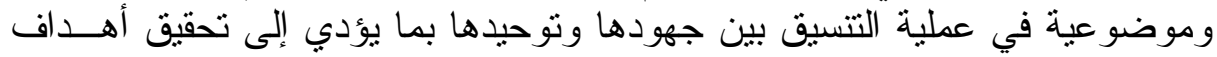

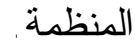

\section{مبادئ وقو اعد إعداد الموازنة

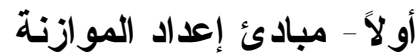

لكي يتم إعداد المو ازنة بصورة صحيحة ودئة ودقيقة فلابد من وجود مبادئ علمية تقـوم

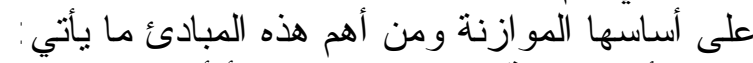

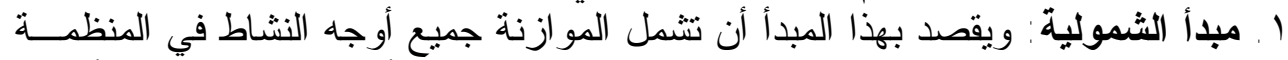

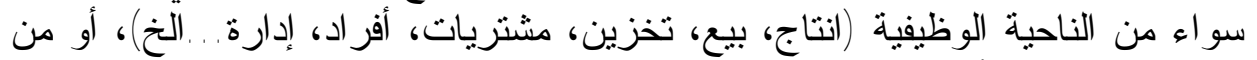

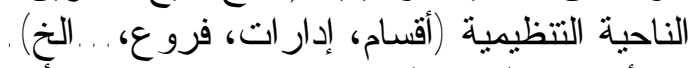

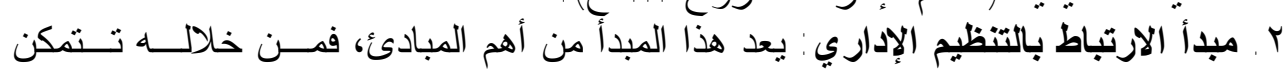

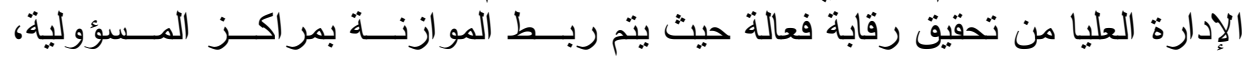

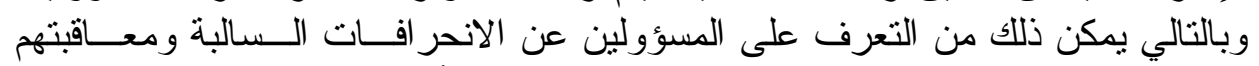

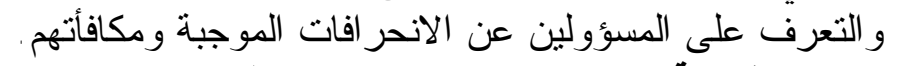

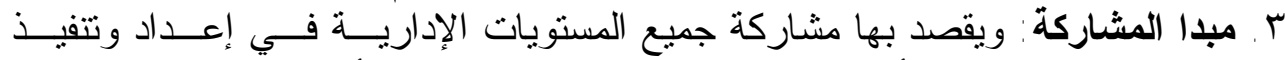

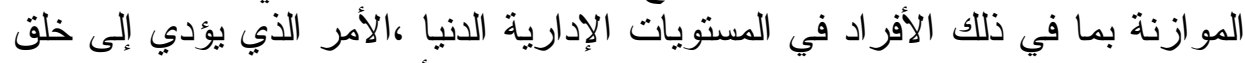

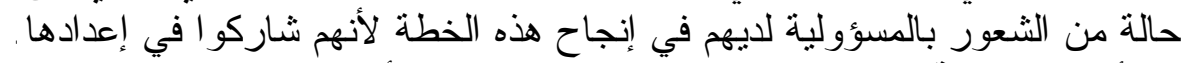

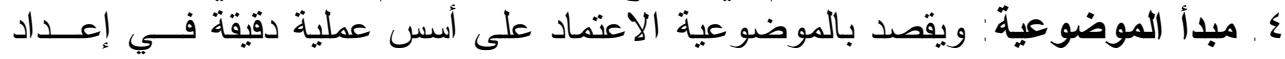

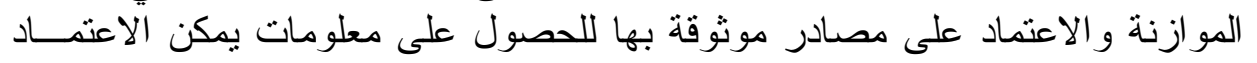
عليها.

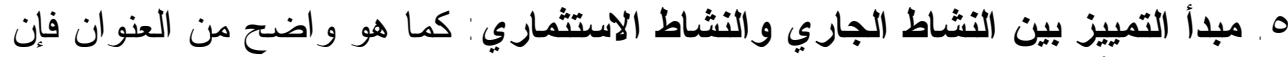

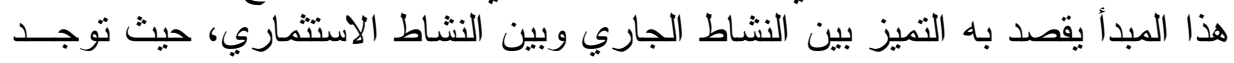

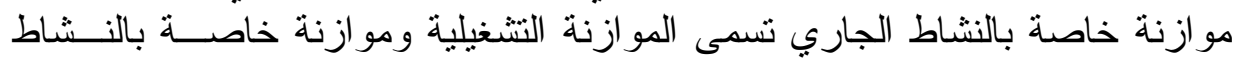

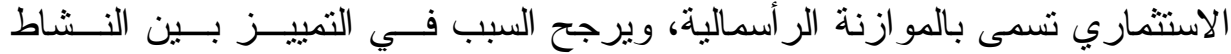

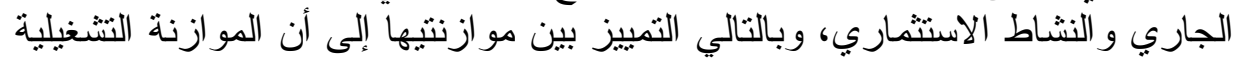

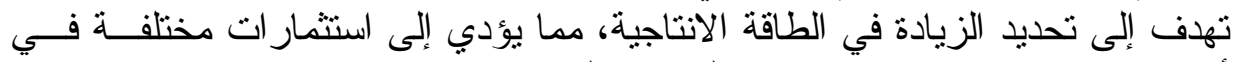

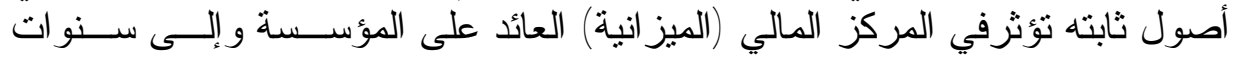
كثيرة قادمة. 


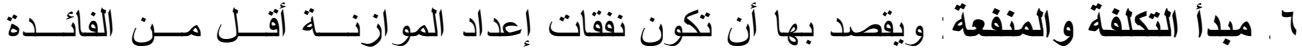

المرجوة من إعداد الموازنة، لأنه كلما كانت نفقات إعداد الموازنة أكبات أكبر من فائـــنها

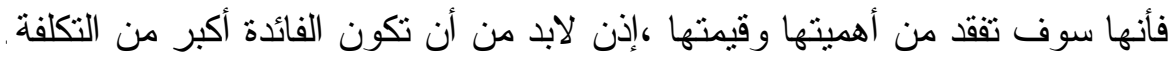

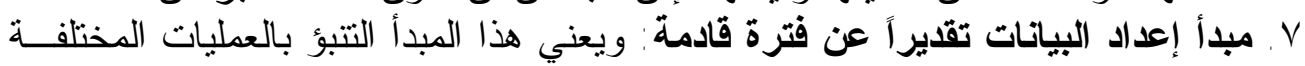

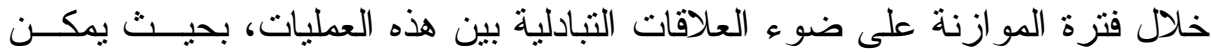

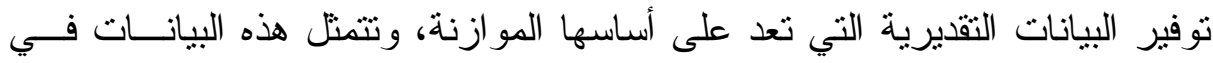

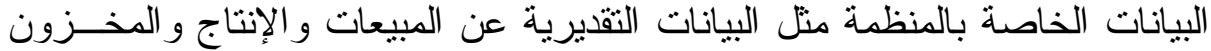

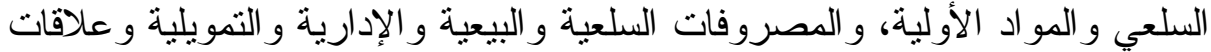

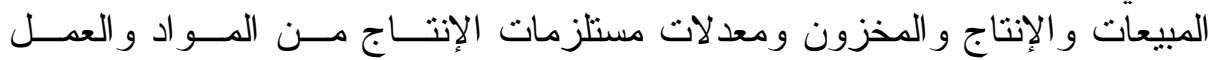

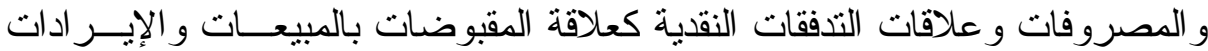

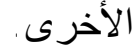

^. مبدأ التتــسيق: إن أهمية التتسيق تظهر في تحقيق التوازن بين العمليــات و والأنـشطة

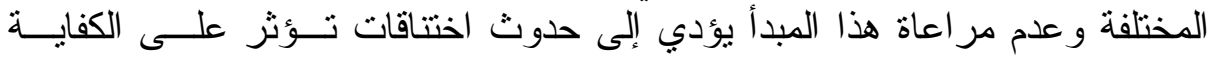
الإنتاجية للمنظمة، ويعني هذا المبدأ تحقيق التجنس بين الجداول التهائ الفرعية المشتقة من

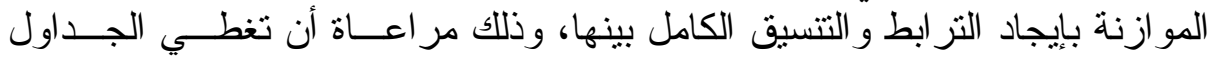

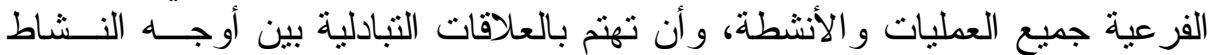

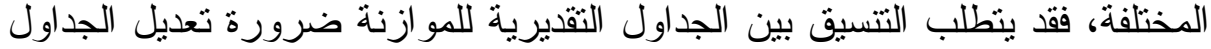

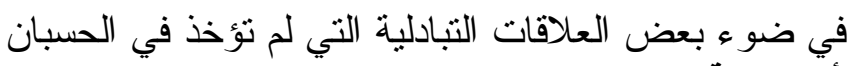

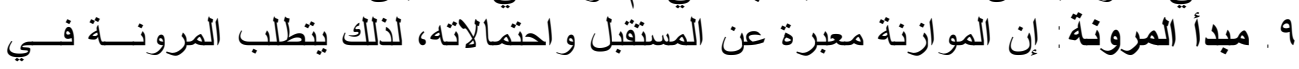

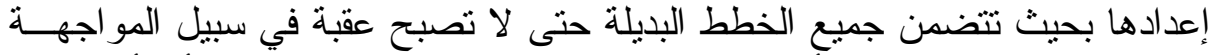

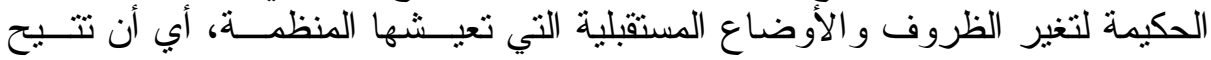

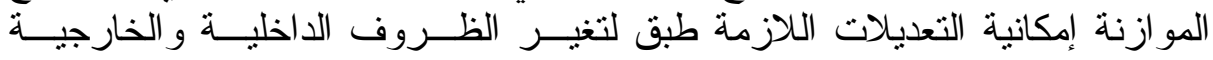
للمنظمة.

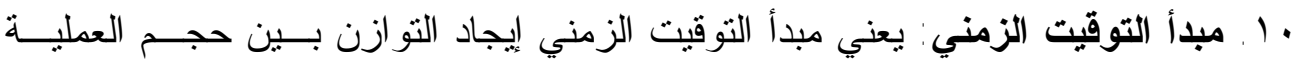

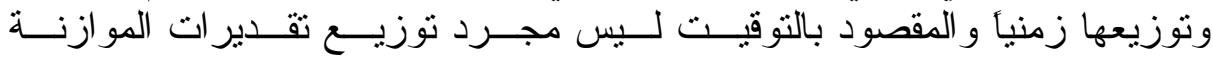

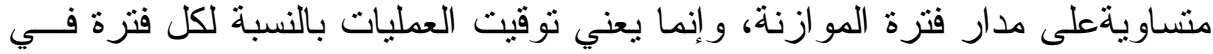

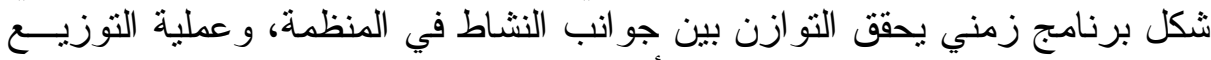

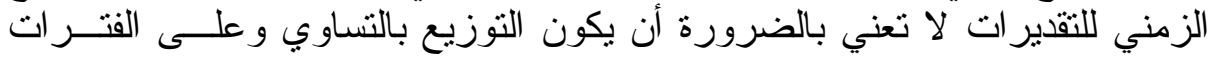

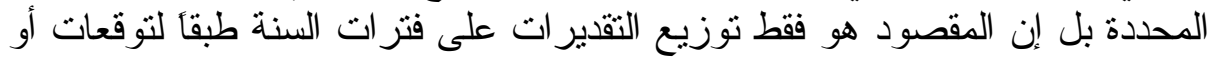

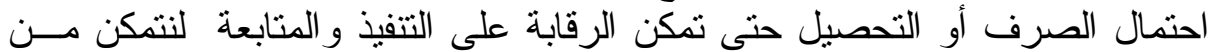
تجنب أي ارتباكات مالية.

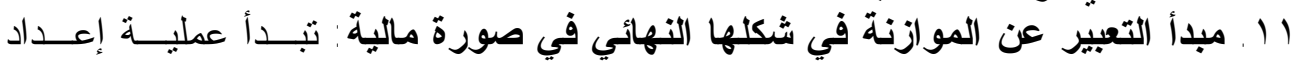

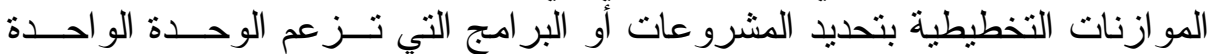

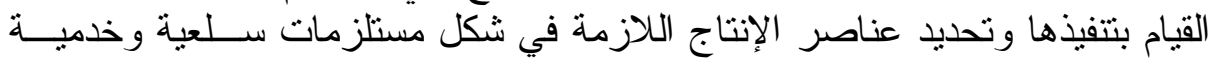

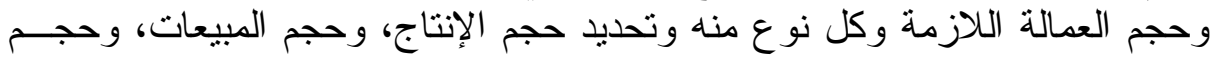

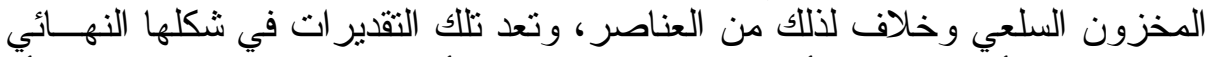

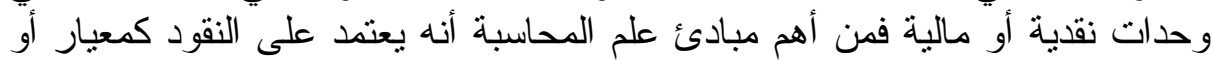

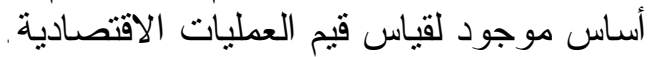




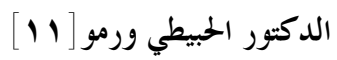

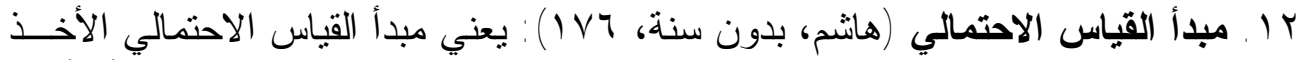

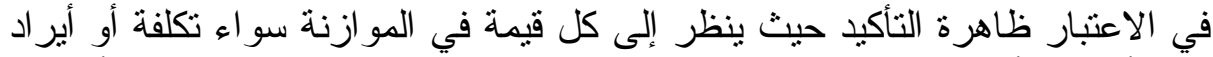

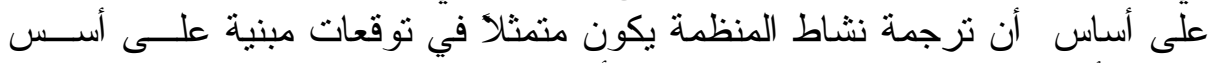

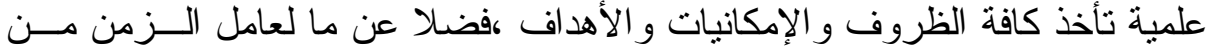

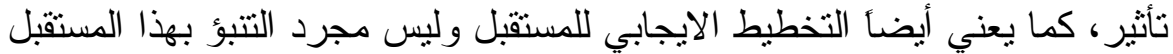

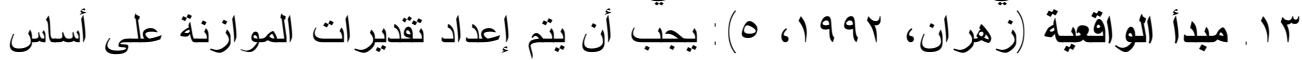

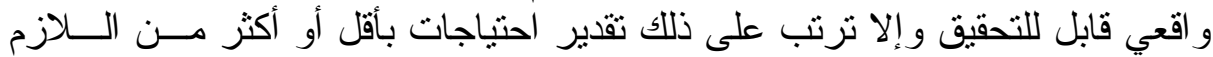

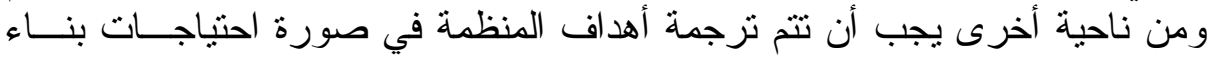

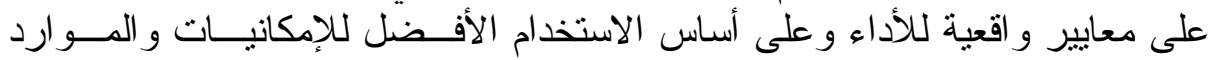

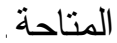

ـ ا ـ المبدأ السلوكي للموازنات: مما لاثك فيه أن نجاح أو فثل الموازنة التخطيطية كأداة

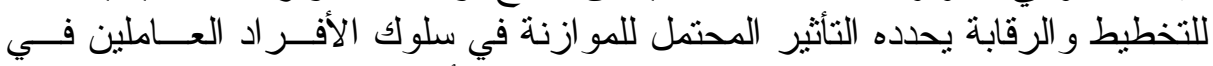

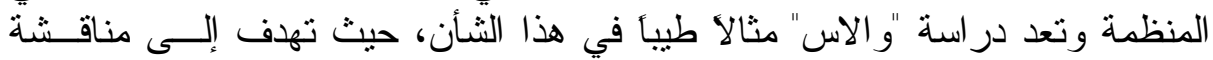

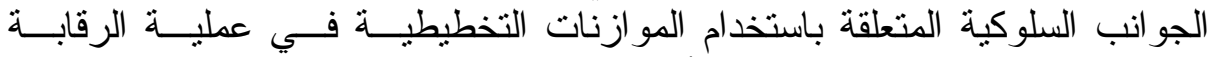

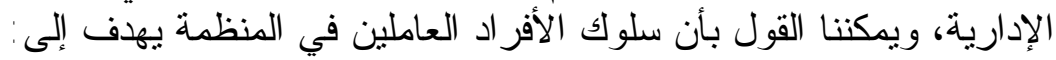
- ت تحقيق أهداف عامة المنظمة.

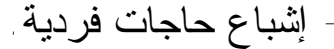
فيما ياتي المكملات السلوكية قد تنتج عن عدم التو افق بين هذين الهدفين:

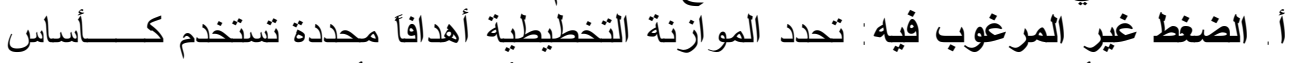

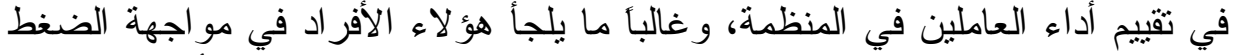

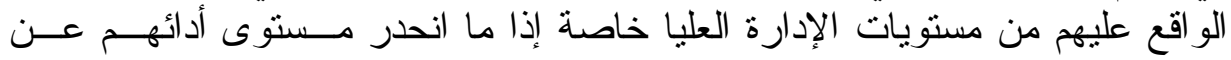

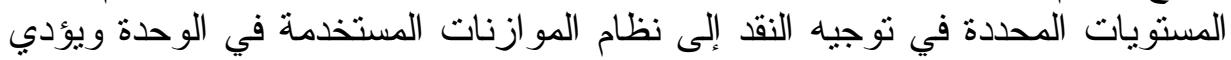

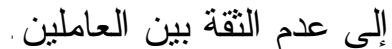

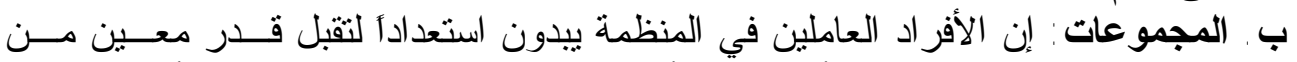

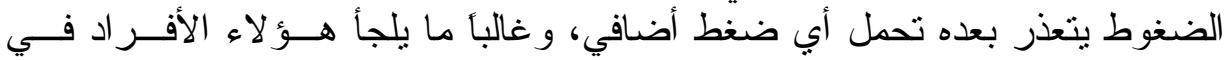

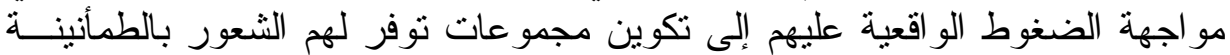

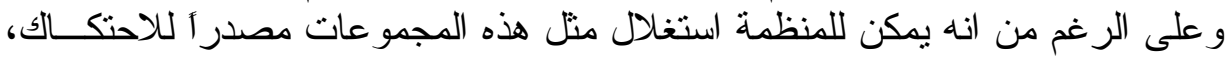

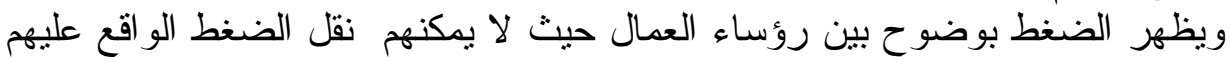

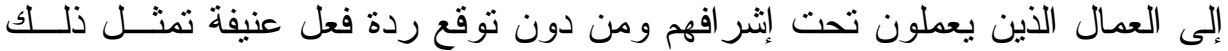

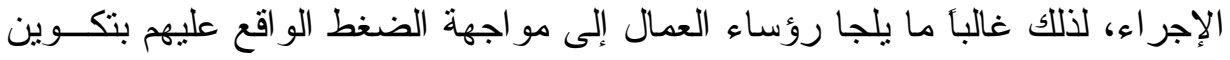
مجمو عات منهم.

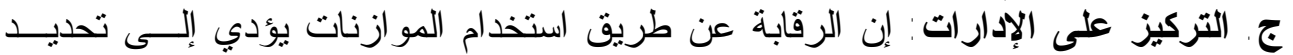

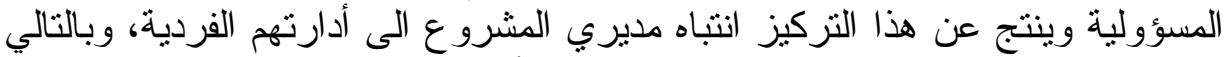

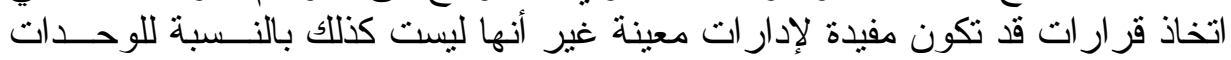

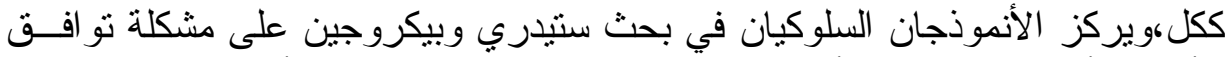

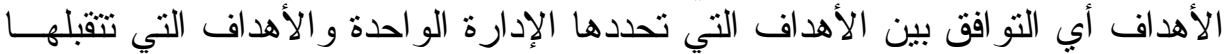

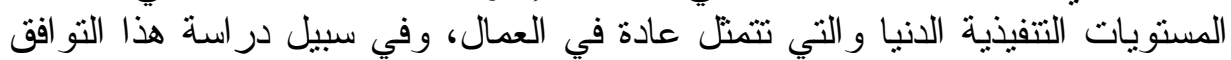

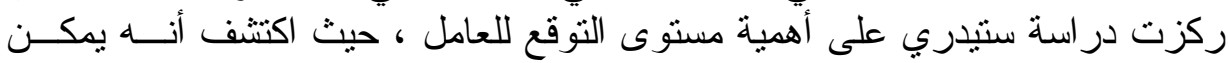


تحقيق مستويات أفضل للأداء إذا ما ارتبطت الموازنة التخطيطية بمسـتوي التوقـع

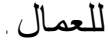

كما إنه تم التركيز على هذا المبدأ في تعريف الموازنة حيث عرفت الته على أنها: أنها:

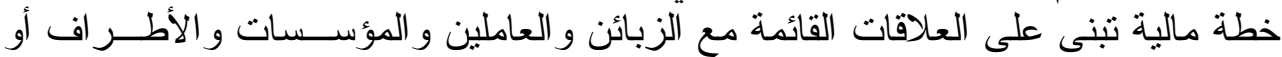

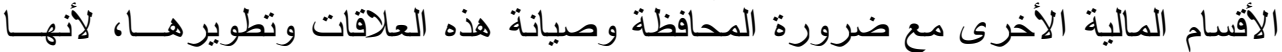

تانغير باستمر ار تغير الظروف (حسين، 10

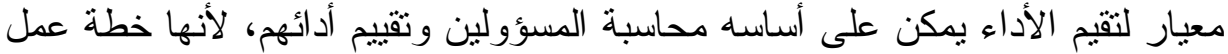

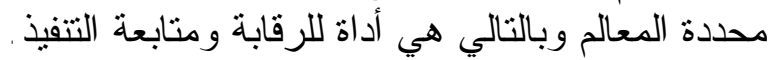

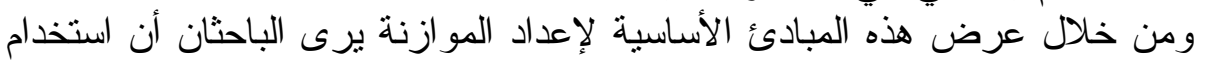

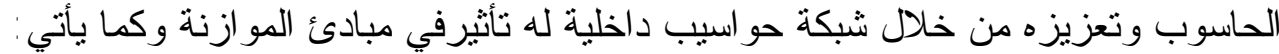

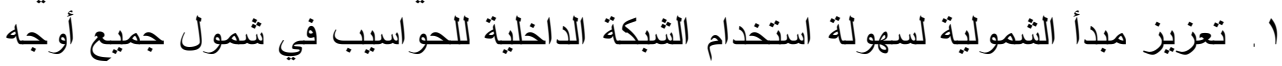

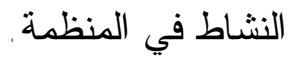

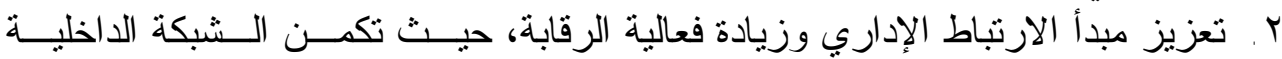

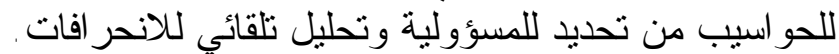

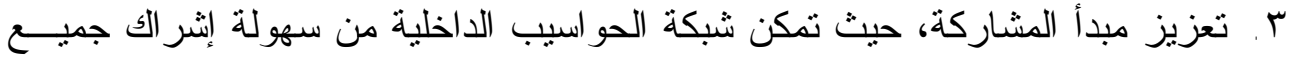

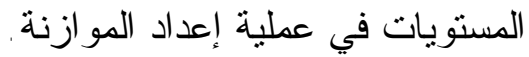

ع. . تعزيز مبدأ الموضوعية، حيث تتضح أهمية استخدام الحاسوب في تحقيق الموضو عية الهية

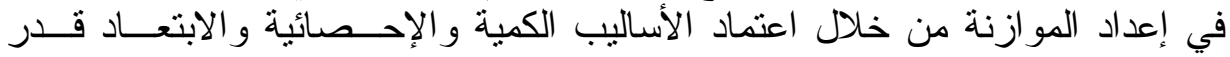

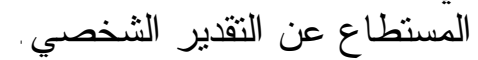
ه. تحقيق مبدأ الكلفة والمنفعة، حيث يؤدي استخدام الحاسوب إلى تقليل الكلف المستخدمة

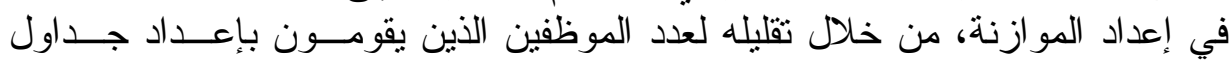

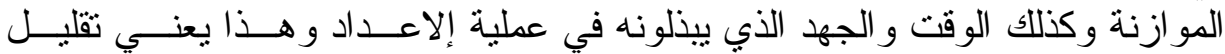
لتكاليف إعداد المو ازنة.

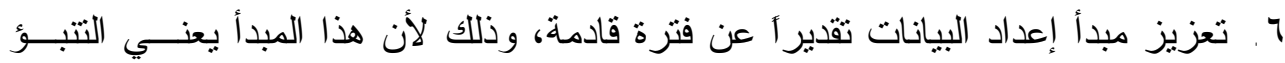

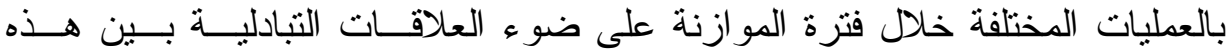

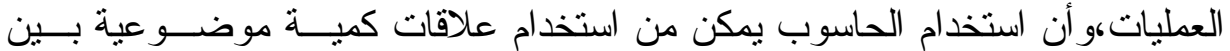

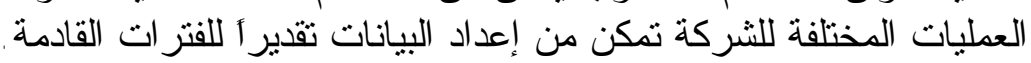

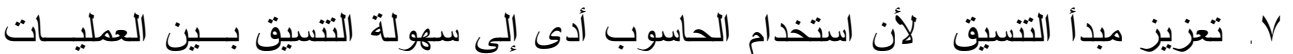
و الأنشطة المختلفة من خلال تحقيق التجنس بين الجداول الفرعية المشتقة من الموازنة لإنة بإيجاد التز ابط و النتسيق الكامل بينها.

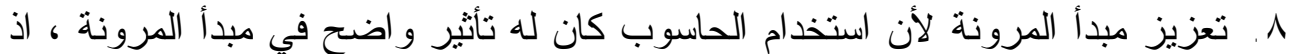

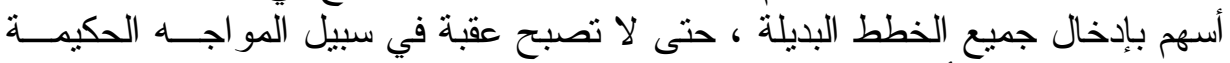

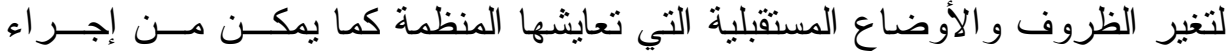
التعديلات اللازمة طبقاً لتغير الظروف الداخلية و الخارجية للمنظمة.

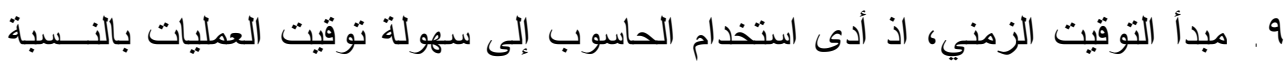
لكل فترة في شكل برنامج زمني يحقق التوازن بين جوانب النـشـاط فــي المنظمـــة 


\section{الدكتور الحبيطي ورمو[ب أ]}

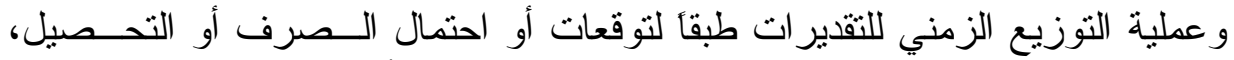
حتى يمكن الرقابة على التتفيذ ومتابعته وحتى يمكن تجنب أي الزئ ارتباكات مالية.

\section{ثثانياً - قو اعد وخطو اته إعداد الموازنة}

عند إعداد الدوازنة فأنه يؤخذ بنظر الاعتبار القواعد الاتية: (عبد العسال، ....؟،

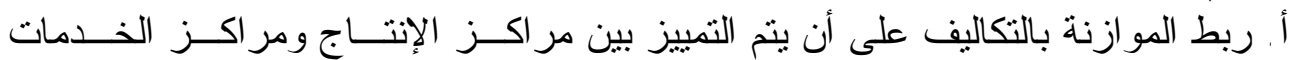

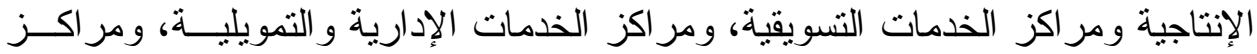

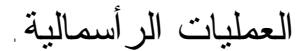

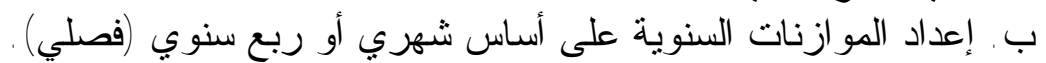

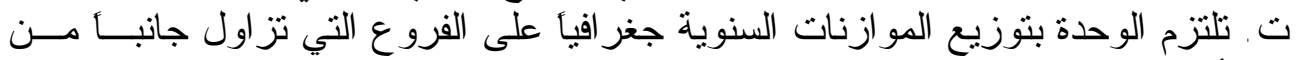
أنثطنها الاقتصادية الرئيسية.

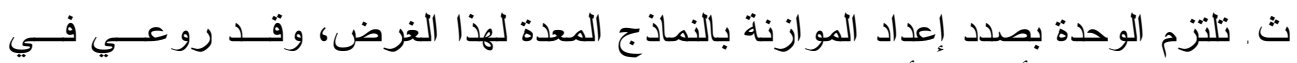

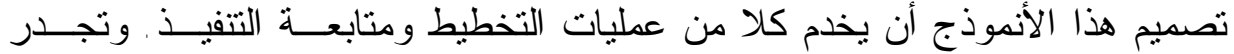

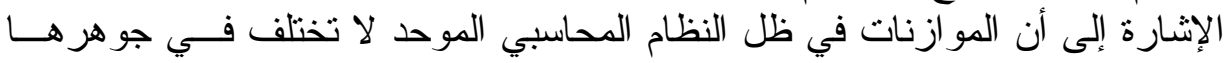

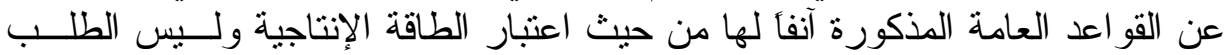

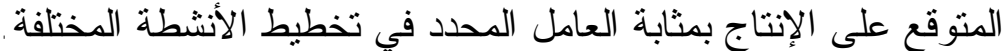

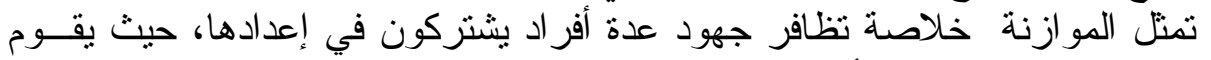

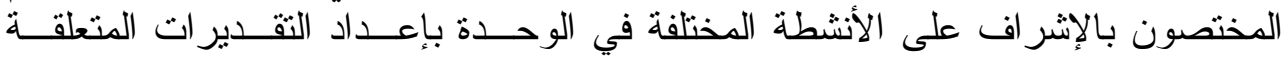

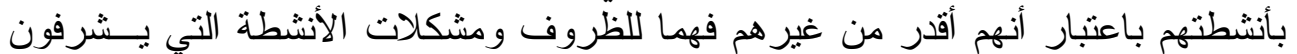

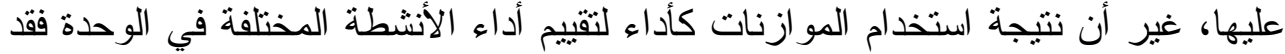

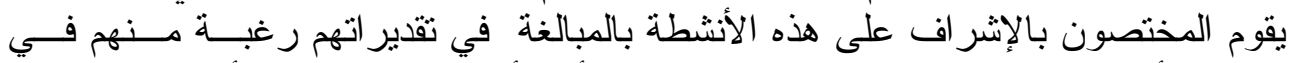

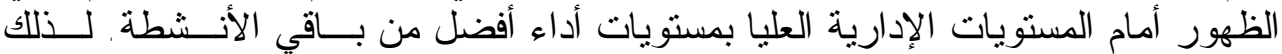

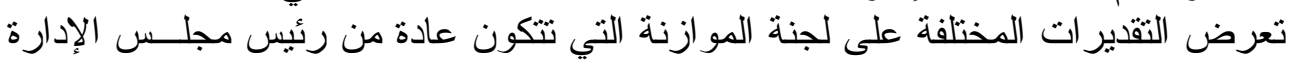

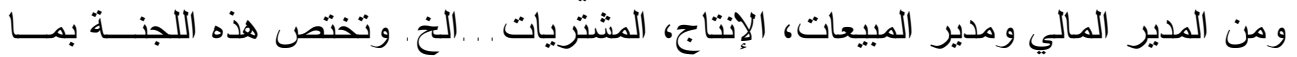

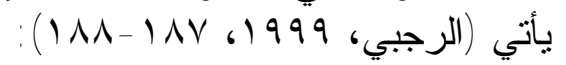

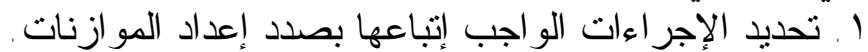

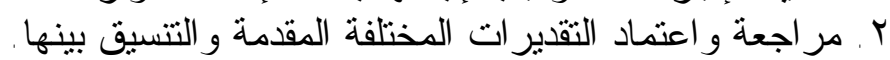

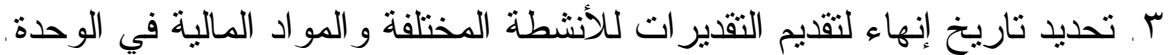

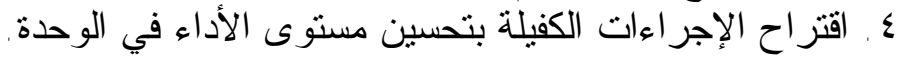

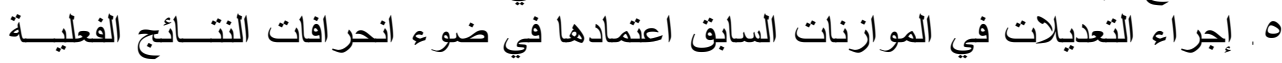

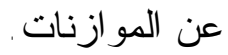
7. تحديد بداية ونهاية فترة إعداد الموازنات في ضوء المستجدات و الظروف التي تتـأثر

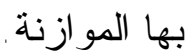

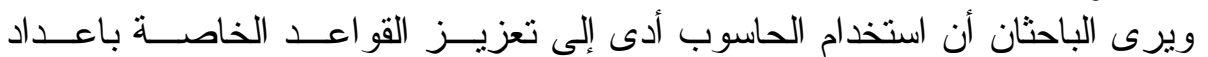
المو ازنة وسهولة تحقيقها من خلال :

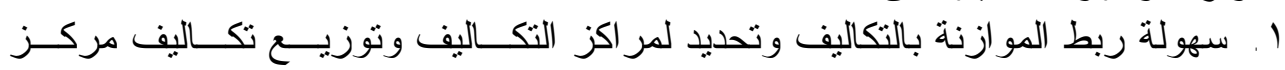
الخدمات على المر اكز الإنتاجية وبشكل تلقائي. 
r. إعداد الموازنة على أساس شهري أو فصلي أو نصف سنوي وبشكل تلقائي.

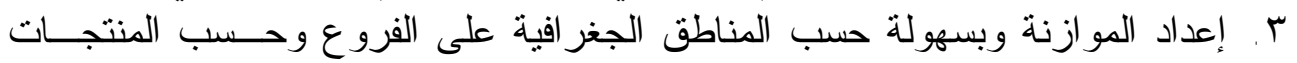
و على المستوى الكلي وبشكل تلقائي.

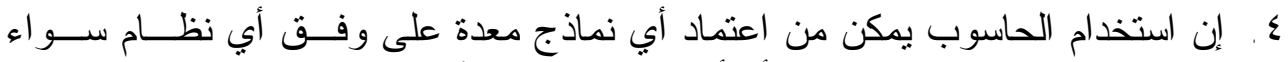

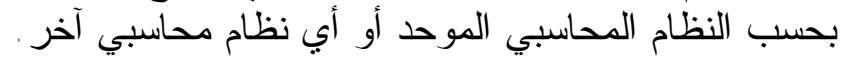

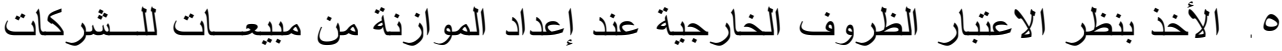

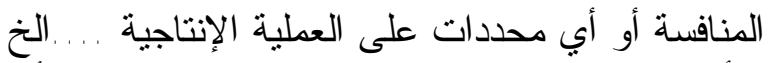

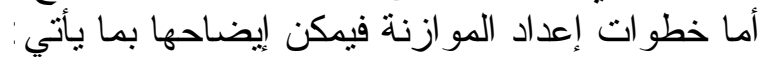

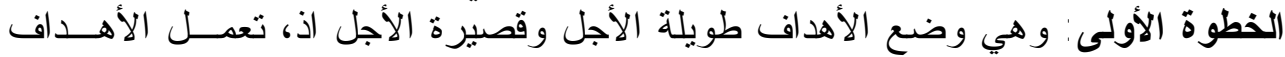

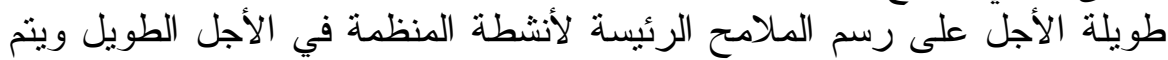

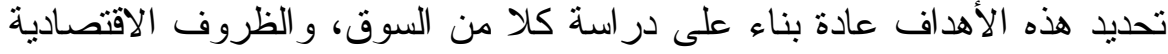

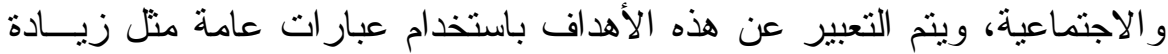

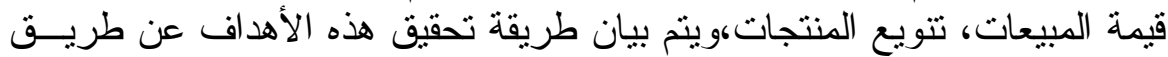

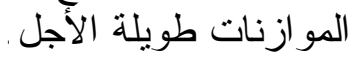

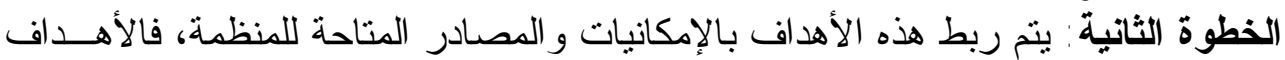

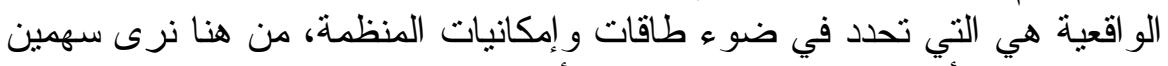

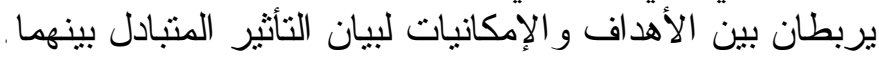

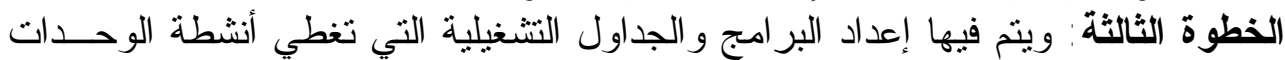

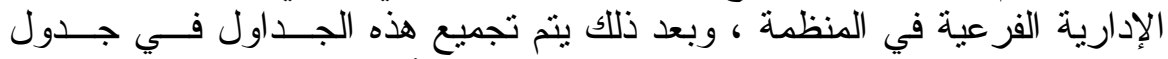

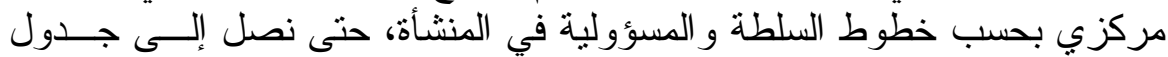

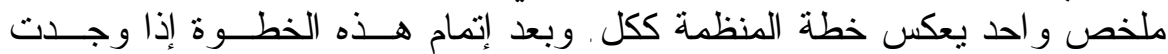

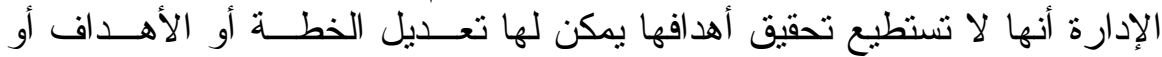

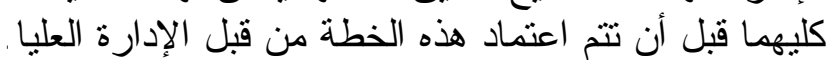

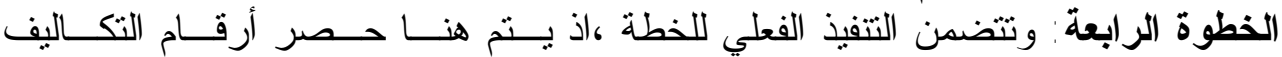

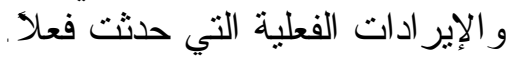

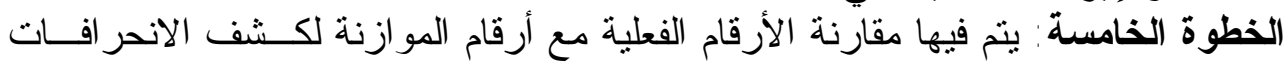

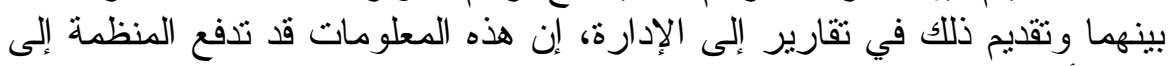

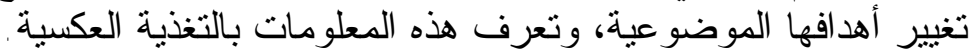

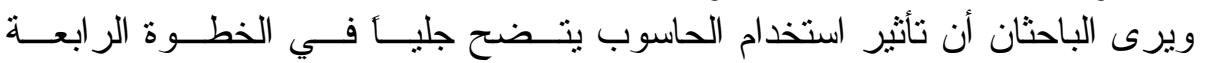

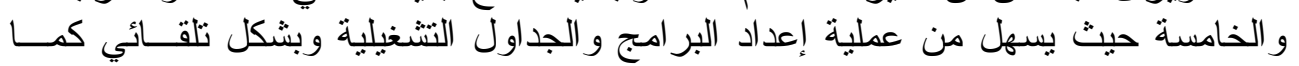

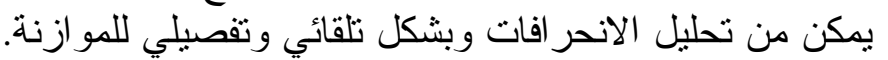

استخدام برنامج أكسل في إعداد الموازنة (حالة دراسية)

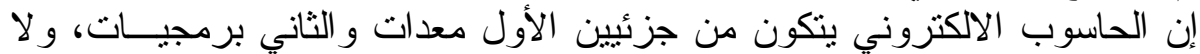

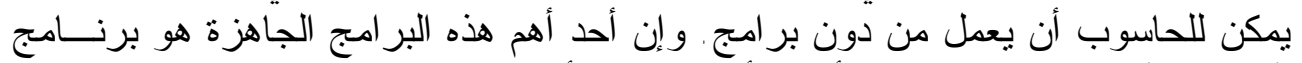
(EXCEL)

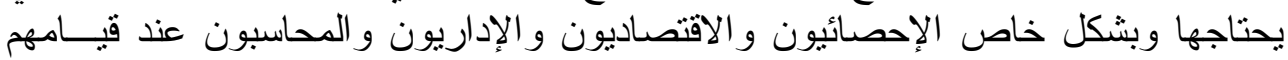

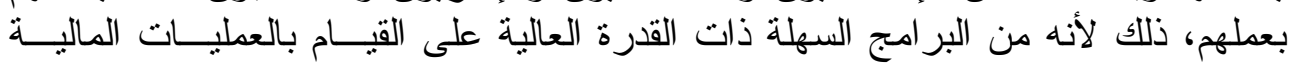




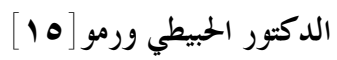

و الإحصائية و الاقتصادية سو اء في مجال المحاسبة المالية أو استخدام المحاسبة الإداريــة أو أي فرع من فروع الإنحاسبة بالمعنى الثنامل لعلم المحاسبة.

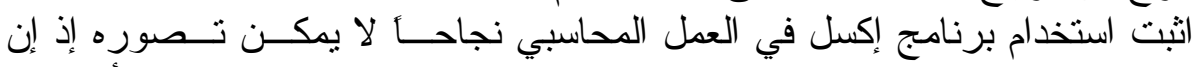

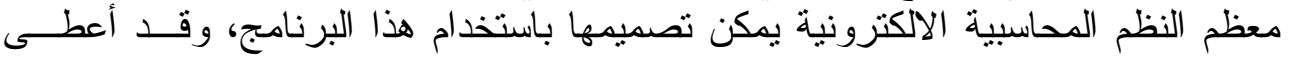

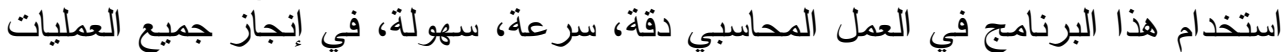
التي يمكن القيام بها داخل النظام المحاسبي.

\section{أولاً - حالة دراسية - مبية}

لبيان كيفية استخدام البرامج في إعداد الموازنة الثاملة نفترض الحالــة الدراســبة

تقوم شركة الموصل الصناعية بإنتاج نو عين من المنتجات أرب وتقوم بتسويقها فــي

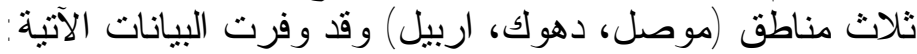

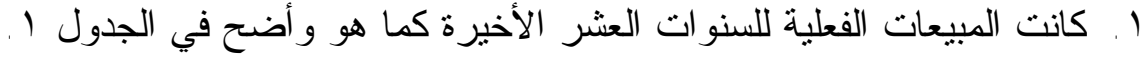

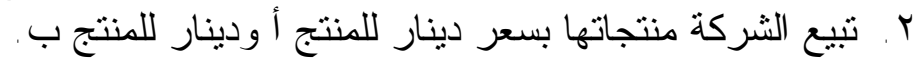

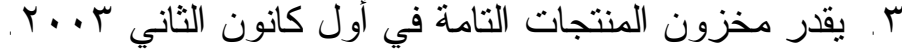

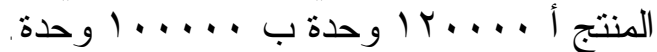

مخزون المنتجات تامة الصنع في نهابة الفترات الثهرية للربع الأول و الفترات ربع

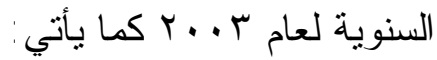

\begin{tabular}{|c|c|c|}
\hline المنتج ب & المنتج أ & الثشهر \\
\hline $9 \ldots$ & $11 \ldots$ & كانون الثاني \\
\hline$\wedge \ldots$ & $1 \ldots \ldots$ & شباط \\
\hline$v \ldots$ & $9 \ldots$ & اذذار \\
\hline$v \ldots$ & $9 \ldots$ & الربع الاول \\
\hline $7 \ldots$ & $\wedge \ldots$ & الربع الثاني \\
\hline $0 \ldots$ & $v \ldots$ & الربع الثالث \\
\hline$v \ldots$ & $9 \ldots$ & الربع الر ابع \\
\hline
\end{tabular}

ع. تستخدم الثركة ثلاثة أنواع من المو اد الأولية هي س ، ص ، ع ع ومعدلات استخدامها لإلتناج الوحدة الو احدة من المنتج كما يأتي:

\begin{tabular}{|c|c|c|}
\hline+ & $i$ & المادة الخام \\
\hline$r$ & - & $\omega$ \\
\hline- & 1 & $ص$ \\
\hline- & $r$ & $\varepsilon$ \\
\hline
\end{tabular}

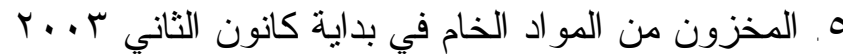




\begin{tabular}{|c|c|c|}
\hline سعر الوحدة & وحدة & المادة \\
\hline$\bullet, r .0$ & ro... & س - س \\
\hline$\bullet, \mu$ & vo... & ص ص \\
\hline$\because .90$ & $r \ldots$. & $\varepsilon$ \\
\hline
\end{tabular}

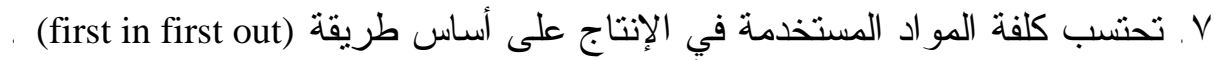

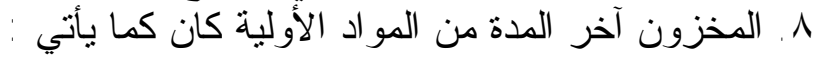

\begin{tabular}{|c|c|c|c|}
\hline المادة ع & المادة ص & المادة س & الثهر \\
\hline r & $\wedge \ldots$ & TRY... & كانون الثاني \\
\hline ro.... & $90 \ldots$ & $r \varepsilon \ldots$. & شباط \\
\hline$r \leq 0 \ldots$ & $\vee \wedge \ldots$ & $r \leq 0 \ldots$ & اذار \\
\hline$r \leqslant 0 \ldots$ & $\vee \wedge \ldots$ & $r \leqslant 0 .$. & الربع الاول \\
\hline ..... & NT... & rro... & الربع الثاني \\
\hline r..... & A $\vee .$. & $r \varepsilon \ldots$ & الربع الثالث \\
\hline ro.... & $9 \ldots$ & $r \leqslant 0 \ldots$ & الربع الر ابع \\
\hline
\end{tabular}

9 ـ تتوقع الثركة دفع الأسعار التقديرية للمواد الخام المشتر اة.

\begin{tabular}{|c|c|}
\hline سعر الوحدة & المادة \\
\hline$\cdot, r \ldots$ & س س \\
\hline •. & ص ص \\
\hline 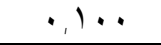 & $\varepsilon$ \\
\hline
\end{tabular}

• ا. معدل الوقت اللازم لإنتاج الوحدة من المنتج النهائي ومعدل الأجر في الساعة كمـا

\begin{tabular}{|c|c|c|}
\hline معدل الاجر & معدل الوقت & المنتج \\
\hline$\cdot, r \cdots$ & $\cdot, 0$. & أ \\
\hline - Y. & •, $\leqslant$. & ب \\
\hline
\end{tabular}

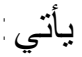


[iv] الدكتور الحبيطي ورمو

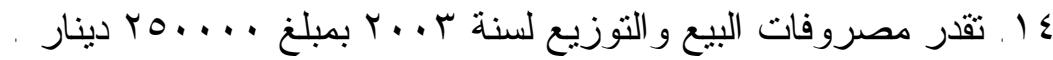

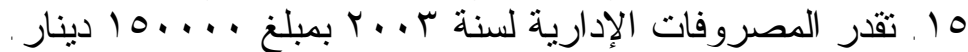

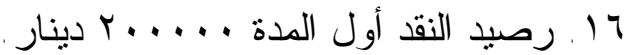

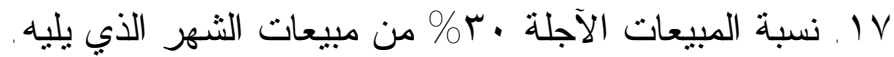

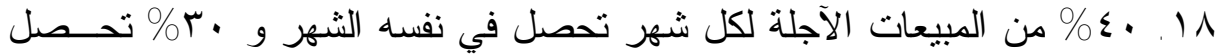

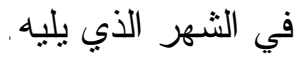
9 1 ـ تكون المدفوعات عن المواد المشتراة .0\% في نفسه الثهر و . \% في الثهر

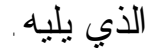
• r ـ تدفع جميع المدفو عات الأخرى نقداً خلال نفسه الثهر .

ثانياً - تنفيذ البرنامج

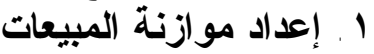

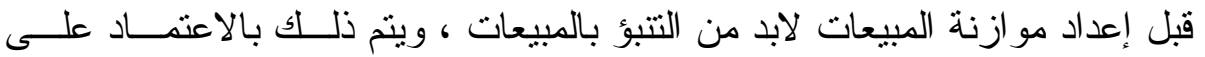

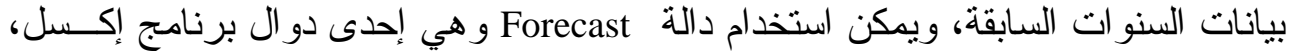
وكما هو واضح في الشكل الآتي:

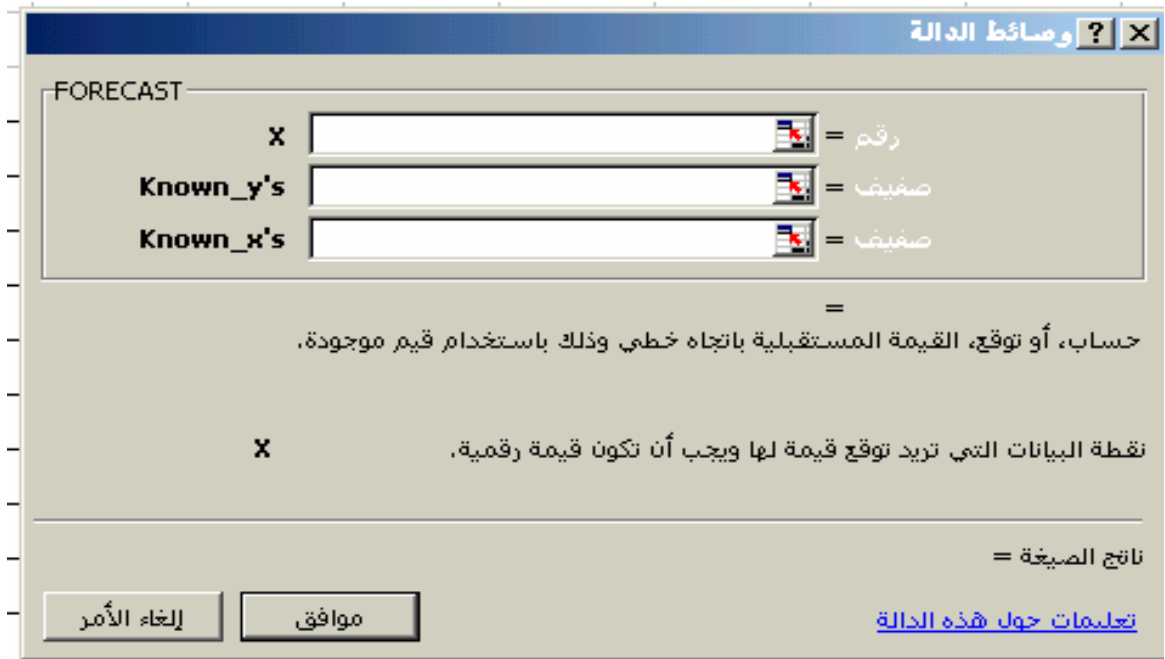

وتستخدم هذه الدالة لحساب أو التتبؤ بقيمة مستقبلية باستخدام قيم موجــودة، تكــون

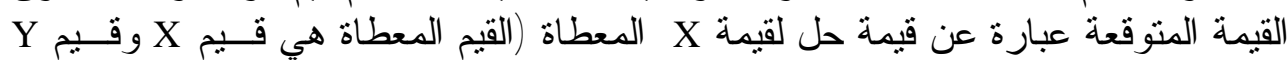
الموجودة، وقيم التتبؤ بالقيمة الجديدة باستخدام الانحدار الخطي) ويمكن استخدام هذه الدالة الذية للتتبؤ بالمبيعات ومتطلبات المخزون و اتجاهات السوق المستقبلية.

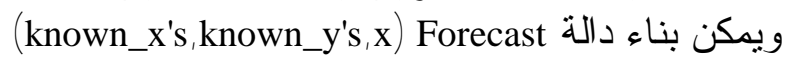
X $x$ Known_y's Known_x's وتكون معادلة Forecast هي 


$$
B=\frac{N \sum X Y-\left(\sum X\right)\left(\sum Y\right)}{N \sum X^{2}-\left(\sum X\right)^{2}}
$$

وتم استخدام هذه الدالة للتنبؤ بمبيعات شركة الموصل الصناعية من خلال البيانـات

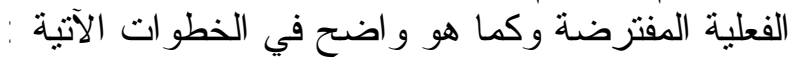

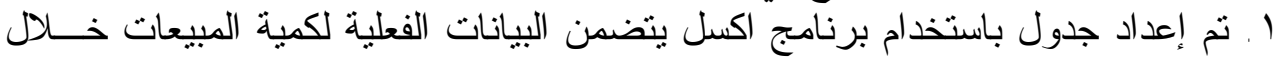

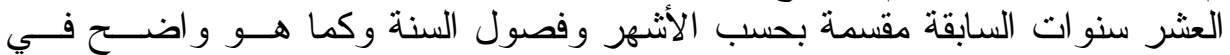

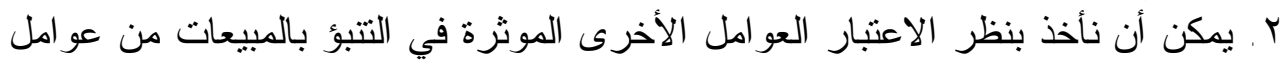

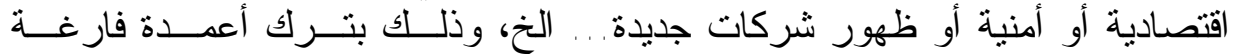

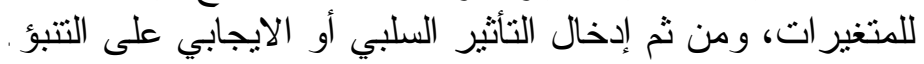

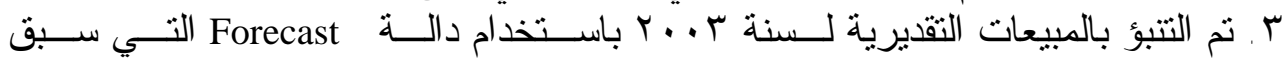
توضيحها.

و الثكل الآتي بيبن انه تم استخدام دالة Forecast في التتبؤ بالمبيعات التقديرية لسنة . r. r

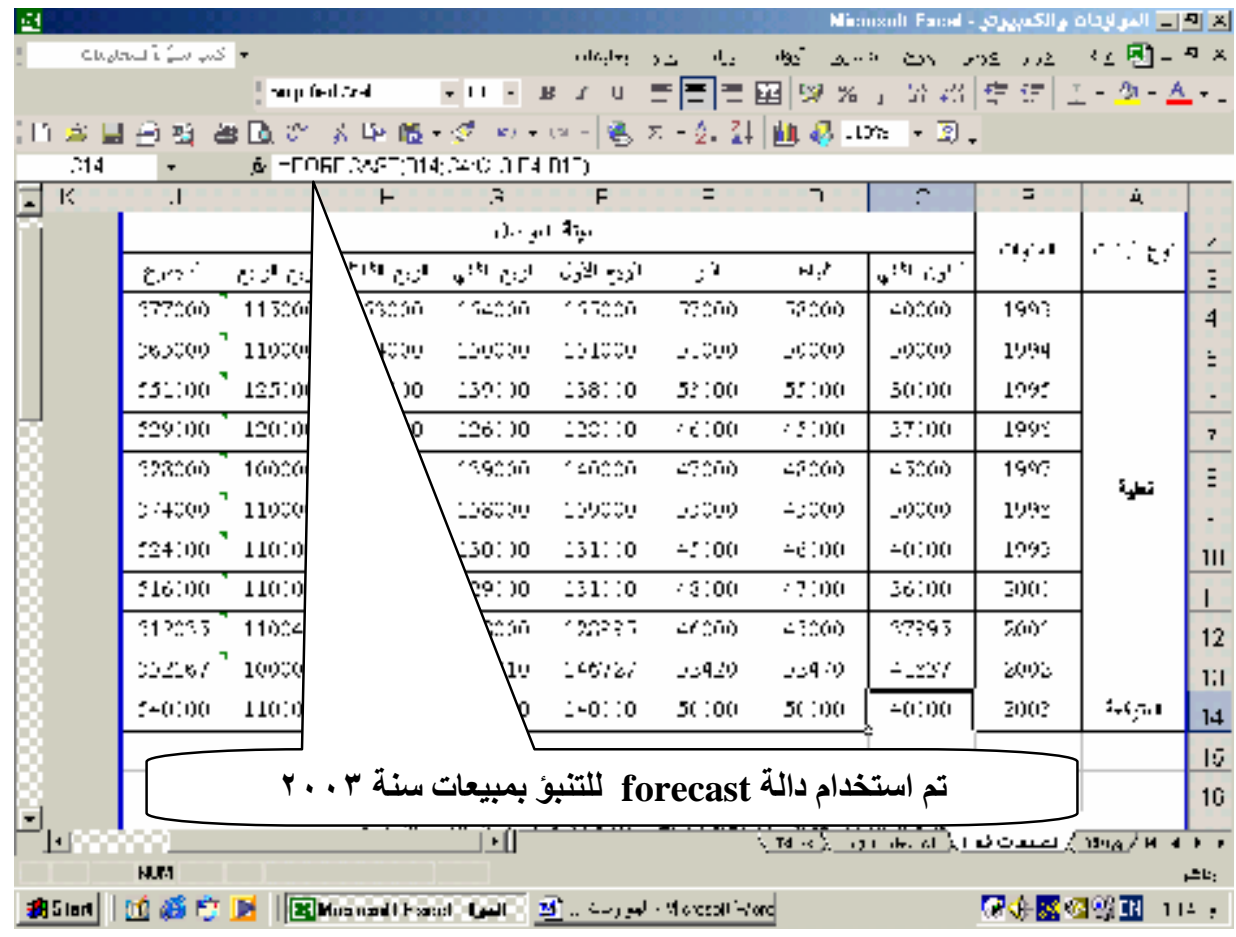

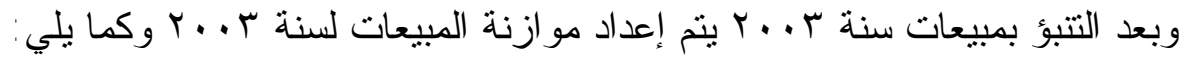


الدكتور الحبيطي ورمو[9]

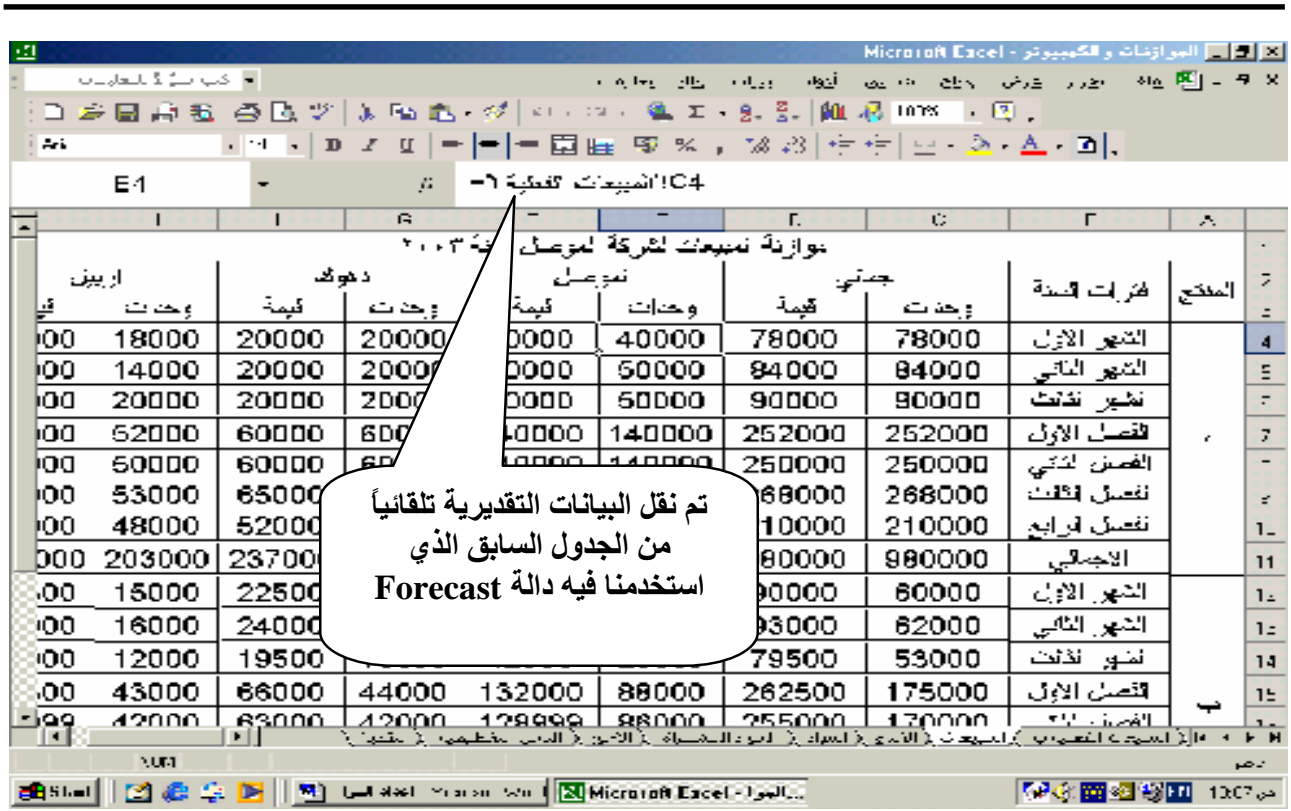

$$
\text { و اضح فما تم إجر آه جميع العمليات الحسابية بشكل تلقائي من جمع وضرب وكمــا هــو }
$$

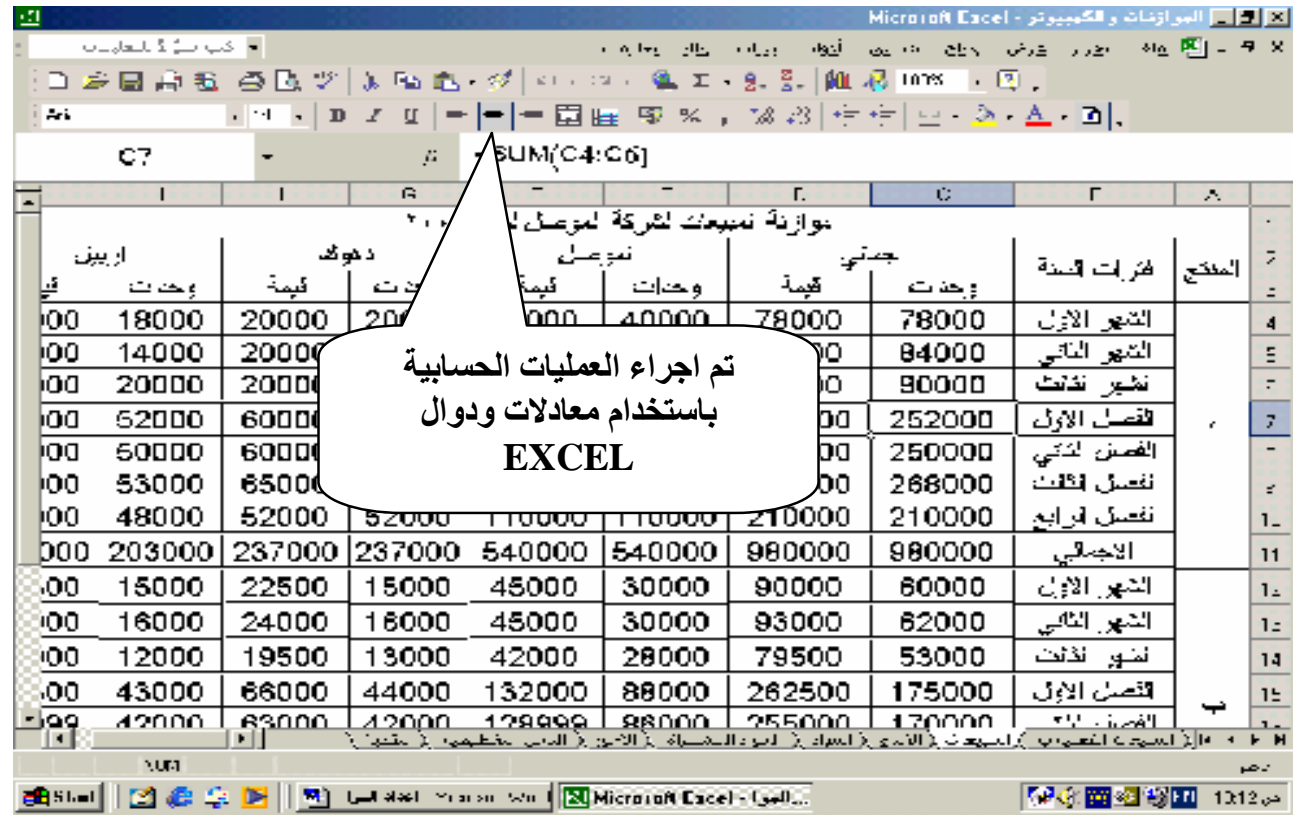

كما تم استخر اج قيمة المبيعات تلقائياً بضرب وحدات المنتج أ بدينار و احد وضرب عدد وحدات المنتج ب بدينار ونصف، و هو سعر الوحدة الو احدة . 


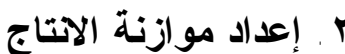

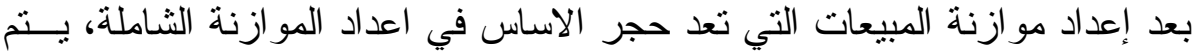
إعداد مو ازنة الانتاج بالاستتاد الى بيانات موازنة العئة المبيعات وباستخدام المعادلة الآتية :

المبيعات + مخزون آخر المدة = (إجمالي الاحتياجات) - مخزون أول المدة = الوحدات المطلوب إنتاجها

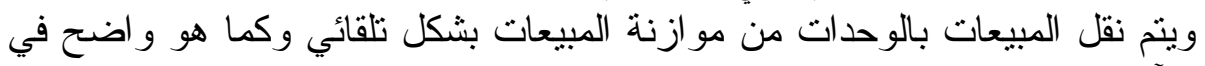

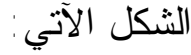

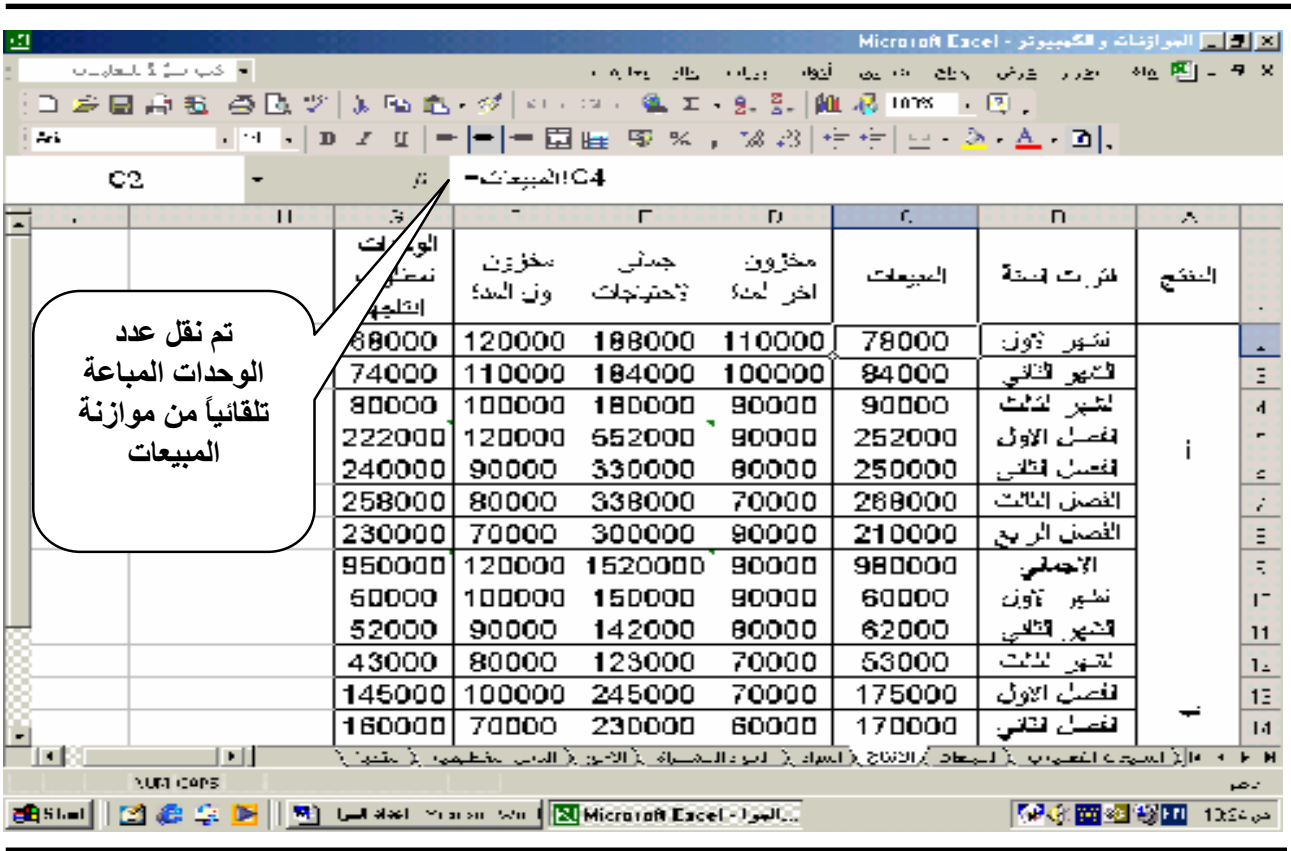

ويتم إجر اء العمليات الحسابية في موازنة الإنتاج بشكل تلقائي باستخدام المعسادلات

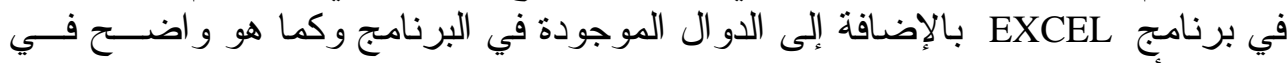
الثّكل الأتي:

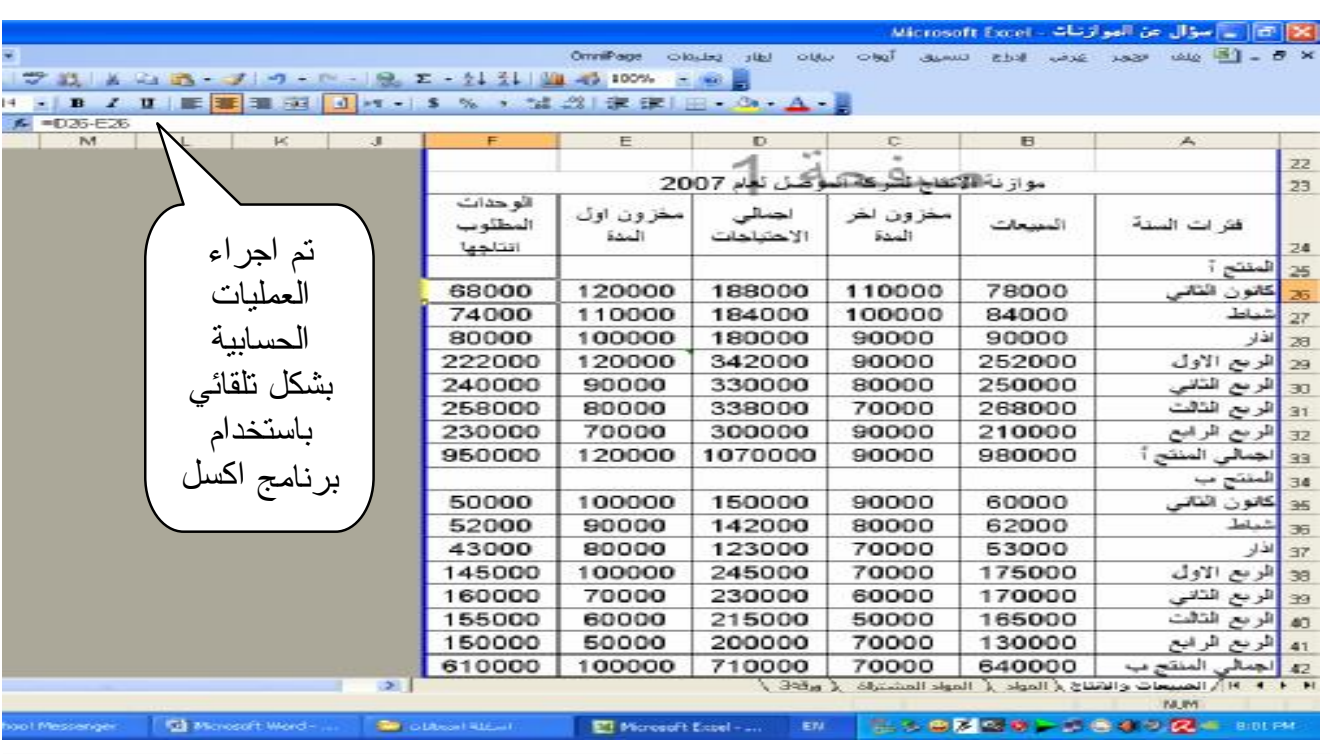




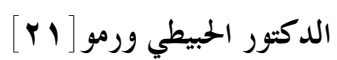

r ب إعداد موازنة المواد بعد الانتهاء من إعداد موازنة الإنتاج ينم إعداد موازنة المواد التي نحتاجها لإنتاج

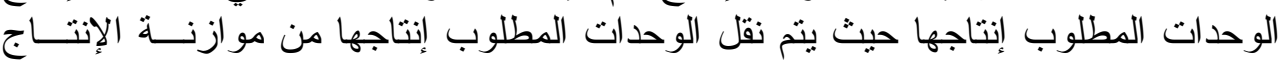
بشكل تلقائي وكما هو و اضح في الثكل الآتي :

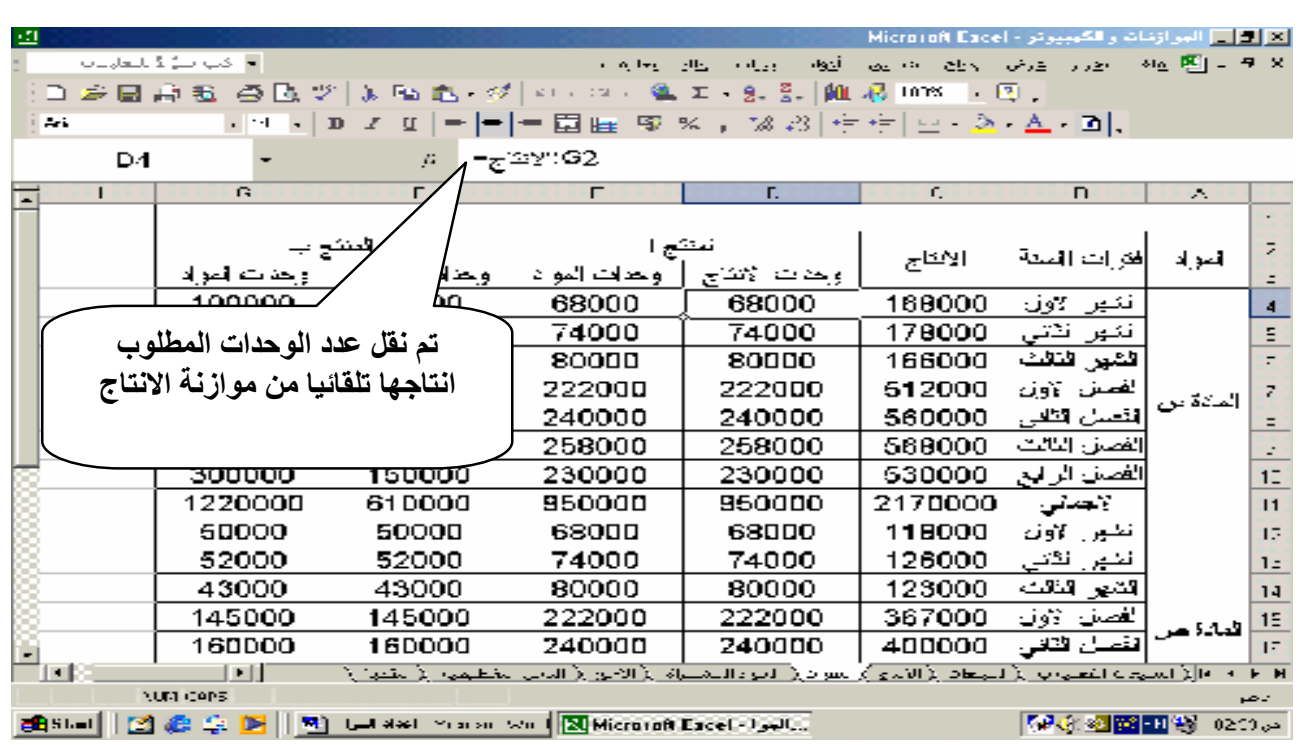

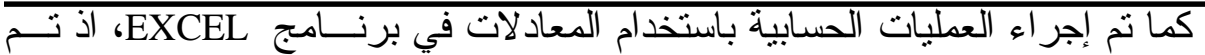

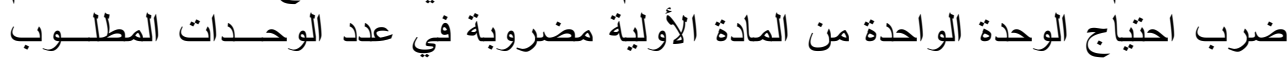

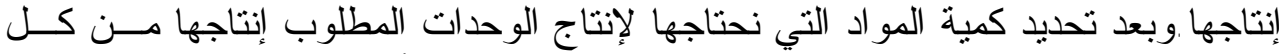

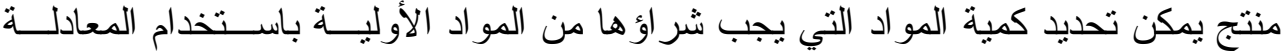
الآتية :

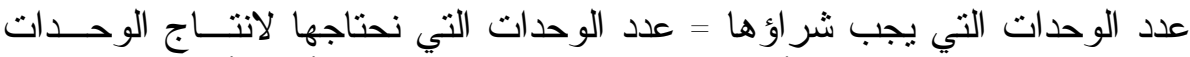

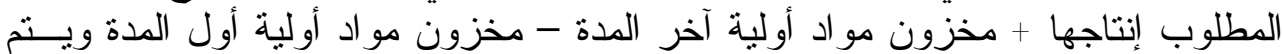

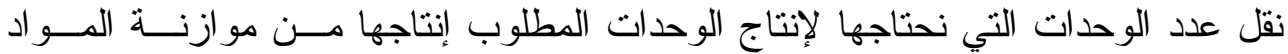

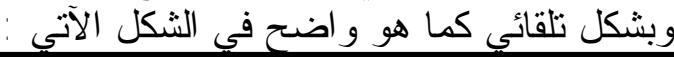

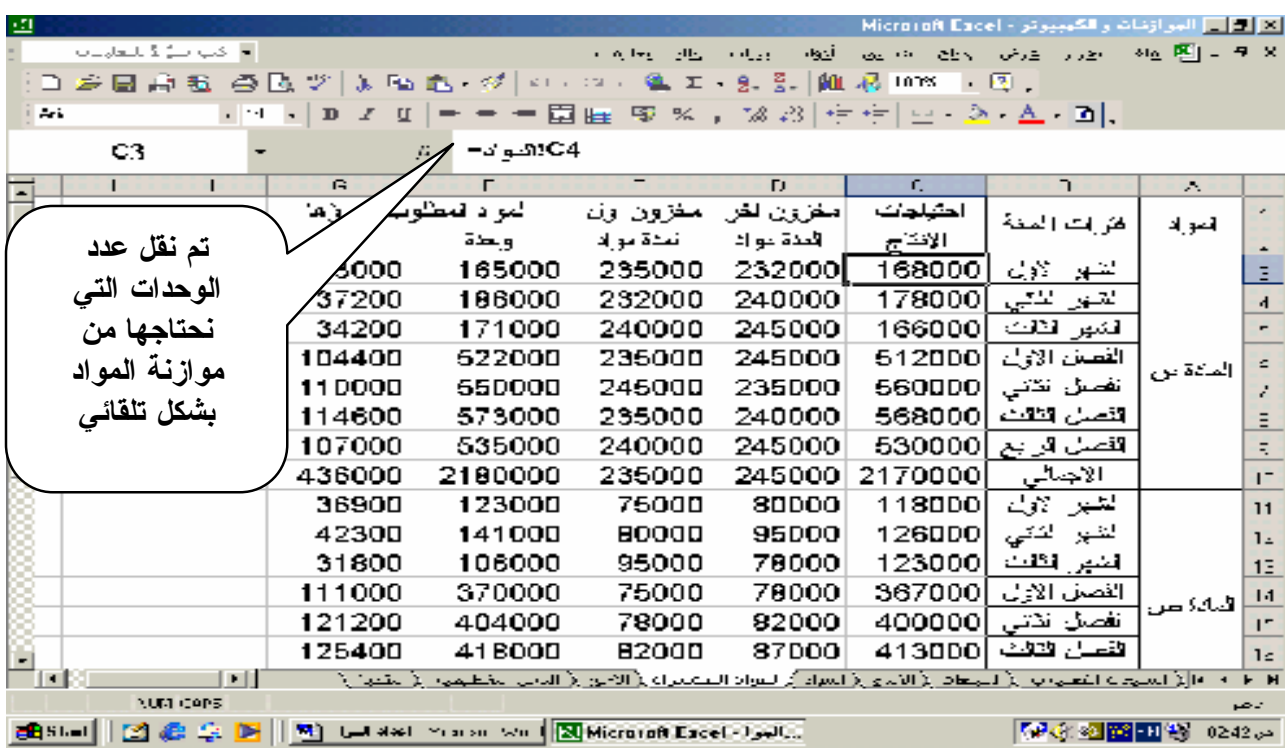




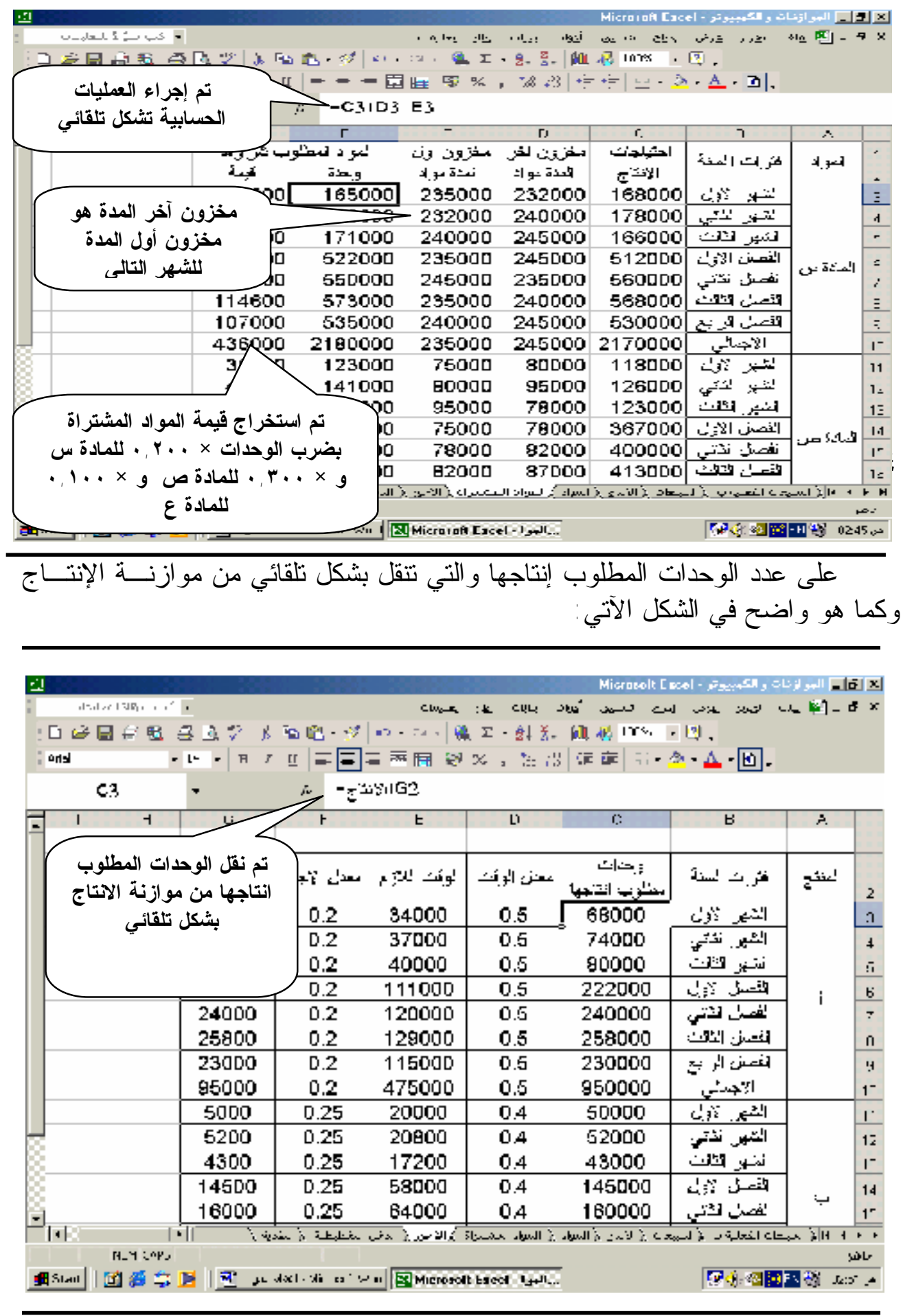




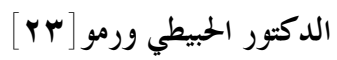

كما تم إجر اء العمليات الحسابية باستخدام المعادلات في البرنامج فضلاعن الــدوال

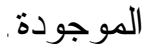

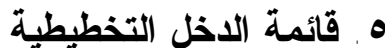

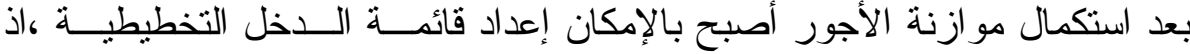

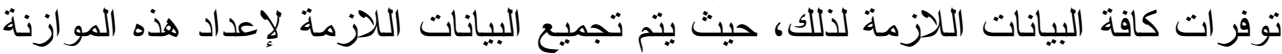

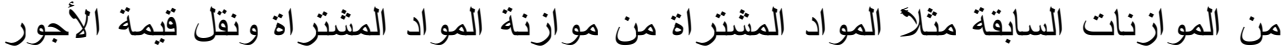
من موازنة الأجور وكما هو واضح في الثنكل الآتي :

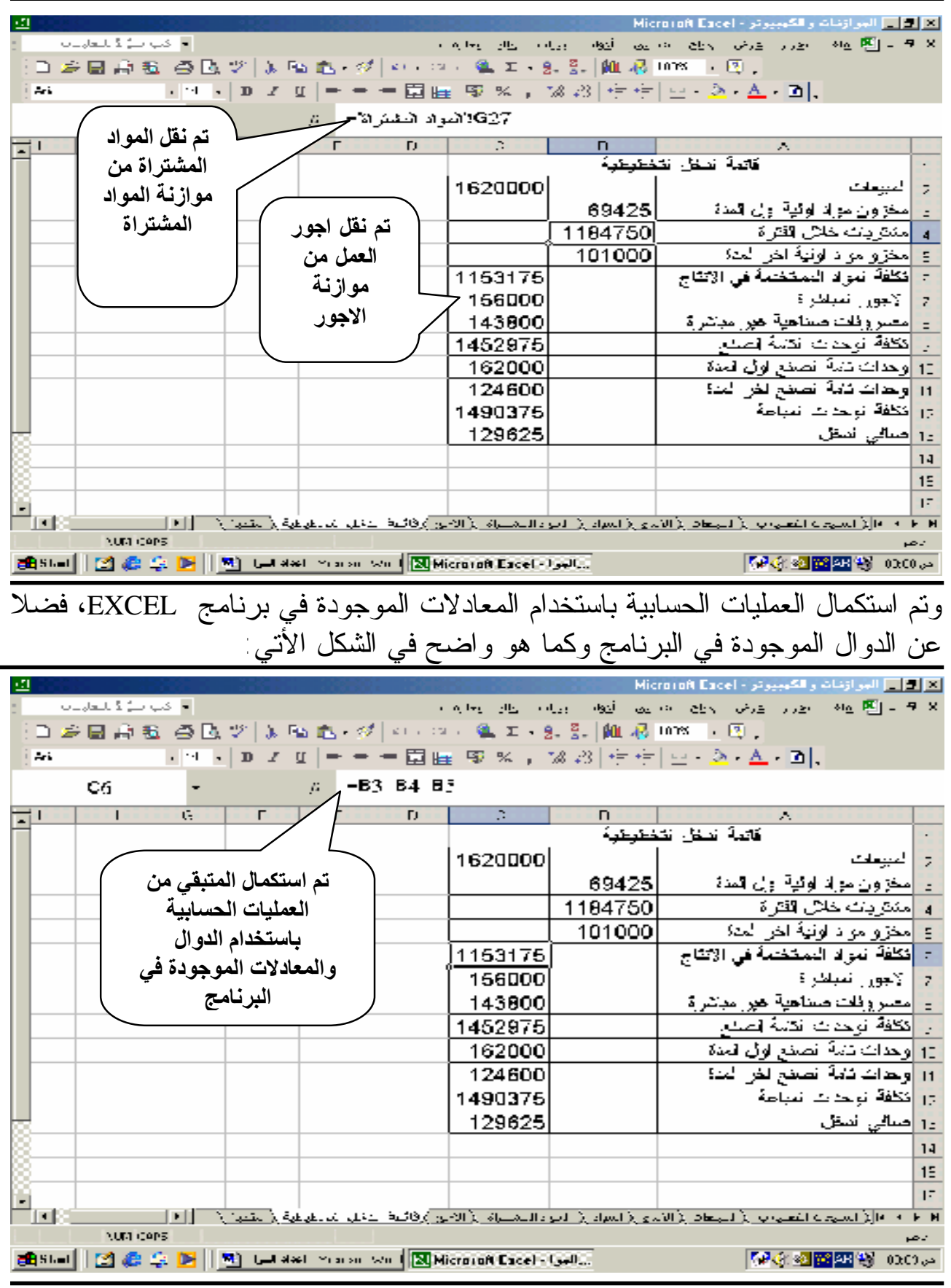




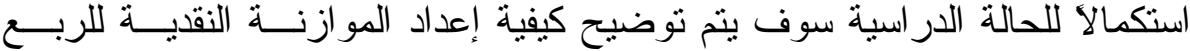

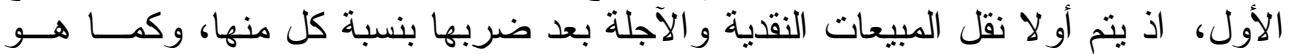

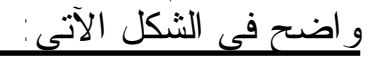

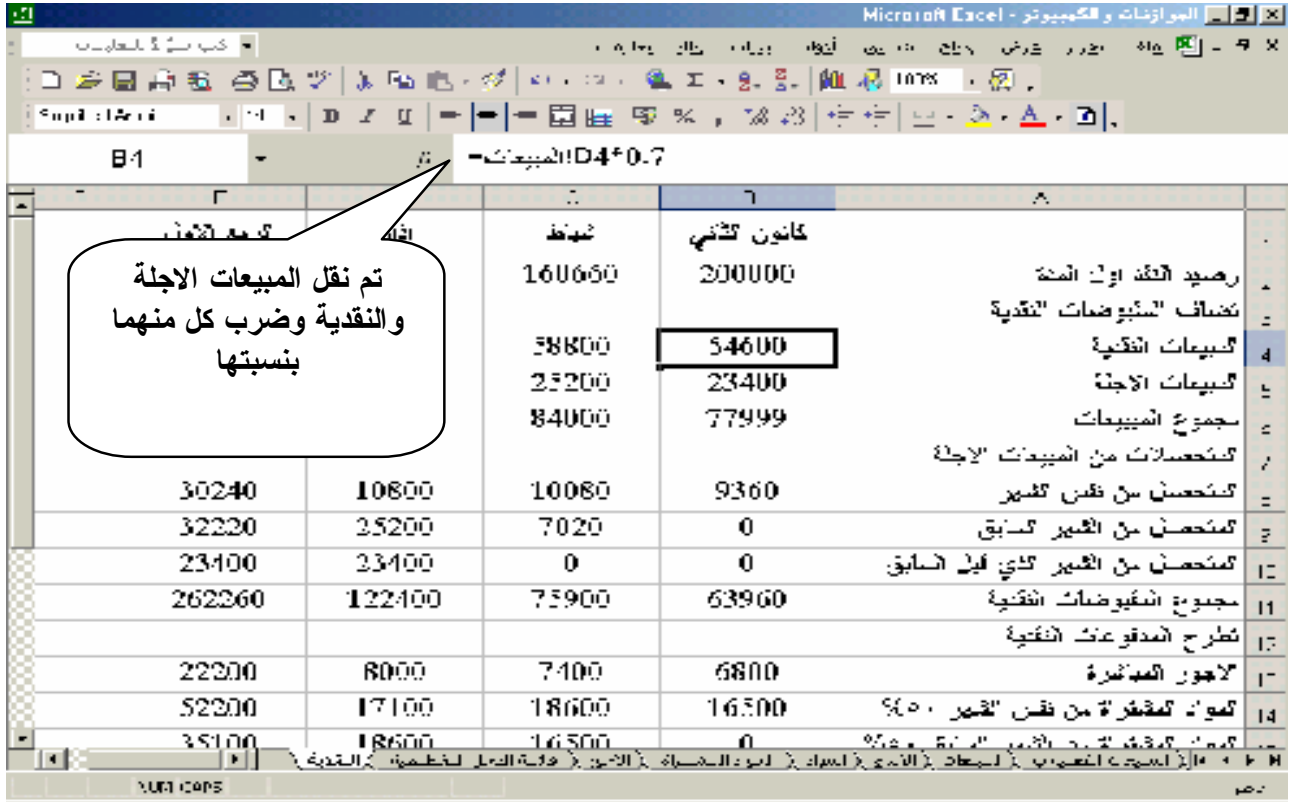

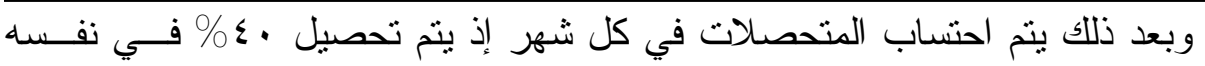

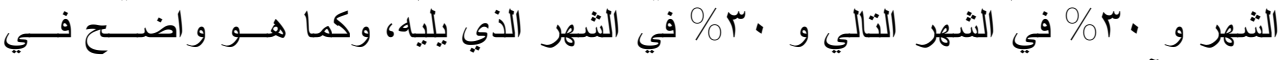
الشكل الآتي : (x)

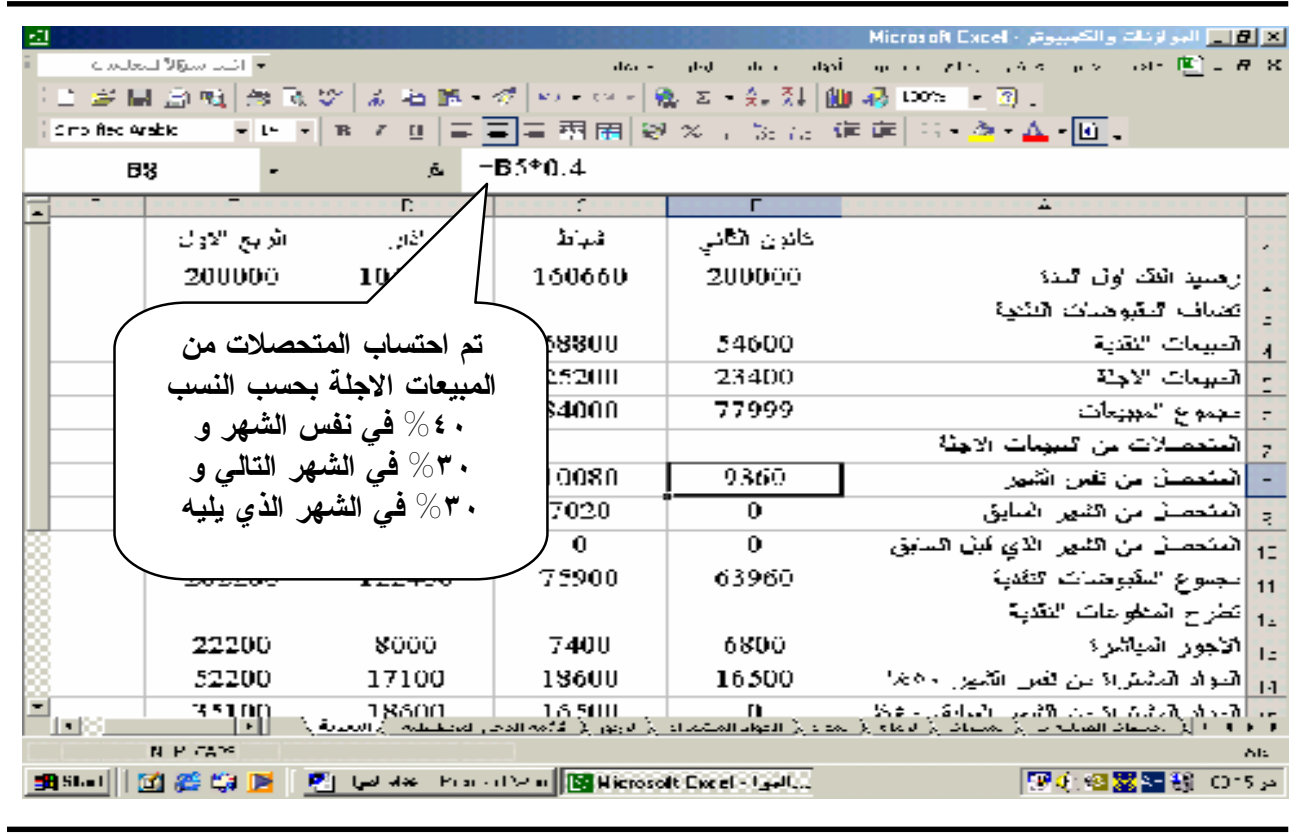




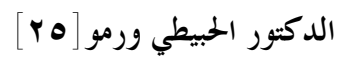

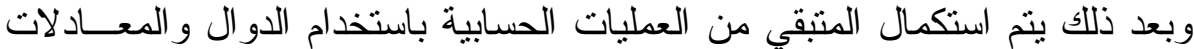

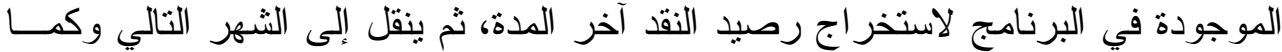

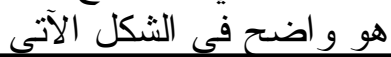

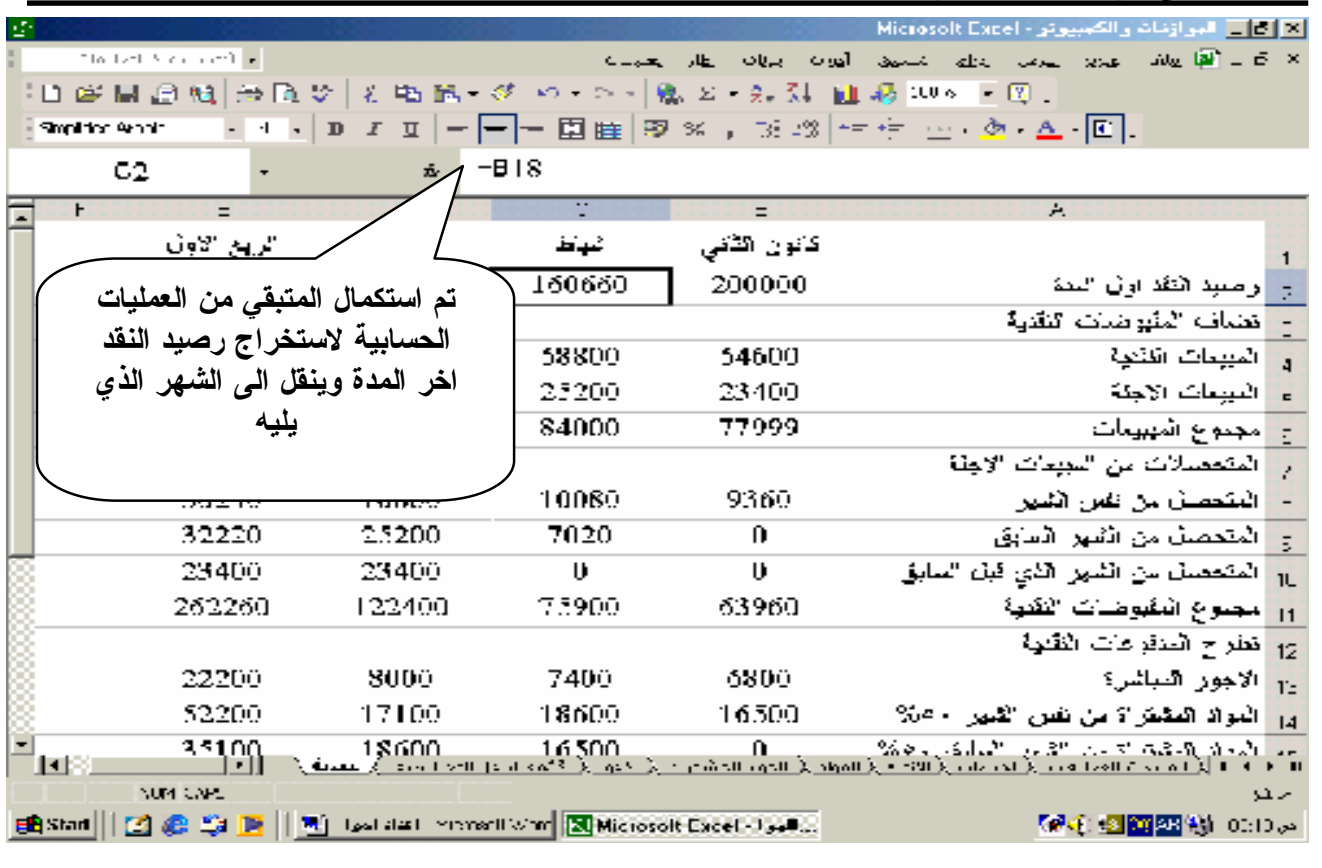

وبعد نوضيح وبيان كيفية إعداد الموازنة الثاملة فإنه يمكن طباعتها و إظهار بياناتها

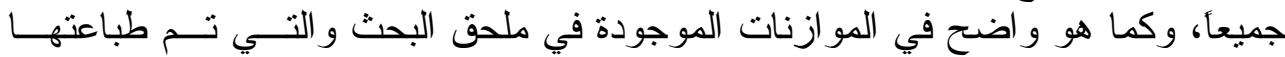

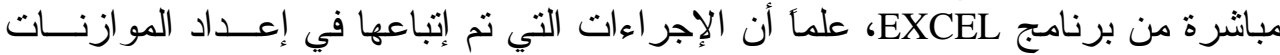

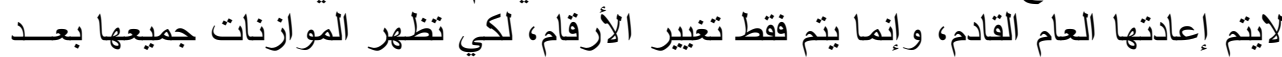

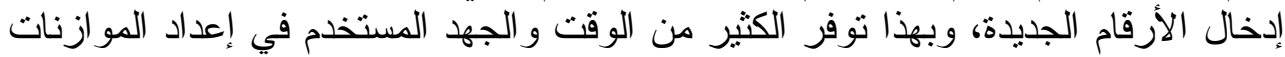

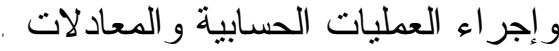

الخلاصة من خلال در اسة مشكلة البحث تم التوصل إلى مايأتي :

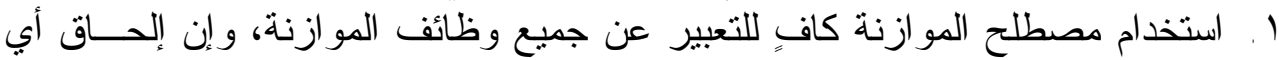

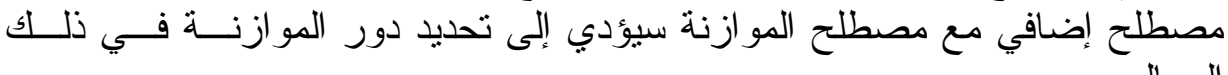

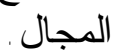
r. إن استخدام الحاسوب في عملية إعداد الموازنة لم يكن له تأثير فــي تغييــر مفهـوم

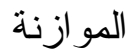

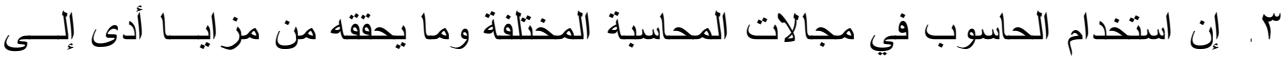

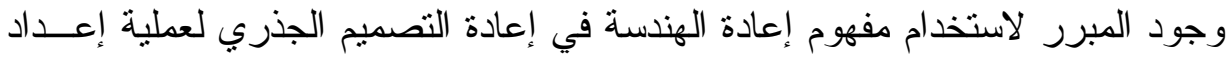

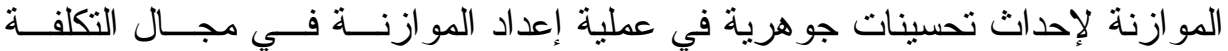


و الجودة وسر عة الانجاز بوصفها خطة شاملة لأنشطة المشروع معبر ا عنها بـصورة مالية.

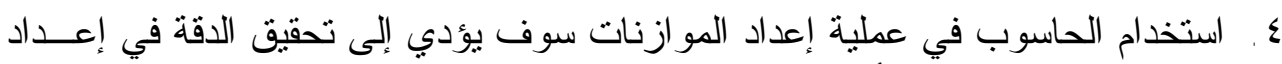

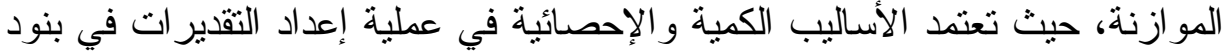

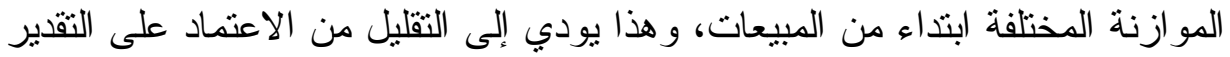

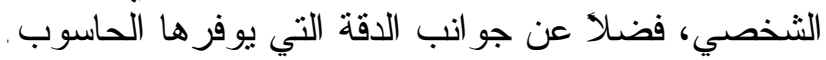
0. استخدام الحاسوب لم يؤثر على أهداف عملية إعداد الموازنة بشكل مباشر ، ولكنه أثز

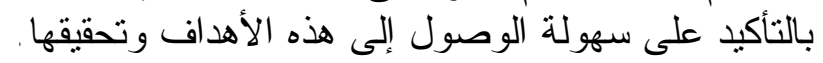

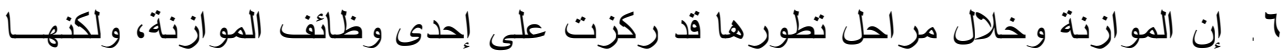

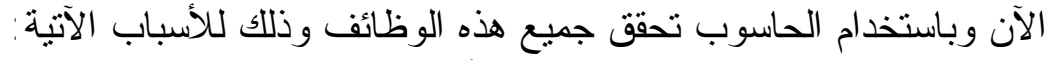

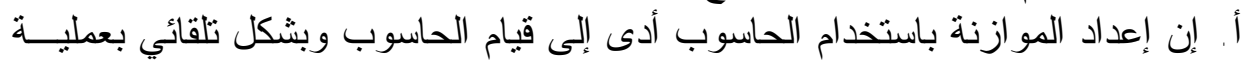

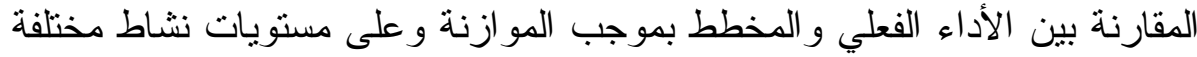
بمجرد إدخال البيانات الفعلية.

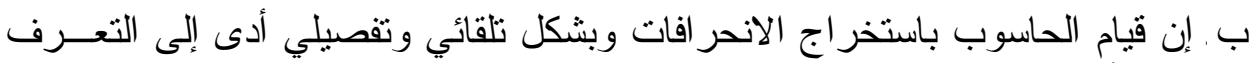

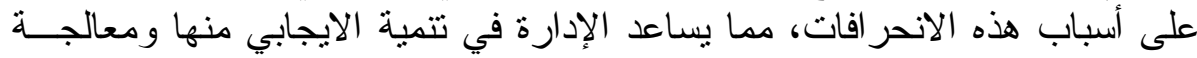
السلبي.

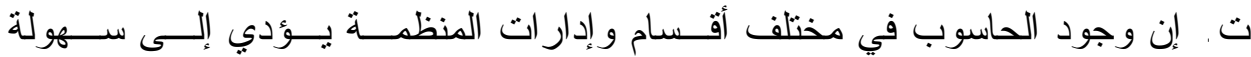

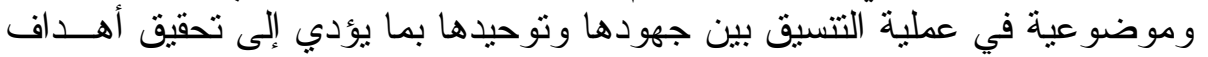
المنظمة من خلال تحقيق أهدافها.

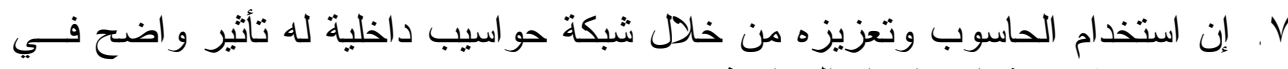

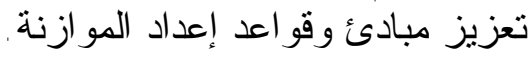

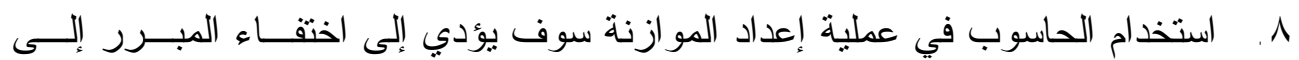

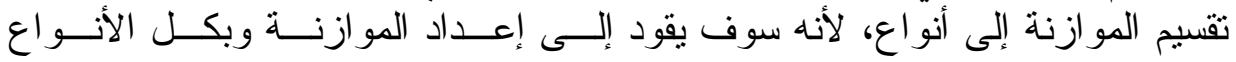
المتعارف عليها.

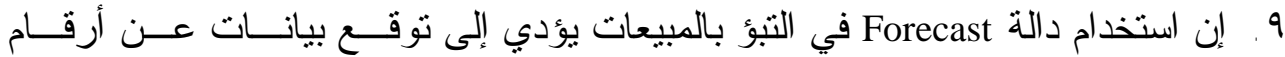

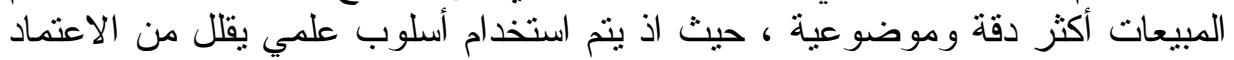

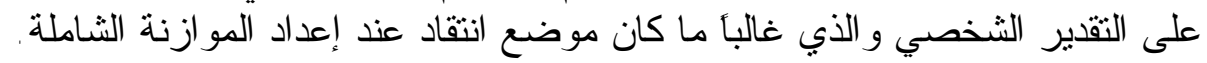

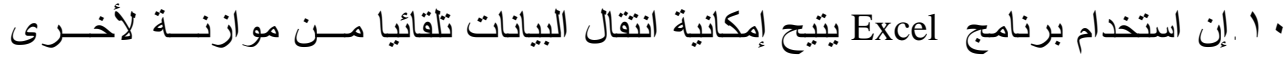

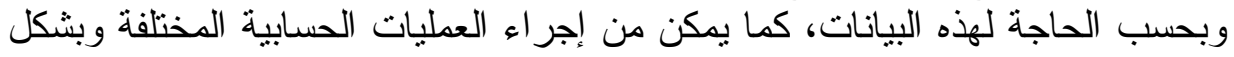

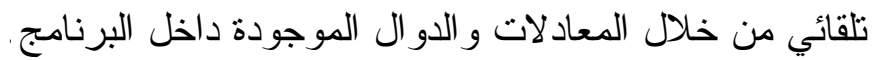

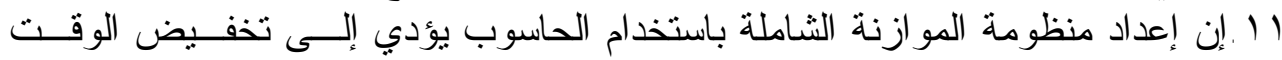

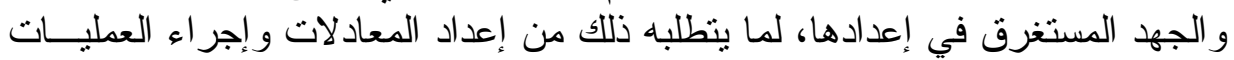
الحسابية سنويأ و التي تستغرق معظم الوقت المستخدم في إعداد الموازنة .

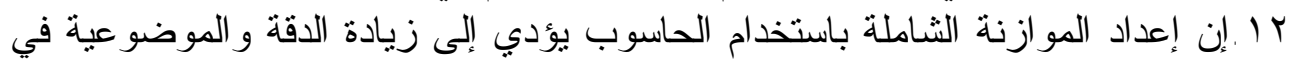

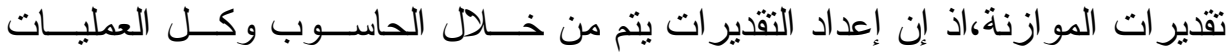

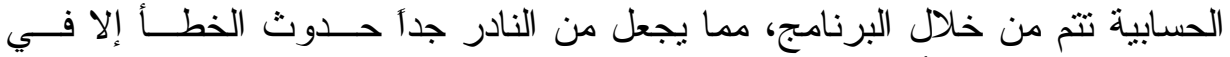




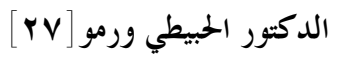

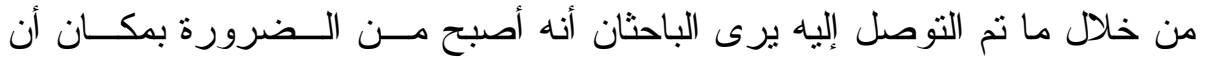

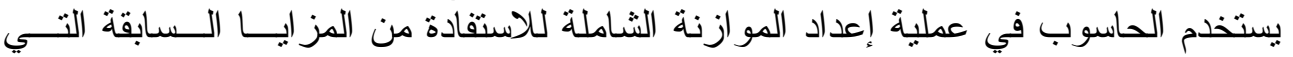

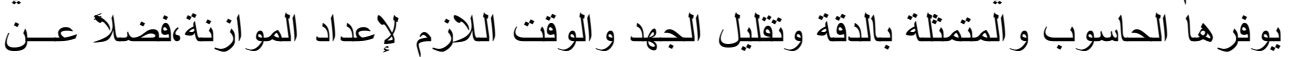

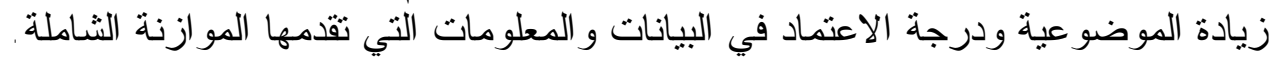

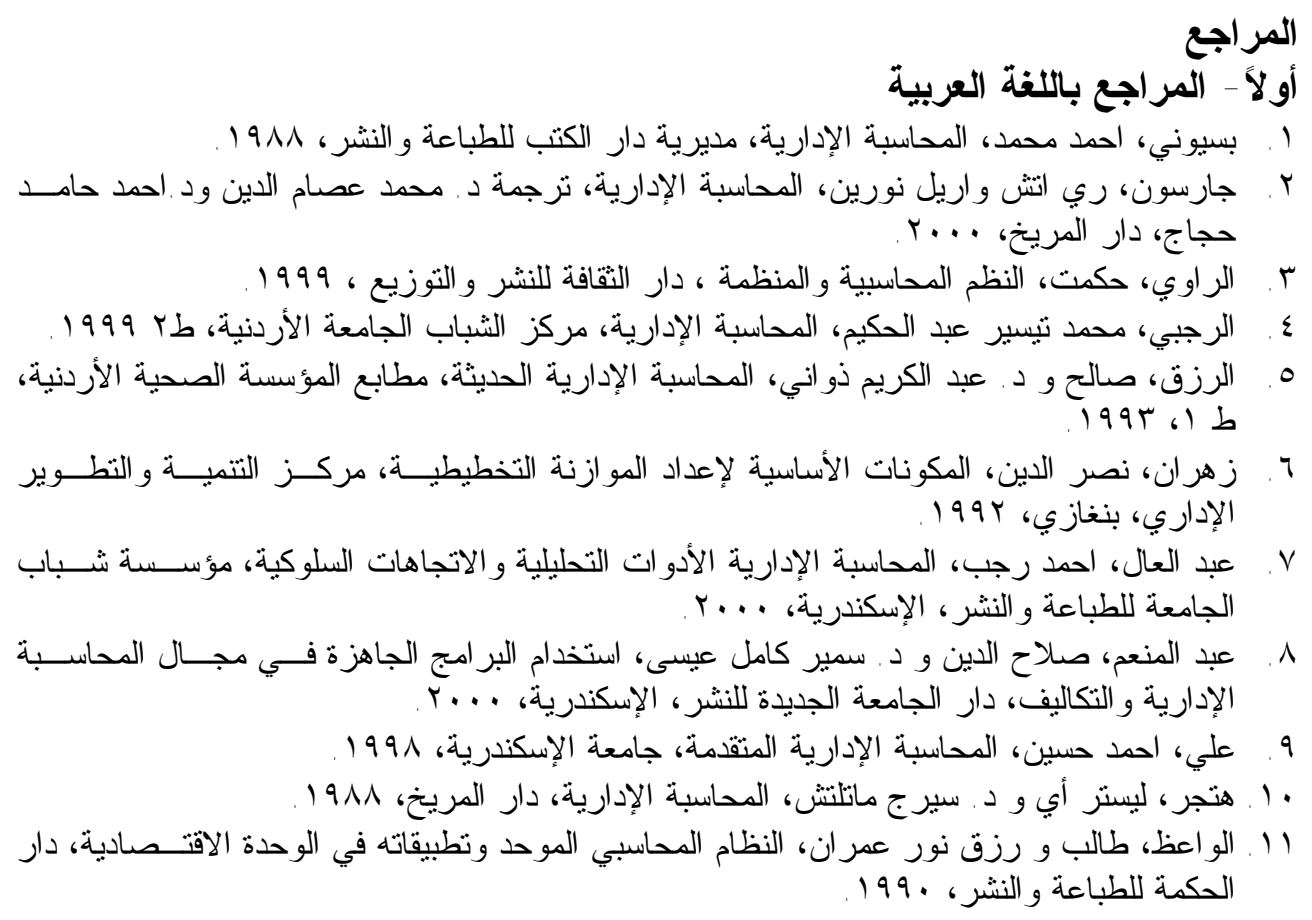

ثانياً - المر اجع باللغة الاجنبية

1. Hammer And Champy, Reengineering The Corporation: A manifesto For Business Revolution, 1993 .

2. Horngron ,Cost Accounting and Managerial , 10 th , macro Hill , 2002 .

3. Neill And Sohal, Business Process Reengineering Areviw Of Recent Literature, 1999.

4. Raymond L. Manganelli, The Reengineering Hand book, A macom, 1edition, 2003. 